\title{
The Influence of Foot Posture and Load on Lumbar Biomechanics During Trunk Bending
}

Atefeh Malekinezhad

Follow this and additional works at: https://researchrepository.wvu.edu/etd

\section{Recommended Citation}

Malekinezhad, Atefeh, "The Influence of Foot Posture and Load on Lumbar Biomechanics During Trunk Bending" (2017). Graduate Theses, Dissertations, and Problem Reports. 6147.

https://researchrepository.wvu.edu/etd/6147

This Thesis is protected by copyright and/or related rights. It has been brought to you by the The Research Repository @ WVU with permission from the rights-holder(s). You are free to use this Thesis in any way that is permitted by the copyright and related rights legislation that applies to your use. For other uses you must obtain permission from the rights-holder(s) directly, unless additional rights are indicated by a Creative Commons license in the record and/ or on the work itself. This Thesis has been accepted for inclusion in WVU Graduate Theses, Dissertations, and Problem Reports collection by an authorized administrator of The Research Repository @ WVU. For more information, please contact researchrepository@mail.wvu.edu. 
The influence of foot posture and load on lumbar biomechanics during trunk bending

Atefeh Malekinezhad

Thesis submitted to the College of Engineering and Mineral Resources at West Virginia University in partial fulfillment of the requirements for the degree of Master of Science in Industrial Engineering

Xiaopeng Ning, Ph.D., Chair

Majid Jaridi, Ph.D.

Ashish Nimbarte, Ph.D.

Department of Industrial and Management System Engineering

Morgantown, West Virginia

2017

Key Words: Low Back Pain, Trunk Flexion and Extension, Flexion-Relaxation Phenomenon, Electromyography

Copyright 2017 Atefeh Malekinezhad 


\begin{abstract}
The influence of foot posture and load on lumbar biomechanics during trunk bending
\end{abstract}

\title{
Atefeh Malekinezhad
}

Low back pain imposed huge expenditures to the industry with many days away from work. Despite industrialization, statistics show the number of work injuries, work transfer, work restriction and absenteeism in recent years is still high. Various factors are involved in low back injuries, which make it complicated to deal with. In many industries (such as construction, transportation, and healthcare) low back pain is highly prevalent.

In the current study, we recruited 14 participants to investigate the effect of staggered foot posture on lifting biomechanics and to understand if maintaining a staggered foot posture could reduce spinal tissue loading and its influence on the spinal active and passive tissue interaction. The study involved a total of 24 trunk flexion and extension motions ( 3 different foot postures, two levels of load and four repetitions). Each trial involved seven seconds to move from an upright standing posture to reach to a fully flexed trunk posture, to stay six seconds in full flexion trunk posture and then use another seven seconds to move back to upright standing with and without holding an external weight of $15 \mathrm{lb}$. Results of this study showed that during performing trunk bending motions with staggered foot posture, unbalanced cumulative electromyography (CEMG) would be observed among the two sides of lumbar extensor muscles and with the increase of foot distance, trunk kinematics would change, and the flexion-relaxation phenomenon (FRP) of lumbar muscle would alter. 


\section{ACKNOWLEDGEMENTS}

I would like to express my profound gratitude to my advisor, Dr. Xiaopeng Ning, for his generous guidance and support of the research for my master's thesis. The door to Dr. Ning's office was always open for me and without his ongoing support and patience, I could not have overcome the obstacles to complete this thesis.

I am grateful to the rest of my Committee members, Dr. Majid Jaridi and Dr. Ashish Nimbarte for their time and their precious comments. Their comments improved my research insight and helped me to go deeper in my research from different perspectives. I want to express my sincere gratitude to Dr. Jaridi for all his support during my studies at West Virginia University.

My deepest thanks to my parents for providing me with support and encouragement throughout my life and especially during my graduate studies and while I was conducting research for my Master's thesis. Finally, I would like to thank my husband. I could not have completed my research without his constant motivation and enduring love. 


\section{TABLE OF CONTENT}

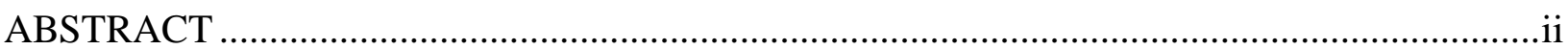

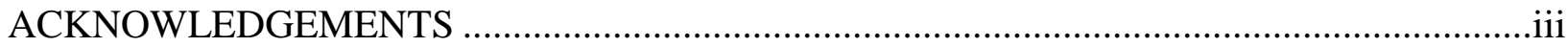

TABLE OF CONTENT ….....................................................................................................

TABLE OF FIGURES ................................................................................................ vi

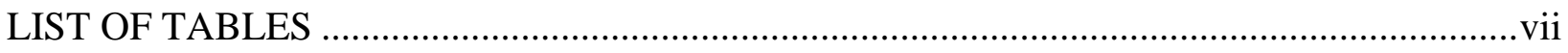

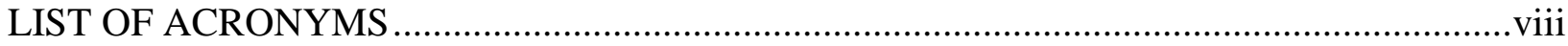

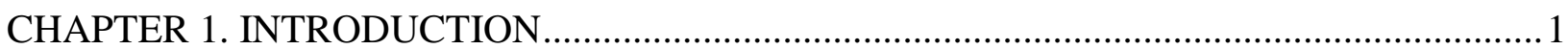

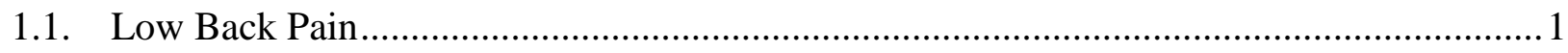

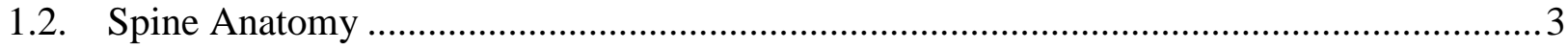

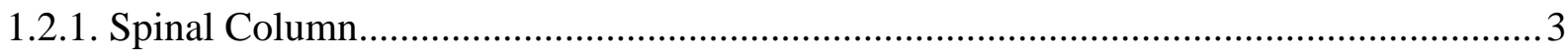

1.2.2. Vertebrae and Intervertebral Discs ...................................................................

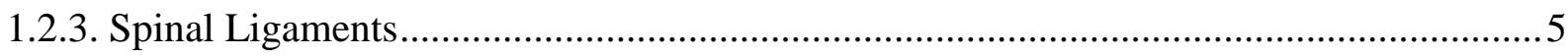

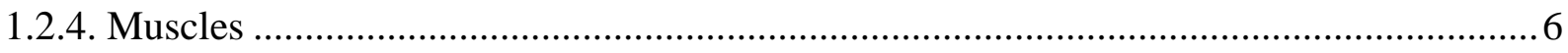

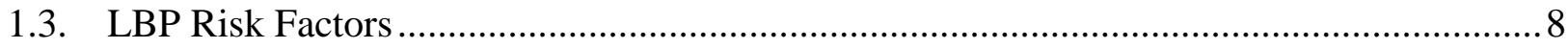

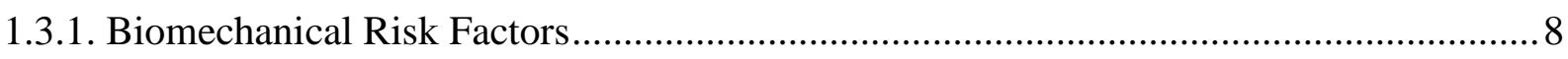

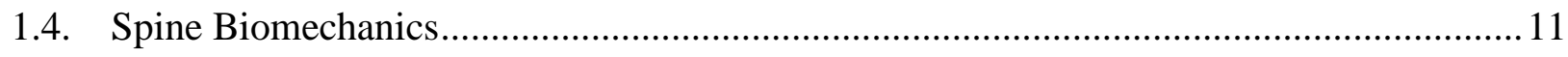

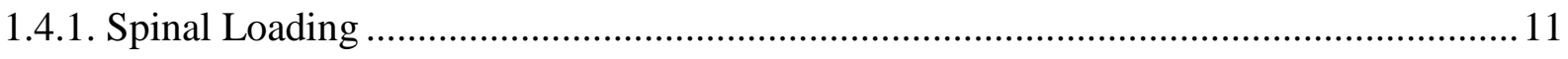

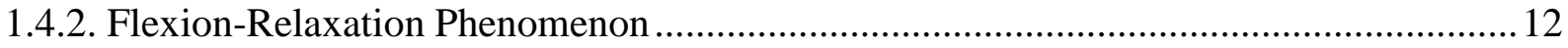

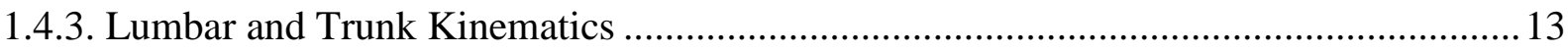


1.4.5. Foot Posture and Ground Condition ..................................................................... 14

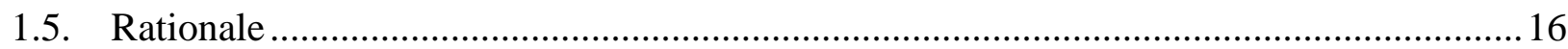

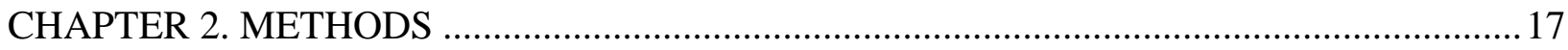

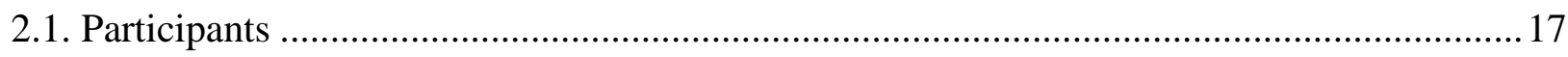

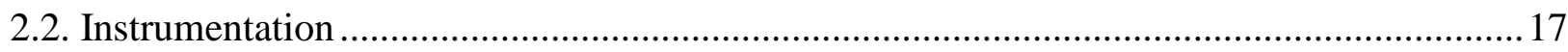

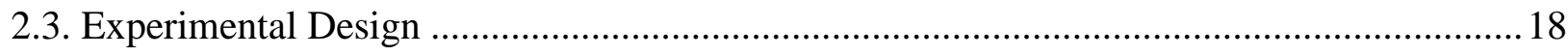

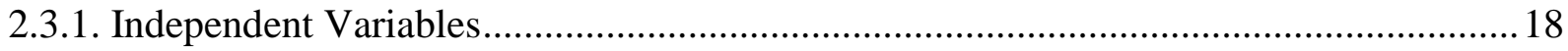

2.3.2. Dependent Variables ......................................................................................... 21

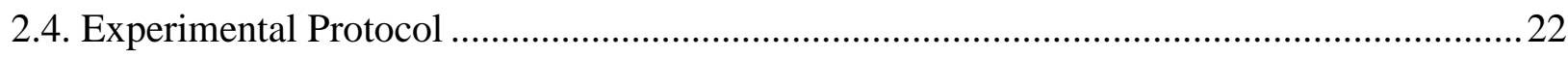

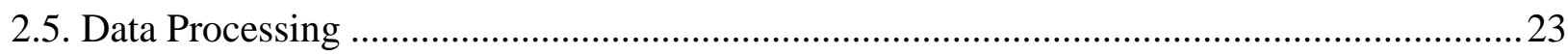

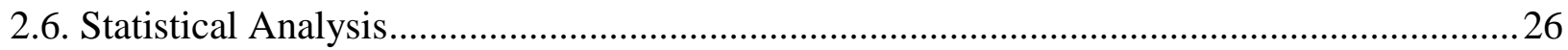

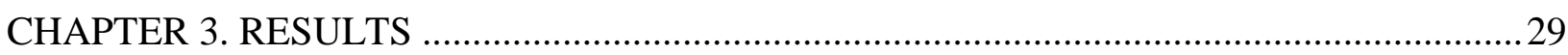

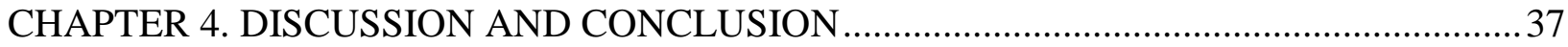

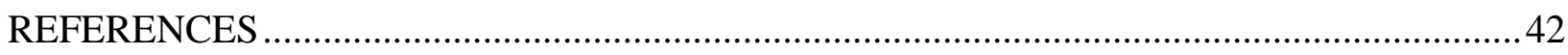

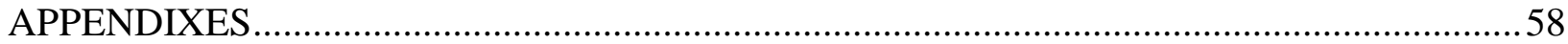

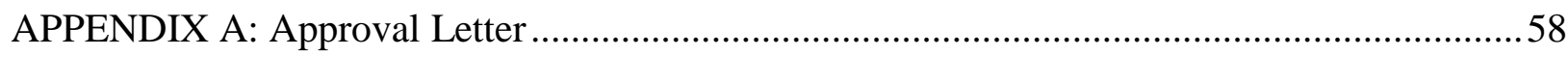

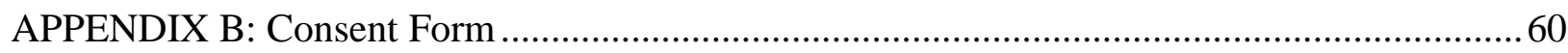

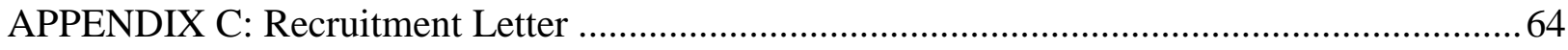

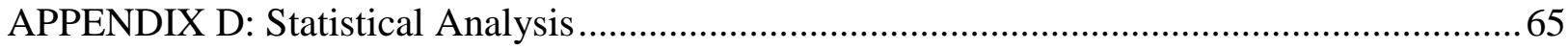




\section{TABLE OF FIGURES}

Figure 1: The spine regions and shape (Gray's Anatomy-2015) ..............................................

Figure 2: Components of the intervertebral disc $($ Gail, 1980) ..................................................5

Figure 3: Different ligaments position in the spine (www.coloradospineinstitute.com) .................5

Figure 4: Illustration of Abdominal Muscles (www.dailyhealthpost.com).................................

Figure 5: Bipolar surface EMG electrodes and their positions on the skin................................. 17

Figure 6: The HUMAC Norm system with a back flexion and extension module....................... 18

Figure 7: a, b and c: Illustration of different foot postures and load handling ............................20

Figure 8: Demonstration of three different stance width .....................................................20

Figure 9: An illustration of the mechanism of the "resample" function in MATLAB ..................24

Figure 10: Illustration of integrating EMG and calculating CEMG .....................................22

Figure 11: The output of power analysis in Minitab .........................................................2 28

Figure 12: Effects of foot posture on the CEMG during trunk flexion ...................................... 32

Figure 13: Effects of foot posture on the CEMG during trunk extension....................................32

Figure 14: Effects of foot posture on EMG-off lumbar angle ..................................................33

Figure 15: Effects of foot posture on EMG-off trunk angle................................................ 33

Figure 16: Effects of foot posture on the Max Trunk angle (MT) ......................................... 34

Figure 17: Effects of foot posture on Max Lumbar angle (ML) ............................................... 34

Figure 18: Changes of corresponding lumbar angle in three different foot postures for different percent changes in trunk angle during trunk flexion.

Figure 19: Changes of corresponding lumbar angle in three different foot postures for different percent changes in trunk angle during trunk extension. 


\section{LIST OF TABLES}

Table 1: Results of ANOVA and MANOVA on dependent variables

Table 2: Results of ANOVA and MANOVA for CEMG and FRP after excluding

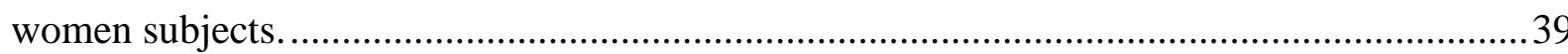

Table 3: Comparing the average and SD of age and body weight and height of subjects

before and after excluding women subjects..................................................................40 


\section{LIST OF ACRONYMS}

\begin{tabular}{|c|c|}
\hline LBP & Low Back Pain \\
\hline MSD & Musculoskeletal Disorder \\
\hline EMG & Electromyography \\
\hline FRP & Flexion-Relaxation Phenomenon \\
\hline WBV & Whole Body Vibration \\
\hline MVC & Maximum Voluntary Contraction \\
\hline SD & Standard Deviation \\
\hline FSD & Featured Standard Deviation \\
\hline $\mathrm{C} 7$ & The 7th Cervical Vertebra \\
\hline $\mathrm{T} 12$ & The 12th Thoracic Vertebrae \\
\hline S1 & The 1st Sacral Vertebrae \\
\hline ES & Erector Spinae \\
\hline $\operatorname{Tr} \mathrm{A}$ & Transversus Abdominis \\
\hline $\mathrm{OI}$ & Obliquus Internus Abdominis \\
\hline $\mathrm{OE}$ & Obliquus Externus Abdominis \\
\hline ANOVA & Analysis of Variance \\
\hline MANOVA & Multivariate Analysis of Variance \\
\hline
\end{tabular}


LCEMGExt Left paraspinals Cumulative EMG during trunk Extension

RCEMGExt Right paraspinals Cumulative EMG during trunk Extension

RCEMGFlex Right paraspinals Cumulative EMG during trunk Flexion

LCEMGFlex Left paraspinals Cumulative EMG during trunk Flexion

LATAFX Percent Lumbar Angle corresponding to the X\% trunk Flexion

LATAEX Percent Lumbar Angle corresponding to the X\% trunk Extension

CEMG Cumulative EMG

LL Left paraspinals EMG-off Lumbar angle

LT Left paraspinals EMG-off Trunk angle

RL Right paraspinals EMG-off Lumbar angle

RT Right paraspinals EMG-off Trunk angle

ML Maximum Lumbar angle

MT Maximum Trunk angle 


\section{CHAPTER 1. INTRODUCTION}

\subsection{Low Back Pain}

Low back pain (LBP) is an important public health issue which causes extraordinary expenditures with considerable health care use annually, and it is the main cause of work absenteeism (Cassidy et al., 1998). Although it may not be life-threatening, back and spine disorders are the most common disorders among young and middle-aged people (Andersson, 1999). One study investigated compensation claims from 600,000 U.S. workers and found that one-third of those claims were due to back injuries (Janicak, 1996). According to a recent report from the U.S. Bureau of Labor Statistics (BLS), musculoskeletal disorders (MSDs) account for about 32 percent of all injuries (BLS, 2016). This report also emphasizes that for all occupations, the incident rate for MSDs (number of injuries and illnesses per 10,000 full-time workers) is about $25 \%$ and these workers required about eight days to recover. About $65-80 \%$ of adults experience LBP at least once during their whole life (Baldwin, 2004). LBP accounts for approximately $25 \%$ of all work-related injuries (Williams, 1998). It is the second main cause of physician visits, the third main reason for surgical procedures and the fifth cause for hospitalization (Taylor et al., 1994; Hart et al., 1995). One study reported LBP as the number one cause of disability in individuals 45 years and younger and the third cause of disability for ones who are older than 45 years (Mayer et al., 1988). It was shown that LBP caused $9 \%$ of students in the USA to miss their school days (Olsen et al., 1992). Another study indicates that the age of the first onset of LBP is below 25 years among workers, and this fact will increase the probability of chronic low back disorders (Burton et al., 1989).

LBP is associated with enormous direct and indirect costs (Tulder et al., 1995; Luo et al., 2004; Katz, 2006; Dagenais et al., 2008). It is claimed that LBP is the single most costly 
workers' compensation claim that an organization faces (Janicak, 1996). In 1990, the direct healthcare costs for LBP was estimated about $\$ 24.3$ billion, and the indirect costs were $\$ 75-\$ 100$ billion for the productivity loss in the United States (Frymoyer et al., 1991). Despite the industrialization in recent years, in the United States treating back disorders cost about $\$ 90$ billion per year (Luo et al., 2004). This study indicates that the healthcare costs for patients with LBP are $60 \%$ higher than the patients without LBP. The annual loss in productivity due to back pain (as an indirect cost) in the United States was estimated to be approximately $\$ 28$ billion (Rizzo et al., 1998). This productivity cost is mainly due to work absenteeism. According to a study, the annual costs of medical treatment for LBP were at least 100 billion dollars in the United States (Katz, 2006). It was suggested that LBP was a great source of the cost that does not decrease each year despite technological advances in diagnosis and the introduction of numerous interventions in recent years (Dagenais et al., 2008). These costs make the LBP a source of concern to employers, insurance companies, and company's decision makers.

It was claimed that the main causes of occupational LBP were lifting and manual material handling (MMH) (Marras et al., 1995). Some other studies showed that these two factors were responsible for about 50 to 75\% of low back disorders (Deros, 2015; Bigos et al., 1986; Snook 1989). Given the huge costs and the wide prevalence of the LBP problem, it is important to identify LBP risk factors and find appropriate strategies to reduce the prevalence of work-related LBP. 


\subsection{Spine Anatomy}

\subsubsection{Spinal Column}

The main structure of the back is the spinal column or spine which consists of 33 individual bones to form an S-shaped column. It also consists of muscles, tendons, ligaments, and nerves. Any disease, abnormality, and injury can lead to pain in this part. The spinal column is divided into four different regions: cervical, thoracic, lumbar and sacral (Figure 1). The spine has an "S" shape, which helps it maintain balance, absorb shock, and increase the range of motion. The main functions of the spine system are: supporting body weight, supporting head and trunk, protecting organs in the chest (especially heart and lungs), protecting the spinal cord, and maintaining upright posture (Cailliet, 2004).

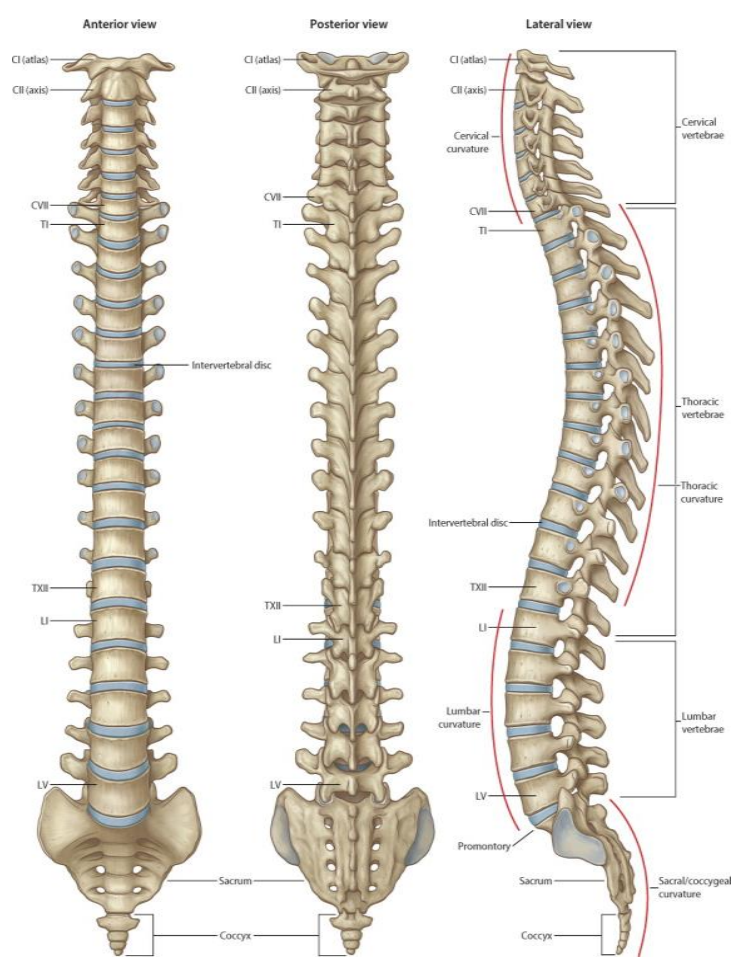

Figure 1: The spine regions and shape (Gray's Anatomy-2015) 


\subsubsection{Vertebrae and Intervertebral Discs}

There are seven cervical vertebrae in the neck or cervical region (C1-C7), twelve thoracic vertebrae in the upper back which are connected to ribs (T1-T12), five lumbar vertebrae in the lower back (L1-L5) and one fused sacrum vertebrae (S1) (Figure 1). Intervertebral discs separate every two vertebrae and prevent the bones from rubbing together. Discs bear the load and distribute it, absorb shock, and store energy (Nachemson, 1975; Hirsch et al., 1963; Kulak et al., 1976). The structure of the disc consists of the annulus fibrosis, the nucleus pulposus, and the cartilaginous end-plates (Macnab, 1977) (Figure 2). Intervertebral discs account for one-third of the spinal height (Raj et al., 2008). One study indicates that the nucleus pulposus consists of 7090 percent water, but as the body gets older, it loses its water content, resulting in a reduction in disc height (Jayson et al., 1973). In our body, vertebrae become thicker and wider at a lower level. This feature enables lower vertebrae to tolerate greater loads in the lumbar region.

It was shown that the lower the disc level, the higher the prevalence of disc herniation should be expected (Okada et al., 2011, Weiler et al., 2011). About 95\% of all the spinal injury and the disc degeneration and herniation occurs at the two lowest levels (L4/L5) and (L5/S1) of the spine (Gracovetsky. 1990). The small moment arm of L4/L5 joint (which is about 4 to 6.5 cm) resulting in a large reaction moment at the L4/L5 level (McGill 1997, Skotte, 2001). To counterbalance this torque the back muscles, especially the erector spinae (ES) muscle, should generate a high amount of compression force (Chaffin et al., 1973). 

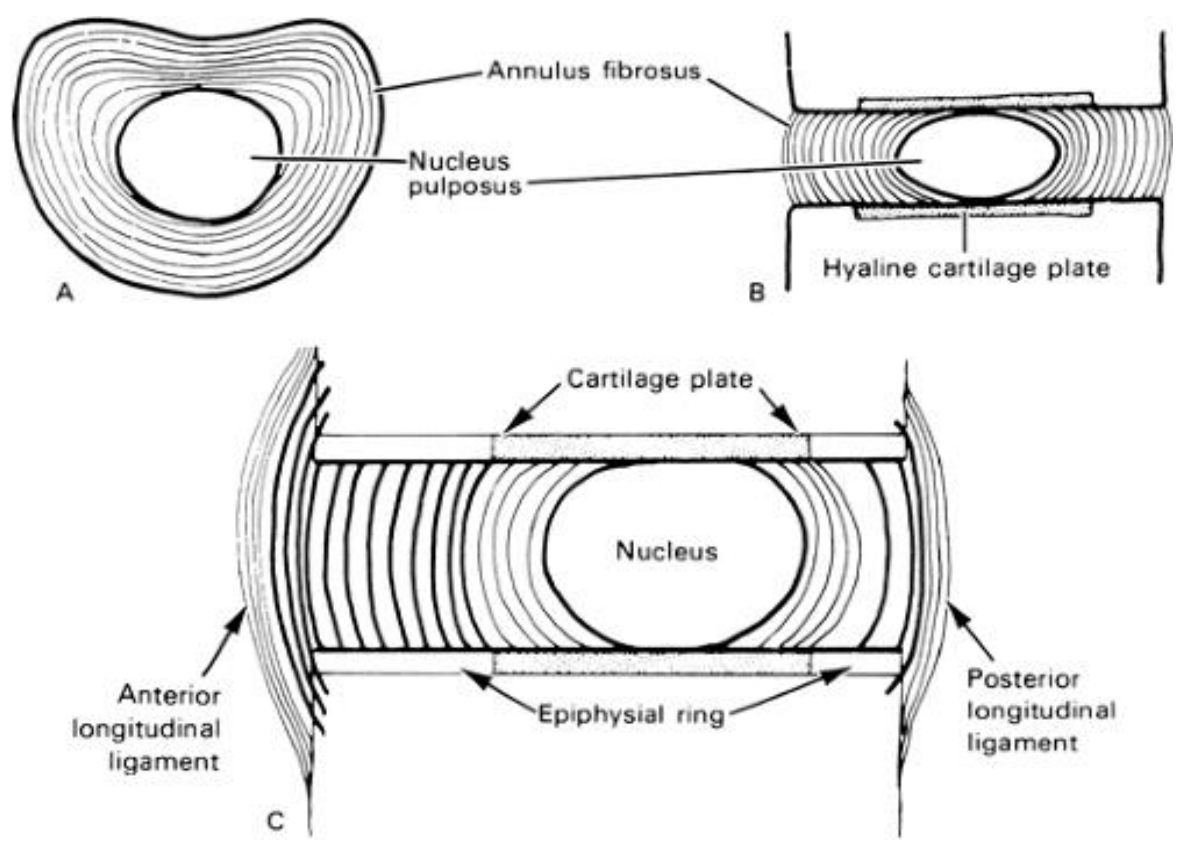

Figure 2: Components of the intervertebral disc (Gail, 1980)

\subsubsection{Spinal Ligaments}

Spinal ligaments help to hold vertebrae together and stabilize the spine. They are fibrous bands which preserve the spine from injuries by preventing excessive flexion and extension movement in the spinal region. The main spinal ligaments are shown in Figure 3.

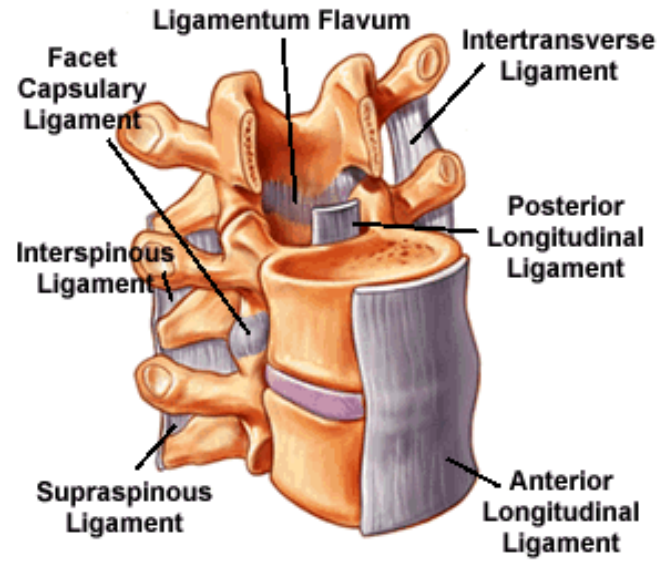

Figure 3: Different ligaments position in the spine (www.coloradospineinstitute.com) 


\subsubsection{Muscles}

\subsubsection{Extensors}

\subsection{Erector Spinae}

ES muscle is assigned to a group of muscles which is the most important lumbar extensor with the largest physiological cross-sectional area in the lumbar region (Marras et al., 2001). ES muscle is responsible for resisting and controlling the bending moment and anterior shear forces during lifting and lowering tasks (Macintosh et al., 1986; McGill et al., 1988). ES muscle includes the longissimus, iliocostalis, and spinals. The ES muscle is mainly made of Type I fibers at the thoracic level which makes this muscle fairly suited to repetitive lumbar motions (Mannion et al., 1997; Sirca et al., 1985; Thorstensson et al., 1987).

\subsection{Multifidus}

The multifidus muscle has a major role in the lumbar spine stability and consists of a series of small muscles attached to the lumbar vertebrae. The main function of the multifidus is posterior sagittal rotation (Macintosh et al., 1986). Among the lumbar muscles, the ES is supposed to generate about $30 \%$ of the total external torque, and the multifidus generates $20 \%$ of the external torque (Bogduk et al., 1995). Multifidus helps body control trunk motions by stiffening the spine (Biering-Sorensen et al., 1984; Wilke et al., 1995). This muscle is responsible for more than two-thirds of the increase in stiffness during sagittal movements (Wilke et al., 1995). 


\subsubsection{Flexors}

Evidence shows that abdominal muscles have important roles in controlling and helping the movement of the lumbar spine and pelvis (Cholewicki et al., 1999; Hodges, 2000). The abdominal muscles that have an effective contribution on the performance of the back muscles are: transversus abdominis (TrA), obliquus internus abdominis (OI) and obliquus externus abdominis (OE) (Williams et al., 1999) (Figure 4). These muscles have different functions in the body movement. For example, previous studies showed that the upper fascia of TrA arising from the costal cartilages might stabilize the rib cage, the middle fascicles attaching to the thoracolumbar fascia may have role in control of the lumbar spine, and the lower fascicles arising from the iliac crest may contribute to generating forces that compress the sacroiliac joints (Richardson et al., 2002).

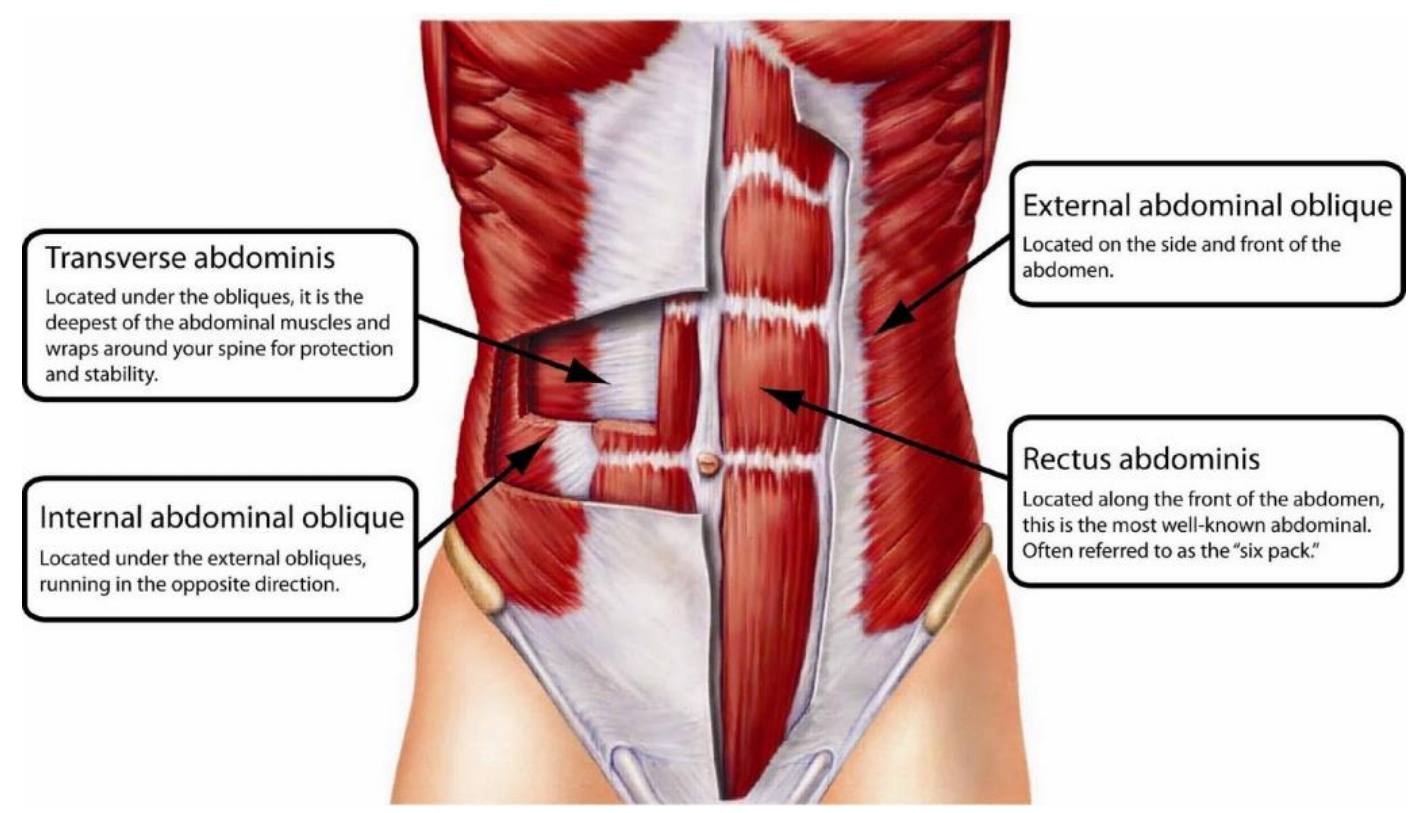

Figure 4: Illustration of Abdominal Muscles (www.dailyhealthpost.com) 


\subsection{LBP Risk Factors}

The etiology of LBP is highly complex (Borenstein, 2001) and the cause of LBP is multifactorial in nature (Kumar, 2001, Junqueira et al., 2014). In general, four categories of LBP risk factors are often considered, and they are: genetic, individual, psychological and biomechanical risk factors (Kumar, 2001).

Genetic factor leads to LBP development in all ages (Hartvigsen et al., 2007; Hartvigsen et al., 2009). One study denotes that the main cause of disc degeneration, which is one of the leading causes of LBP, may be directly linked to genetic reason (Battie, 2009). Also, there is evidence that shows chronic LBP is highly dependents on genetic factors (Junqueira et al., 2014).

Individual factors such as age, gender, race, smoking habits and years of employment have been shown to be associated with the occurrence of LBP (Andersson, 1981; Deyo et al., 1989; Ferguson et al., 1997; Heliovaara et al., 1991, Boshuizen et al., 1993).

Studies also showed that the risk of LBP is associated with psychosocial risk factors such as mental workload (Johansson et al., 1994) and job satisfaction (Violante et al., 2005). Some studies suggest that stress in the work place increases the risk of low back disorders (Mehrdad et al., 2010).

\subsubsection{Biomechanical Risk Factors}

It was claimed that all lower back problems basically related to a biomechanical reason (Marras, 2012). There are several biomechanical risk factors associated with LBP such as: high force exertion, awkward postures, sudden loading, muscle fatigue, whole body vibration (WBV), the frequency of lifting and twisting, the velocity of trunk movement, pushing and pulling, and 
static work posture. There is a significant body of literature which shows this association (Deyo et al., 1989; Hangai et al., 2007; Andersen, 2007; Coenen et al., 2012; Marras et al., 2006).

High force exertion is the first and most common LBP source, and a good number of previous studies have found a strong connection between the mechanical loading on spinal tissues and the occurrence of LBP (Solomonow et al., 2003; Marras et al., 1995; Harcombe, 2010; Kumar, 2001). One study suggested that the risk of low back disorders and injuries will double if compression force exceeds $6800 \mathrm{~N}$ (maximum permissible limit of compression is 6400N) (Herrin et al., 1986). It was shown that LBP is closely related to the heavy loading and the manual material handling at workplaces (Videman et al., 1990). In this study, it was demonstrated that the existence of the spine degeneration of the 86 cadavers who experienced heavy work. Among U.S. workers, overexertion is the cause of LBP in more than 60 percent of cases (Jensen, 1988). According to the latest report of the BLS, overexertion in lifting accounts for about 32 percent of the total MSDs among workers (BLS, 2016).

The frequency of lifting and twisting greatly increase the physical stressfulness of the task (Singh et al., 2012). Previous studies have identified repetitive motion and prolonged task performance as occupational risk factors for the development of LBP (Marras, 2000; Manchikanti, 2000; Muslim et al., 2013; Hoogendoorn et al., 2000). It was shown that repetitive motion or prolonged task performance during trunk flexion could damage the spinal structure over time and eventually lead to LBP (Coenen et al., 2012; Granata et al., 2004).

Fatigue reduces muscle stiffness, which triggers an elevated co-contraction of antagonistic trunk muscles to maintain spine stability, such elevated co-contraction will finally increase the spinal compression force (Descarreaux et al., 2008). 
Awkward posture is another biomechanical risk factor of LBP. Awkward posture can cause muscle overload and can lead to ligaments and tendon injury (Kumar, 2001). Kumar claims that awkward postures will cause muscle and tendon inflammation because of microstructure compression.

Sudden loading is one of the major risk factors of LBP during the manual material handling (McCoy et al., 1997; Omino et al., 1992). The increased co-contraction of back and abdominal muscles during sudden loading elevates spinal compressive and shear forces (Marras et al., 1997, Lavender 1989). This excessive force combined with the low stability of the spine during the sudden loading can lead to low back injuries during the work (Granata 2000; Lavender 1993).

Exposure to WBV is another factor that contributes to LBP (Frymoyer et al., 1983, Kumar, 2001). A report denotes that about $4 \%$ to $7 \%$ of all employees in the U.S., Canada, and some European countries are exposed to WBV (International Social Security Association, 1989). One study claims that WBV is the main reason for LBP, and herniated disc among professional drivers (Hulshof et al., 1987). However, a safe exposure limit of WBV is not determined (Ling et al., 2000).

Lifting tasks involve about 50 to $75 \%$ of low back disorders (Bigos et al., 1986). Jobs that require heavy lifting loads will cause MSDs eight times more than jobs with sedentary nature (Shirazi-Adl et al., 2005). Frequent lifting, twisting, and lateral bending can have a combination which is a leading cause of LBP at workplace (Andersen, 1981; Marras et al., 1995). LBP can be generated due to muscular contraction. This may happen during the performance of manual tasks that involve substantial trunk bending, excessive spinal compression and shear forces, and ligament tension (Ning et al., 2015; Arjmand et al., 2005). Previous studies claim that the 
occupational low back disorders are predictable if there is a combination of lifting frequency, load moment, lateral trunk movement, trunk twisting and sagittal movement (Arjmand et al., 2011; Marras et al., 2009, Craig et al., 2003).

Some other studies have investigated the effect of the velocity on the spine (Marras et al., 1995; Davis et al., 2000). Based on Marras' findings, trunk strength will reduce by increasing the speed of dynamic trunk motion.

Pushing and pulling of objects may lead to two different risk factors: spinal stresses caused by applied hand force, and slipping or tripping problems (Knapik et al., 2009; Schibye, 2001).

Static postures consist of bent over working posture and seated working posture, and are the cause of LBP (Magora 1970; Kelsey, 1975). It was claimed that maintaining the same posture during the work, even with a combination of frequently changing the posture, will increase the risk of LBP (Magora, 1973).

\subsection{Spine Biomechanics}

\subsubsection{Spinal Loading}

Spinal tissues can be categorized into two different types of tissues: passive tissues and active tissues. Active tissues are a contractile component of trunk muscles; passive tissues consist of ligaments, intervertebral discs, and bones (Wagner et al., 2005). The interaction between spinal active and passive tissues during trunk bending motions has been studied extensively to better understand the neuromuscular control and human spine movements (Olson et al., 2009; Ning et al., 2015; Shin et al., 2007). 
During the spine loading, spinal extensor muscles contract and generate active contractile force, passive spinal tissues deform (e.g., elongates or rotates) and generate an elastic force. These forces result in compressive and shear forces on the spinal column, when these forces are high enough, intervertebral disc herniation (Adams et al., 2000) and other low back injuries can occur (Marras et al., 2001a).

\subsubsection{Flexion-Relaxation Phenomenon}

During trunk flexion, the interaction between spinal active and passive tissues can lead to the occurrence of FRP. Fick introduced the idea of FRP for the first time by claiming that during the full spine flexion, the ES muscle relaxes (Fick et al., 1911). Floyd and Silver used EMG technique for the first time as an experimental evidence to support Fick's claim (Floyd et al., 1951). They defined the sudden cessation of lumbar muscular activity toward the trunk full flexion posture as FRP (Floyd et al., 1955). FRP is caused by the shift of loading from lumbar paraspinal muscles to the lumbar posterior passive tissues during the bending motion. Previous studies have found several task-related factors such as load magnitude (Pialasse et al., 2010), motion speed (Dai B et al., 2010), muscle fatigue (Descarreaux et al., 2008) and ground conditions (Hu et al., 2013, 2016) that could significantly influence lumbar muscle FRP and the associated load sharing mechanism among lumbar tissues. Recent studies also demonstrated that asymmetric bending and unbalanced foot postures could alter lumbar muscle FRP (Ning et al., 2011). It can be noted that when trunk reaches close to full flexion, lumbar muscle EMG "turns off."

Moreover, pelvis has a key role in the spinal stability. The pelvis is the foundation of the movement of the spinal column. In the body movement, active muscles of the trunk, hip and 
thigh coordinate with the passive pelvic tissues to control the pelvic rotation and keep the spinal column stable (Wingerden et al., 1993).

\subsubsection{Lumbar and Trunk Kinematics}

The biomechanical models that investigate the lifting and lowering tasks require kinematic data collected during the movement. Previous studies show a reduction in lumbar muscular activity during FRP and spinal kinematics at an inter-vertebral level (Ning et al., 2011; Ning et al., 2012). Kinematic is the description of the body movement independent of forces that cause this movement (Kippers et al.,1984). During flexion task, there is a transition of the load from active tissues to passive tissues (Ning et al., 2012). During lowering phase, the moment arm is increasing at the L5/S1 joint so there should be a larger external moment on this joint. Though we would expect an increase in low back muscle activity level to compensate for this increased external moment. However, at the same time, passive tissues stretch and this stretch will counterbalance the external torque caused by upper body weight. Finally, there will be no muscle activity in the lumbar muscles (EMG-off point). During extension task, the lumbar muscles start activity at a certain point (EMG-on point). FRP is directly affected by lumbar curvature, so the EMG-off and EMG-on points are described in terms of lumbar flexion angle or trunk inclination angle. It was also shown that changes in stance posture might influence trunk kinematics and therefore this will make changes in the lumbar tissue synergy (Hu et al., 2013).

\subsubsection{Trunk Muscle Co-Contraction}

The antagonistic co-contraction is the activation of muscles generating force components acting in opposition to the desired trunk moment (Granata et al., 2005). This simultaneous 
contraction of both the agonist and the antagonist muscles is believed to enhance trunk stability. Ignoring co-contraction during the trunk flexion or extension may underestimate actual values in spinal load measurements (Granata et al., 2005).

\subsubsection{Foot Posture and Ground Condition}

The influence of different foot postures and ground condition on spinal loading was investigated in previous studies (Hu et al.; 2016, Ning et al., 2010; Mirka et al., 2011). Several studies have suggested that the squat (knee bent while the back is straight) lifting posture is preferable over the stoop lifting posture (Wang et al., 2015) but other studies preferred the stoop over the squat posture because of high energetic cost of squat posture and better balance in stoop posture (Welbergen et al., 1991; Bazrgari et al., 2007). Because of the load size and sometimes the setup of the work environment, the squat lifting posture is not always feasible (Bazrgari et al., 2007). A comprehensive review of 27 biomechanical studies compared stoop and squat technique and concluded that there is no preference for recommending the squat technique (Van Dieen et al., 1999). One study investigated the physiological cost of the three different techniques of lifting (squat, stoop and free-style) in the symmetric and asymmetric planes (Kumar. 1984). It was shown that the squat technique is a physiologically more demanding technique in terms of oxygen consumption, while the stoop was the least physiologically demanding. Another study suggests that the squat technique generated lower biomechanical stresses on the lower back compared with the stoop technique (Andersson et al., 1986). When the weight of the external load increases the lifting technique changes from squat to stoop (Schipplein et al., 1990). It was also discovered that when muscle fatigue occurs, stoop lifting technique is preferable (Trafimow et al., 1993). 
Several studies focused on different ground conditions during working (Ning et al., 2010;

Mirka et al. 2011; Hu et al., 2013; Lin et al., 2012; Hu et al., 2016). The risk of LBDs could increase during working on an uneven surface. Recent studies found that standing on an uneven ground surface reduces body stability (Lin et al., 2012). 


\subsection{Rationale}

As it was already described, to reduce the risks of work-related LBP, previous studies have investigated the influence of different lifting techniques on spinal loading. However, the effects of lifting techniques on spinal tissue loading and the associated LBP risks remained controversial. Some recent studies suggested that adopting a staggered foot posture may improve spinal stability (Ning et al., 2014) because of its increased base of support (Holbein-Jenny et al. 2007; Zhou et al., 2013). However, the influence of staggered foot posture on spinal tissue loading and the associated risk of LBP has not been explored.

The goal of the current study is to understand the influence of staggered foot postures on lifting biomechanics. More specifically, we were interested in understanding if maintaining a staggered foot posture could help reduce spinal tissue loading (as compared to the normal close foot condition) and to find the influence of this posture on the spinal cumulative electromyography (EMG), and active and passive tissue interactions. Previous studies showed that the increase of knee flexion might create laxity among posterior lumbar tissues which could delay the onset of lumbar muscle flexion-relaxation phenomenon (FRP) (Shin et al., 2004) and increase the cumulative load on paraspinal muscles. Based on the existing evidence we hypothesized that by performing trunk bending motions with staggered foot posture, unbalanced cumulative lumbar muscle exertion is expected, and with the increase of foot distance, trunk kinematics change, and the flexion-relaxation phenomenon (FRP) of lumbar muscle alters. This can elevate CEMG among back muscles in the larger foot distance condition. 


\section{CHAPTER 2. METHODS}

\subsection{Participants}

Our pilot study and the power analysis suggested a sample size of twelve subjects (with $\alpha=0.05$ and 0.9 power). We recruited fourteen volunteers with no chronic or currently experiencing LBP from the student population of West Virginia University. Their average age, body height, and weight were 27.4 (SD 4.5) years, 171.8 (SD 9) $\mathrm{cm}$ and $71.4(\mathrm{SD} 11.3) \mathrm{kg}$ respectively. Written informed consents were obtained from all participants before the experiment; all experimental procedures were reviewed and approved by the Institutional Review Board of West Virginia University.

\subsection{Instrumentation}

Two bipolar surface EMG electrodes (Bagnoli, Delsys, Boston, MA, USA) were placed bilaterally over the paraspinal muscles at L3 level (4 cm away from the spinous process) level to record muscle activities (Figure 5). Three electromagnetic based motion sensors were placed over the skin surface over the C7, T12 and S1 vertebrae (Ning et al., 2011).

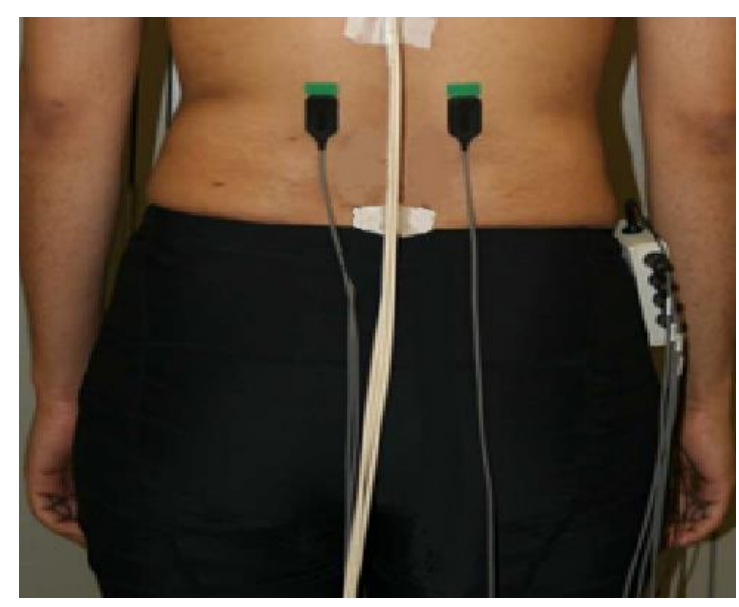

Figure 5: Bipolar surface EMG electrodes and their positions on the skin 
The Motion Monitor software was used to synchronize the EMG and kinematic data at a sampling frequency of $1024 \mathrm{~Hz}$. The maximum voluntary contraction (MVC) was performed using a dynamometer and a trunk flexion-extension attachment (HUMAC Norm, Computer Medicine, Stoughton, MA, USA). HUMAC Norm System is designed to measure the MVC of the paraspinal muscles (Figure 6).

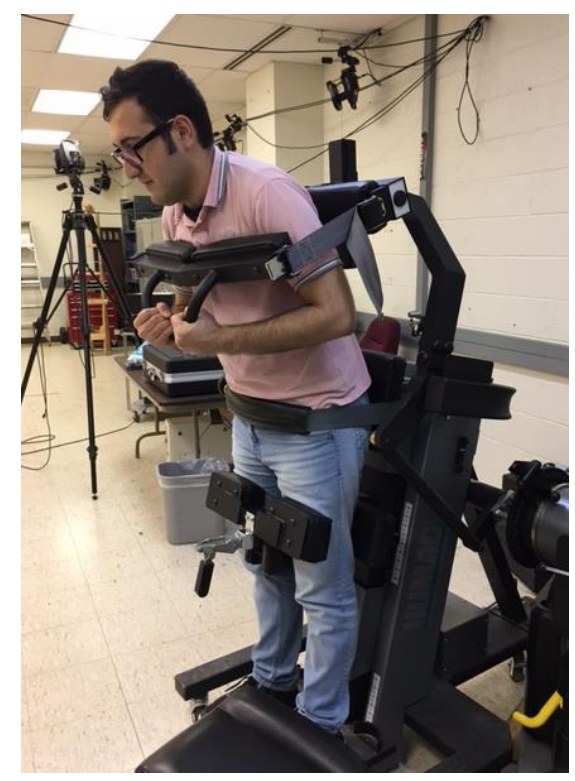

Figure 6: The HUMAC Norm system with a back flexion and extension module.

\subsection{Experimental Design}

\subsubsection{Independent Variables}

There were two independent variables in this study: foot postures (FP) and hand load (L). Three different foot postures were tested: A. Closed foot, B. Staggered with right foot $1 \mathrm{ft}$ forward, C. Staggered with right foot $2 \mathrm{ft}$. forward (Figure 7, 8). Two levels of hand load were tested at 0 lbs. (no load) and $15 \mathrm{lbs}$. During performing weight trials, lifting weight is located at the center of the barbell and the barbell length was almost as long as the shoulder width. 

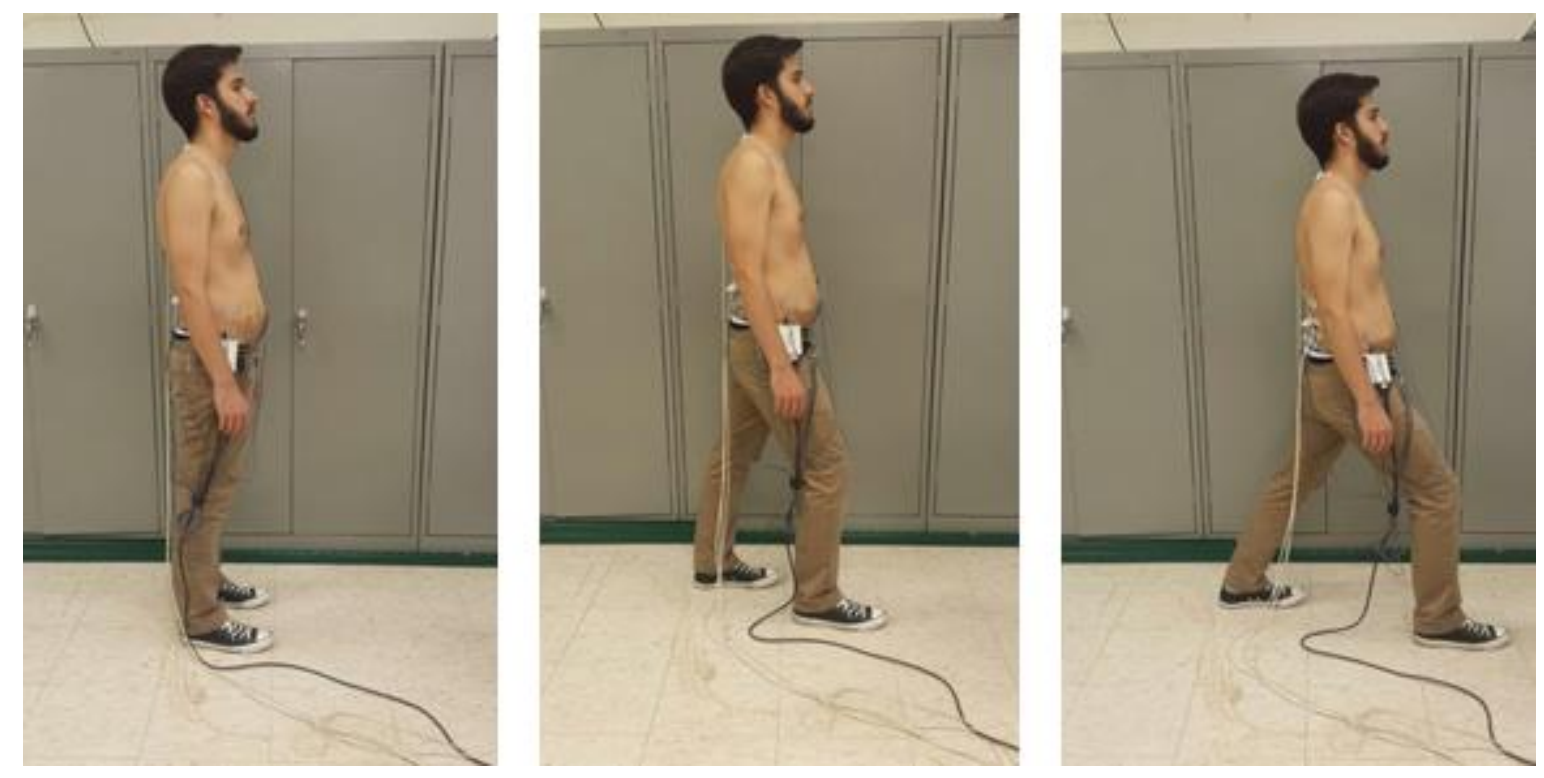

(a)
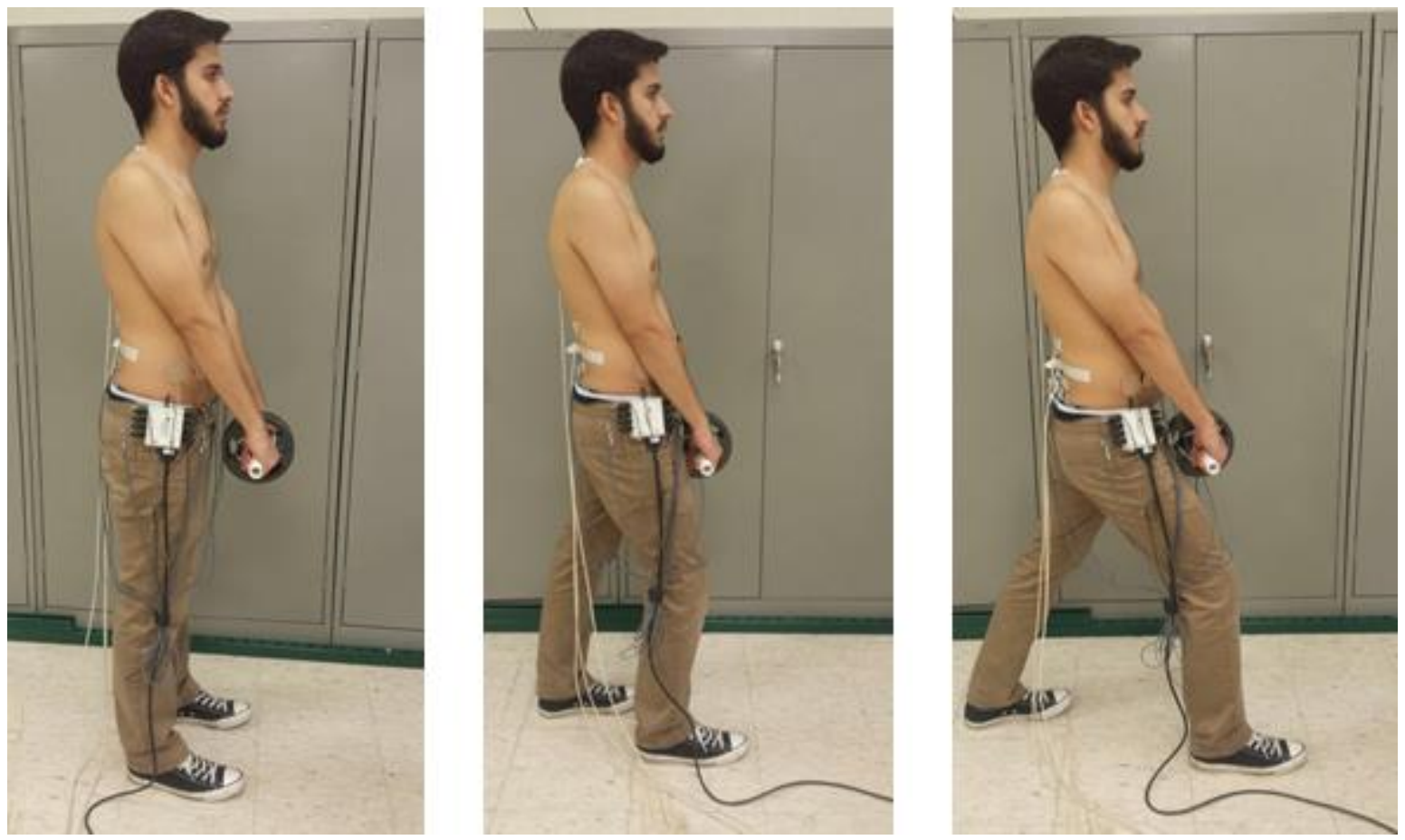

(b) 

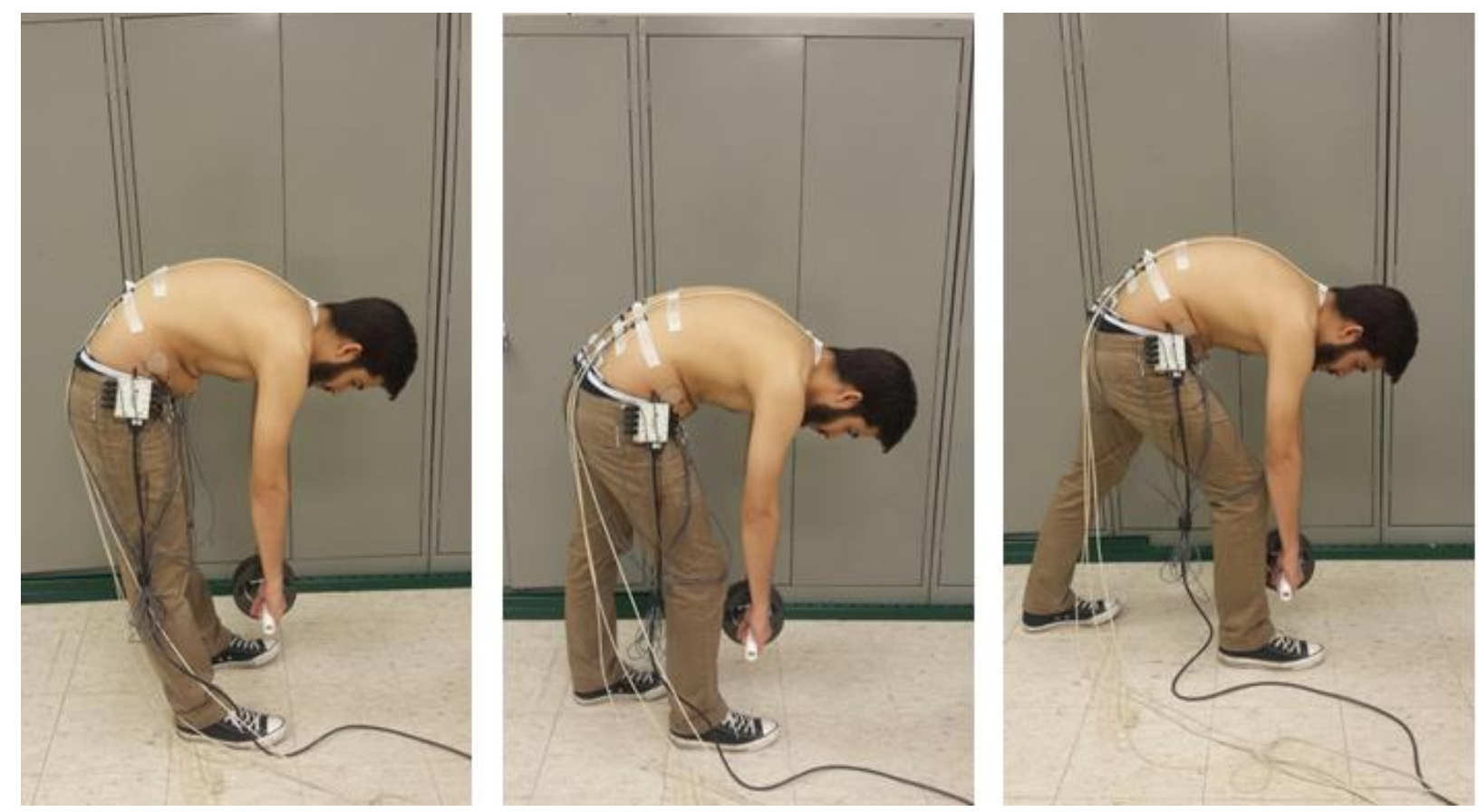

(c)

Figure 7: a, b and c: Illustration of different foot postures and load handling

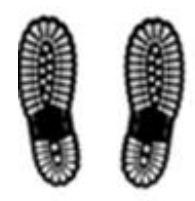

A

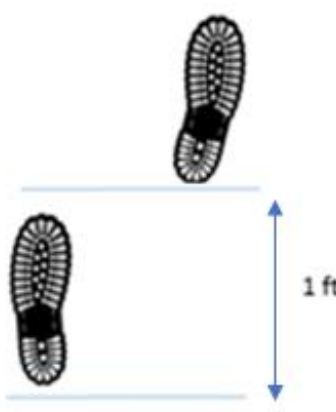

B

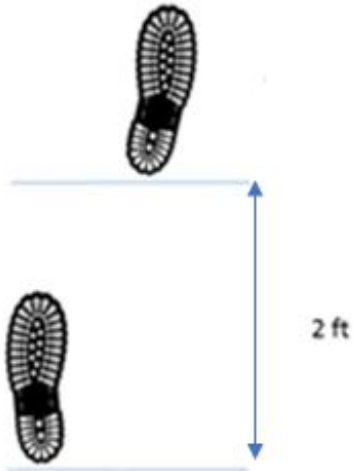

C

Figure 8: Demonstration of three different stance width 


\subsubsection{Dependent Variables}

In the current study, three categories and a total of 28 dependent variables were investigated The first category of the dependent variables described the cumulative muscle work performed during trunk flexion and extension motions. First, CEMG related variables were:

- Left paraspinals cumulative EMG during trunk flexion (LCEMGFlex) and trunk extension (LCEMGExt),

- Right paraspinals cumulative EMG during trunk flexion (RCEMGFlex) and trunk extension (RCEMGExt).

Second, FRP related variables were:

- Left paraspinals EMG-off lumbar angle (LL) and trunk angle (LT),

- Right paraspinals EMG-off lumbar angle (RL) and trunk angle (RT),

- Maximum lumbar angle (ML) and maximum trunk angle (MT).

The third category of dependent variables was the normalized motion coordination related variables. For each trial, lumbar and trunk angles were normalized to their range of motion. The flexion and extension range were both divided into ten equally distanced subsegments based on the normalized trunk angle. Then, the normalized lumbar rotational angles at 10th, 20th, 30th, 40th, 50th, 60th, 70th, 80th, and 90th percentile of normalized trunk rotational angle for both lowering and lifting tasks were compared. There were 18 motion coordination related variables for the flexion ( 9 variables) and the extension (9 variables) parts of this category including:

- Percent lumbar angle corresponding to the $\mathrm{X} \%$ trunk flexion (LATAFX)

- Percent lumbar angle corresponding to the X\% trunk extension (LATAEX) 


\subsection{Experimental Protocol}

Before data collection, the experimental procedure was fully described to the participant. A five-minute warm-up session was provided to have participants become familiar with the experiment and avoid sudden muscle stretch. Surface EMG electrodes and motion sensors were then placed at locations described above. At the beginning of the experiment, participants were asked to perform two MVC exertions. Each exertion lasted six seconds with one-minute rest between each trial to avoid the accumulation of muscle fatigue. In each MVC trial, participants stood in the back flexion-extension attachment with the pelvis and lower extremities fully secured and performed two repetitions of isometric sagittally symmetric maximum trunk extension exertion in a $20^{\circ}$ flexed trunk posture (Mirka and Marras, 1993). After approximately 10 minutes of rest, each participant then completed a total of 24 pace-controlled trunk flexion and extension motions in a randomized order ( 3 -foot postures $\times 2$ levels of load $\times 4$ repetitions). In each trial, participants were asked to use seven seconds to move from upright standing posture to reach to a fully flexed trunk posture, stay in the fully flexed posture for six seconds then use another seven seconds to move back to an upright standing. In the two staggered foot conditions, participants were asked to put their left foot backward, and right foot forward with the right ankle remaining in at $\sim 90$ degrees, and the lower leg (right leg) was perpendicular to the ground surface (Figure 7). During all trials, participants were asked to maintain their arms straight down. One minute of rest was given between trials. The horizontal distance between the feet was as wide as the shoulder width for each subject. 


\subsection{Data Processing}

In the current study, a customized computer program was used to process both EMG and kinematics data (Matlab 2010, MathWorks, Natick, MA, USA). Raw EMG data from the two sampled muscles were first transferred into the frequency domain and passed through a 10-500 $\mathrm{Hz}$ band filter and a notch filtered at $60 \mathrm{~Hz}$ and its aliases.

To calculate CEMG during trunk flexion and extension motions, the filtered EMG data for each muscle was fully rectified and smoothed using a 128 window (which is $1 / 8$ of a second). For each muscle, the peak EMG value from MVC trials was considered as the maximum EMG for the corresponding muscle. Then EMG profiles from sub-maximum trials (i.e., trunk flexion and extension trials) were normalized with respect to their corresponding maximum EMG. In this study, the lumbar rotation angle was defined as the sagittal angular difference between the two motion sensors secured over T12 and S1 vertebrae; the trunk inclination angle was defined as the angular difference between the line that connects the C7 and S1 motion sensors and the normal vertical line. Trunk angle is used to determine the cumulative area of EMG as an indicator of the muscle activity. To standardize the range of motion across all conditions and all participants, we used the 15-degree trunk angle as the starting point and 5 degrees before the maximum trunk flexion angle as the ending point to calculate the CEMG. Among trials with the two-step position, subjects tended to start trial from a slightly forward bent posture because of the body postures in those trials. The reason for choosing the 15 -degree trunk angle was to ensure that all participants had the same starting point in the trunk posture. The ending point (5 degrees before the maximum trunk flexion angle) was selected to eliminate the FRP phase of the trunk motion, so all subjects had the same range of motion across all conditions. Also, by using the "resample" function in MATLAB, the total duration for each lifting or lowering task was 
standardized to 7 seconds (7168 data points) to avoid differences in task performance time and make sure that the same duration was used for all trials. To illustrate the mechanism of the "resample" function, please see figure 9 as a general example in MATLAB. By applying this function, data for each trial was interpolated, and the new uniform fixed rate was extracted using an antialiasing lowpass filter to data.

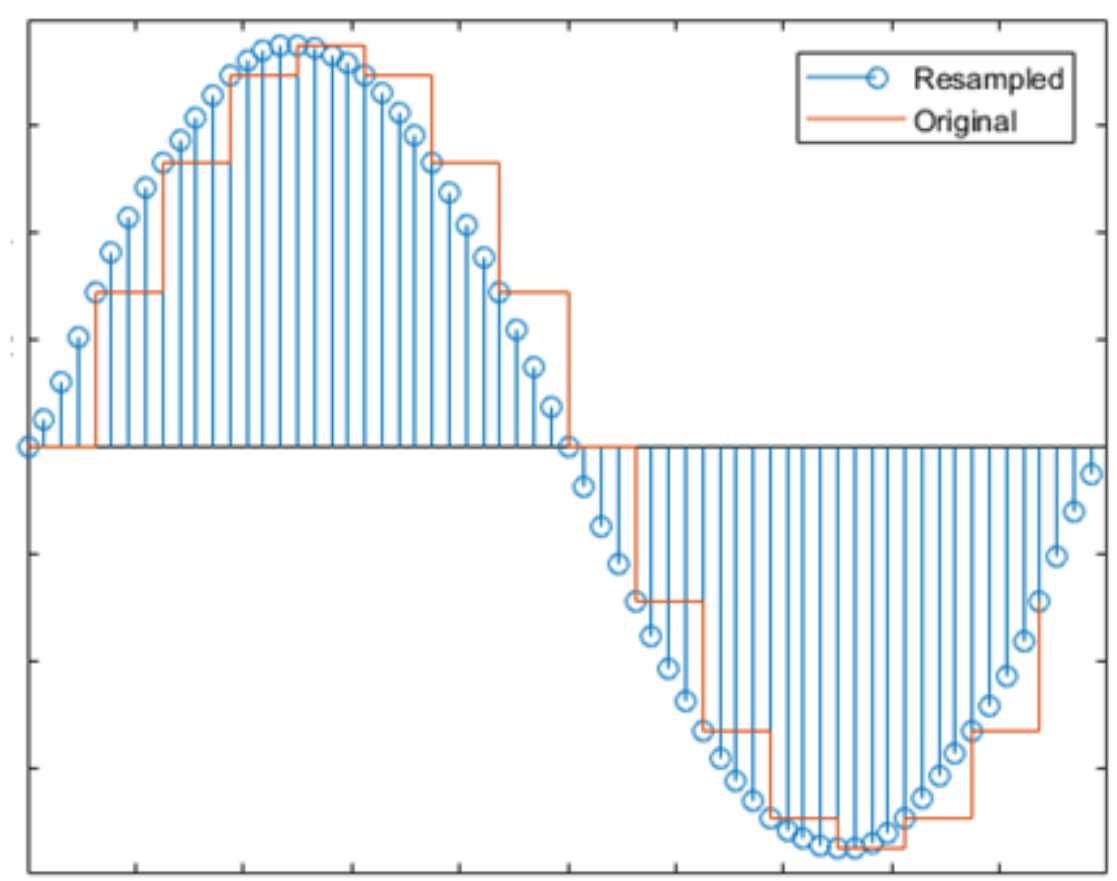

Figure 9: An illustration of the mechanism of the "resample" function in MATLAB

We calculated the average of every 128 data points of the resampled data (EMG data for each muscle was rectified and smoothed using a 128 window which is $1 / 8$ of a second) and multiplied this average by the corresponding time duration (i.e., 128/1024=0.125 second). Then values within all 7 seconds were added up to find the CEMG. Figure 10 illustrates the integration process. 


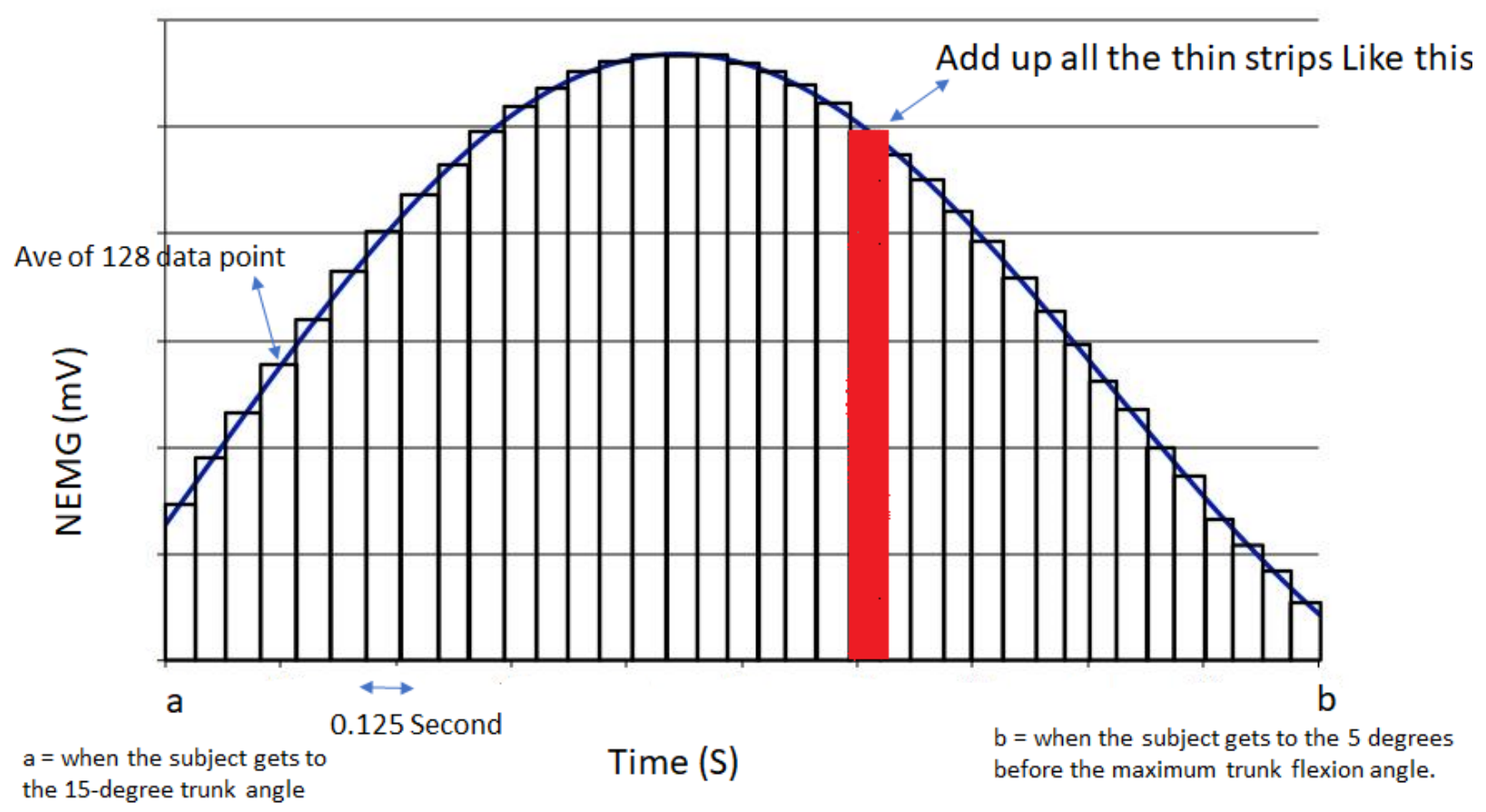

Figure 10: Illustration of integrating EMG and calculating CEMG

The CEMG was then calculated by integrating NEMG during the corresponding duration of lifting or lowering.

To identify the locations of EMG-off and EMG-on points, a standard deviation (SD) profile for the filtered EMG profile was generated using a 128-data points sliding window. A Featured Standard Deviation (FSD) was identified at the full flexion posture for each muscle, then the EMG-off and EMG-on points during trunk flexion and extension motions were identified as the first and last points at which the SD values were less than $3 *$ FSD. The corresponding lumbar flexion and trunk inclination angles at the EMG-off and EMG-on points were then found. In other words, the EMG-off point corresponds to the last point in which the SD of that muscle is larger than $3^{*}$ FSD during trunk flexion (Ning et al., 2011).

The motion coordination between lumbar and trunk angles was also investigated. First, lumbar flexion and trunk inclination angles were normalized from 0 (corresponding to upright 
posture) to 1 (corresponding to full flexion posture) with respect to their standardized range of motion. The flexion and extension ranges were both divided into ten equally distance subsegments based on the normalized trunk angle. Then, the normalized lumbar rotational angles at 10th, 20th, 30th, 40th, 50th, 60th, 70th, 80th, and 90th percentile of normalized trunk rotational angles were compared.

\subsection{Statistical Analysis}

To investigate the effects of independent variables and their interactions on the set of dependent variables multivariate analysis of variance (MANOVA) was performed in the first step. In the second step, the independent variables that had significant effects were further explored by univariate analysis of variance (ANOVA) (Montgomery, 2012). So, the assumptions of the ANOVA procedures were tested (independence of observations, normal distribution of residuals and constant variance of residuals). Variables that did not satisfy one or more assumptions were transformed to meet the criteria (Montgomery 2012). The effects of foot posture and load on each dependent variable were tested, and subjects were considered as a random factor. The following general linear statistical model was used in this study to perform the analysis:

$$
Y_{i j k}=\mu+\tau_{i}+\beta_{j}+\varepsilon_{i j k}
$$

In this model $\mathrm{Y}_{\mathrm{ijk}}, \mu, \tau_{\mathrm{i}}, \beta_{\mathrm{j}}$, and $\varepsilon_{\mathrm{ijk}}$ respectively represent the dependent variables, the overall mean, the main effect of independent variables, subject (block) effects, and the random error. The total sum of squares was calculated using the following equation: 


$$
S S_{T}=\sum_{i=1}^{a} \sum_{j=1}^{b} \sum_{k=1}^{n} Y_{i j k}^{2}-\frac{y_{\ldots}^{2}}{a b n}
$$

Sums of squares for the main effects and block (subject) effects were calculated as:

$$
\begin{gathered}
S S A=\frac{1}{b n} \sum_{i=1}^{a} y_{i . .}^{2}-\frac{y_{\ldots \ldots}^{2}}{a b n} \\
S S B=\frac{1}{a n} \sum_{j=1}^{b} y_{. j .}^{2}-\frac{y_{\ldots}^{2}}{a b n}
\end{gathered}
$$

In this model, each trial was treated as a single observation independent of the other trials, and each subject was considered as a blocking factor. To analyze the differences between the two conditions, for the third step, Tukey-Kramer post hoc analyses were performed on the significant effects between the three different foot postures. The $\alpha$ was set at 0.05 for statistical analyses in all steps.

Minitab's Power and Sample Size tools can help us make sure that we collected enough data to conduct a reliable analysis. In the current study, to perform the power analysis calculation, we used the standard deviation of dependent variables LCEMGFlex, LCEMGExt, RCEMGFlex, RCEMGExt (because of their importance and role in this study). The following figures show that the sample size of 12 is enough in this study. 

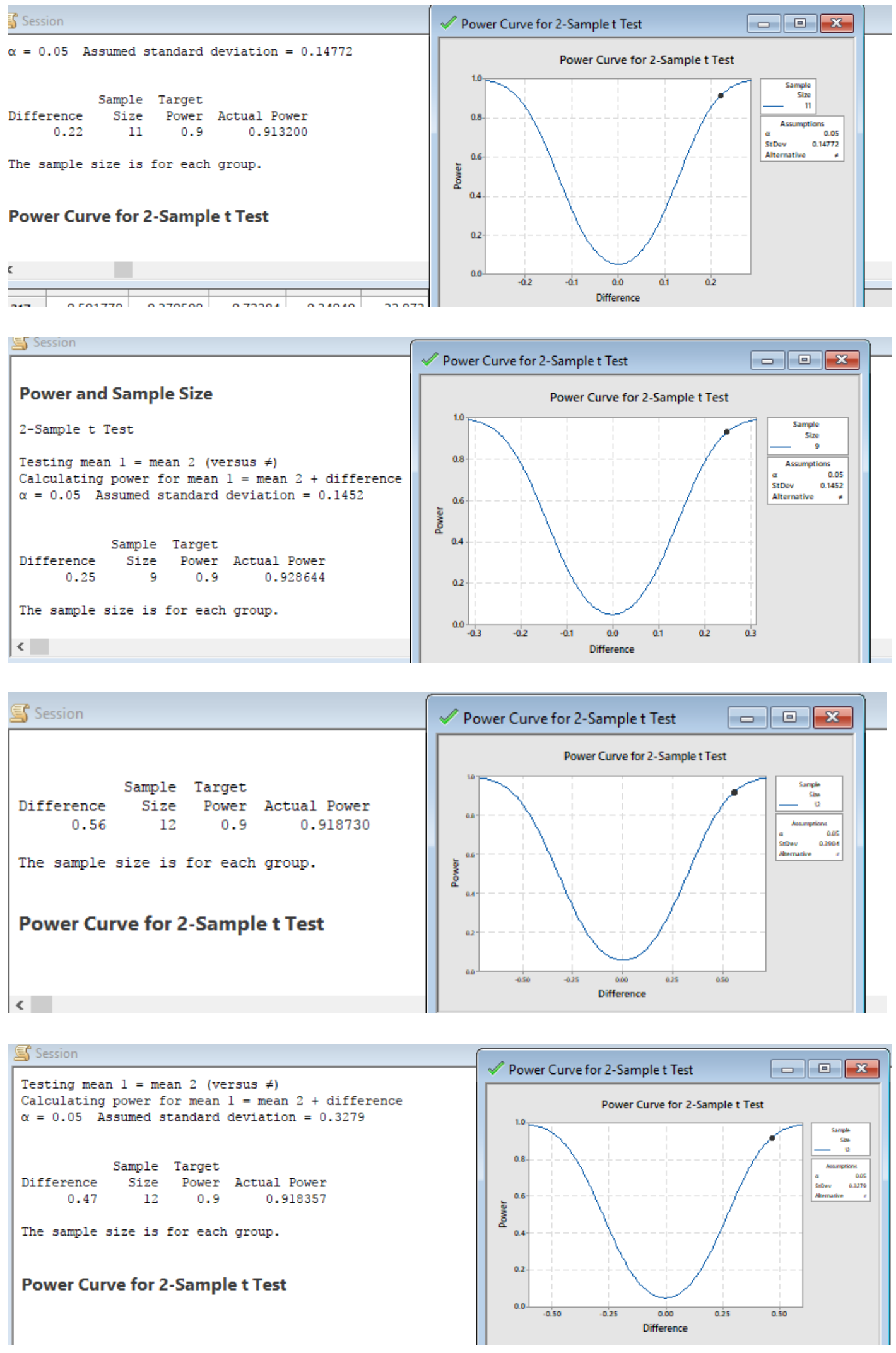

Figure 11: The output of power analysis in Minitab 


\section{CHAPTER 3. RESULTS}

For CEMG variables, results of MANOVA show the effects of both main variables are significant, but their interactions are not significant (Table 1). ANOVA results show that foot posture (FP) and load (L) significantly affects all CEMG related variables (LCEMGFlex, LCEMGExt, RCEMGFlex and RCEMGExt.) (Table 1). During trunk flexion motion, CEMG increases significantly with the increase of the staggered foot distance, and the highest CEMG always exists in the two-step conditions for both left and right sides of the ES (Figure 11). During trunk extension motion, the right side of the ES also demonstrates increased CEMG with the elevation of foot distance; for the left side of the ES, the two-step staggered foot posture shows a similar level of CEMG as the no-step condition, and the one-step staggered foot posture shows the lowest level of CEMG (Figure 12).

Results of MANOVA for the second category of the variables, FRP related ones, show the effects of both independent variables are significant but their interactions are not significant (Table 1). ANOVA results show that for this category, foot posture significantly affects RL, RT, MT, and load significantly affects all FRP related variables (RL, LL, RT, LT, ML, MT) (Table 1). The right side of the erector spinae EMG-off lumbar angle shows a significant reduction in one-step, and there is no significant difference between no-step and two-step, and for the left side, there is no significant difference between different foot conditions (Figure 13). Figure 14 demonstrates that for EMG-off trunk angle for the right side there is a significant reduction when the subjects use one step forward, but there is no significant difference between different foot postures in terms of muscle activity for the left muscle (Figure 14). Maximum trunk angle has a 
significant increase in the one-step condition (Figure 15), and there is no significant change in terms of maximum lumbar angle for different foot postures (Figure 16).

For motion coordination related variables during the flexion, results of MANOVA in Table 1 demonstrates that effects of both foot posture and load are significant, but their interactions are not significant. ANOVA results show that foot posture significantly affects LATAF50, LATAF60, LATAF70, and LATAF80; and load significantly affects all different lumbar angles corresponding to the relative trunk flexion. In the extension part of the second category of dependent variables; the results of MANOVA in Table 1 shows that the effects of both foot posture and load are significant, but their interactions are not significant. ANOVA results show that foot posture significantly affects LATAF40, LATAF50, LATAF60, LATAF70, LATAF80, and LATAF90; and load significantly affects LATAE30 and LATAF90 lumbar angles corresponding to the relative trunk flexion (Table 1).

Figures 17 shows that for 50, 60 and 70 percent of the trunk flexion, there are significant differences between two-step and no-step conditions for related lumbar angles. Figures 18 demonstrates that for $10,40,50,60,70,80$ and 90 percent trunk flexion, there are significant differences between two-step and no-step conditions for related lumbar angles during the extension task. In these two figures (Figures 17 and 18), upright standing posture is defined as 0 , and full flexion posture is defined as one as they are depicted in figures. 
Table 1: Results of ANOVA and MANOVA on dependent variables

\begin{tabular}{|c|c|c|c|c|c|c|c|c|c|c|c|}
\hline \multicolumn{12}{|c|}{ CEMG \& FRP related dependent variables } \\
\hline \multirow[b]{2}{*}{ Variable } & \multicolumn{2}{|c|}{ MANOVA } & \multicolumn{9}{|c|}{ ANOVA } \\
\hline & & RLCEMGFlex & LCEMGFlex & RCEMGExt & LCEMGExt & $\mathrm{RL}$ & $\mathrm{LL}$ & RT & LT & $\mathrm{ML}$ & MT \\
\hline FP & $<0.001$ & $<0.001$ & $<0.001$ & $<0.001$ & $<0.001$ & $<0.001$ & 0.363 & $<0.001$ & 0.205 & 0.125 & $<0.001$ \\
\hline $\mathrm{L}$ & $<0.001$ & $<0.001$ & $<0.001$ & $<0.001$ & $<0.001$ & $<0.001$ & $<0.001$ & $<0.001$ & $<0.001$ & $<0.001$ & $<0.001$ \\
\hline \multirow[t]{3}{*}{$F P^{*} \mathrm{~L}$} & 0.737 & - & - & - & - & - & - & - & - & - & - \\
\hline & \multicolumn{11}{|c|}{$\begin{array}{c}\text { Motion Coordination related dependent variables } \\
\text { Flexion Variables }\end{array}$} \\
\hline & & LATAF10 & LATAF20 & LATAF30 & LATAF40 & LATAF50 & LATAF60 & LATAF70 & LATAF80 & \multicolumn{2}{|l|}{ LATAF90 } \\
\hline FP & $<0.001$ & 0.13 & 0.163 & 0.591 & 0.236 & $<0.001$ & $<0.001$ & $<0.001$ & $<0.001$ & 0.302 & \\
\hline $\mathrm{L}$ & $<0.001$ & $<0.001$ & $<0.001$ & $<0.001$ & $<0.001$ & $<0.001$ & $<0.001$ & $<0.001$ & $<0.001$ & \multicolumn{2}{|l|}{$<0.001$} \\
\hline$F P^{*} \mathrm{~L}$ & 0.096 & - & - & - & - & - & - & - & - & - & \\
\hline \multicolumn{12}{|c|}{ Extension Variables } \\
\hline & & LATAE10 & LATAE20 & LATAE30 & LATAE40 & LATAE50 & LATAE60 & LATAE70 & LATAE80 & \multicolumn{2}{|l|}{ LATAE90 } \\
\hline FP & $<0.001$ & $<0.001$ & 0.356 & 0.862 & $<0.001$ & $<0.001$ & $<0.001$ & $<0.001$ & $<0.001$ & $<0.001$ & \\
\hline $\mathrm{L}$ & $<0.001$ & 0.244 & 0.076 & $<0.001$ & 0.068 & 0.065 & 0.249 & 0.847 & 0.111 & \multicolumn{2}{|l|}{$<0.001$} \\
\hline$F P * L$ & 0.115 & - & - & - & - & - & - & - & - & - & \\
\hline
\end{tabular}




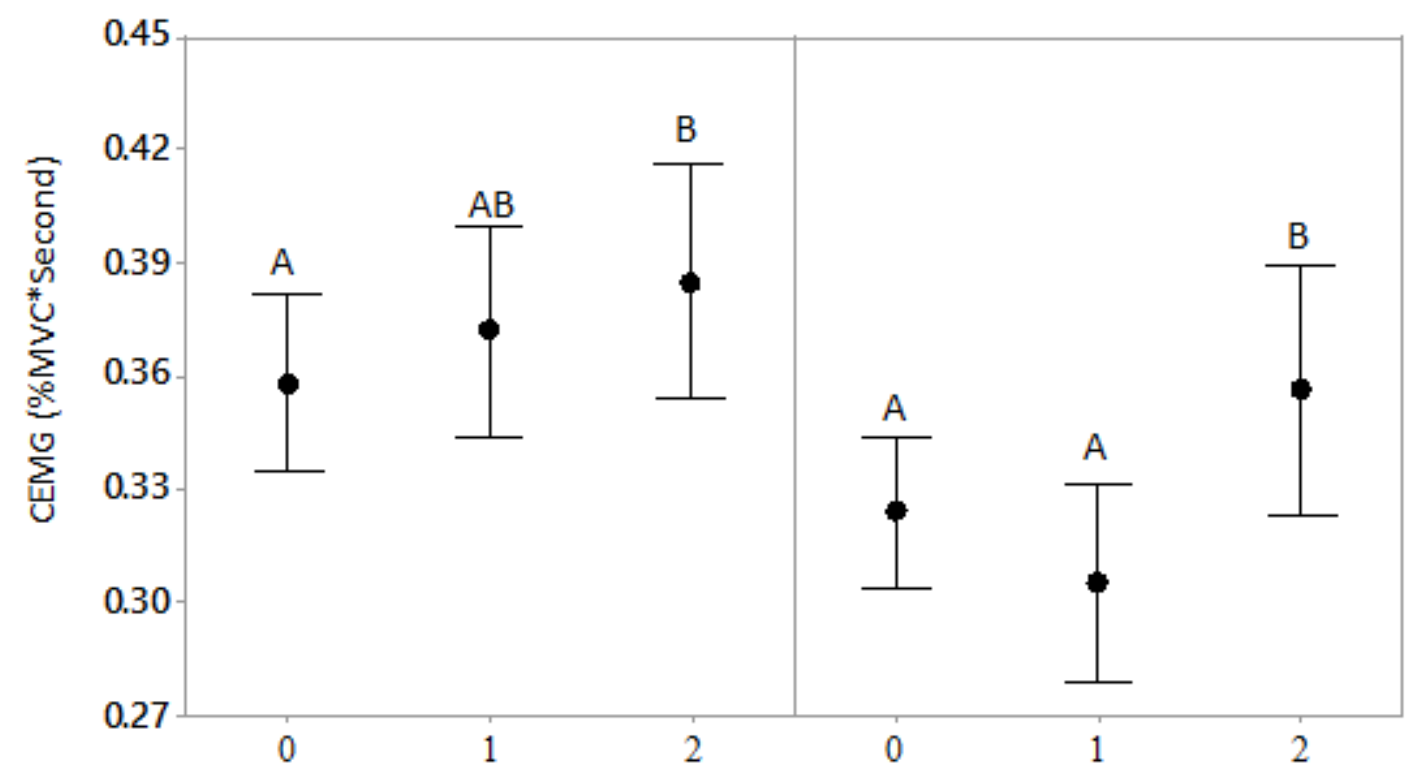

Figure 12: Effects of foot posture on the CEMG during trunk flexion

(The left panel represents the RCEMGFlex, and the right panel represents the LCEMGFlex; 0 `corresponds to no-foot posture, 1 corresponds to one-step foot posture and 2 corresponds to two-step foot posture)

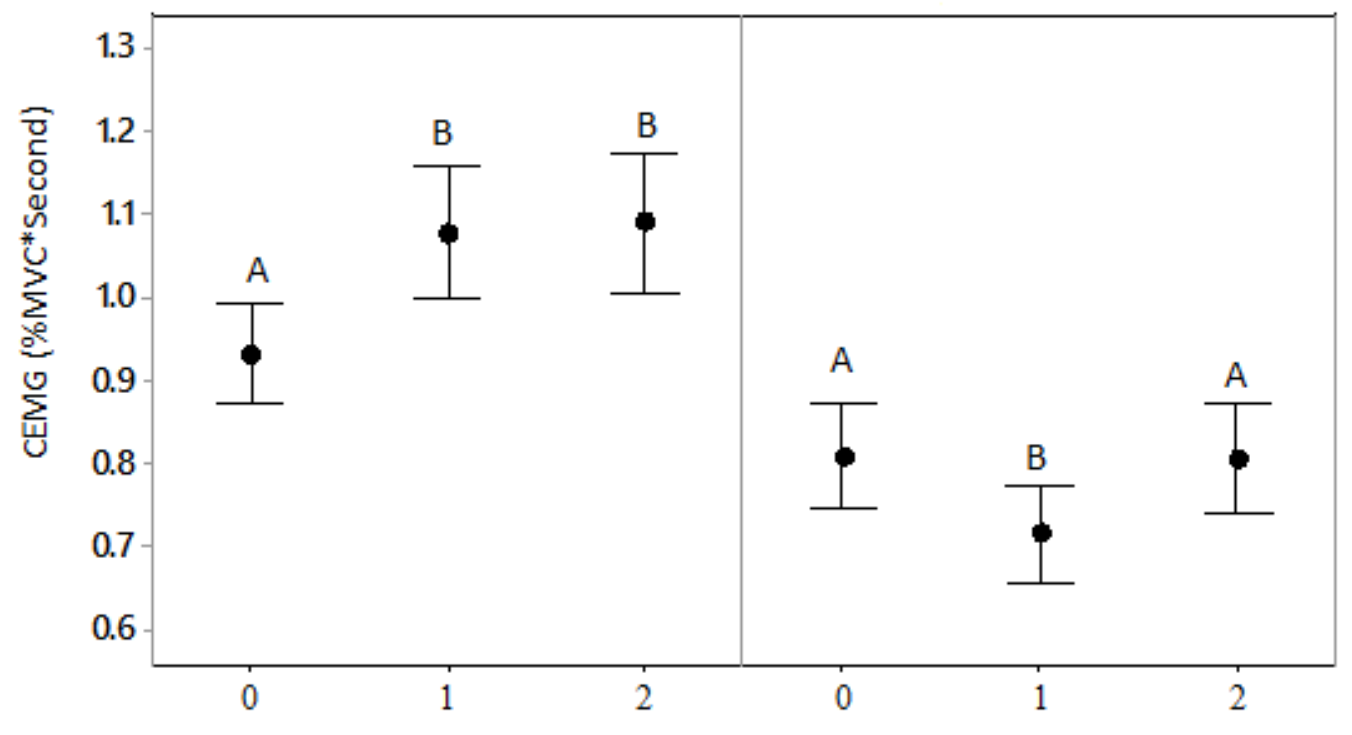

Figure 13: Effects of foot posture on the CEMG during trunk extension

(The left panel represents the RCEMGExt, and the right panel represents the LCEMGExt; 0 `corresponds to no-foot posture, 1 ` corresponds to one-step foot posture and 2 ` corresponds to two-step foot posture). 


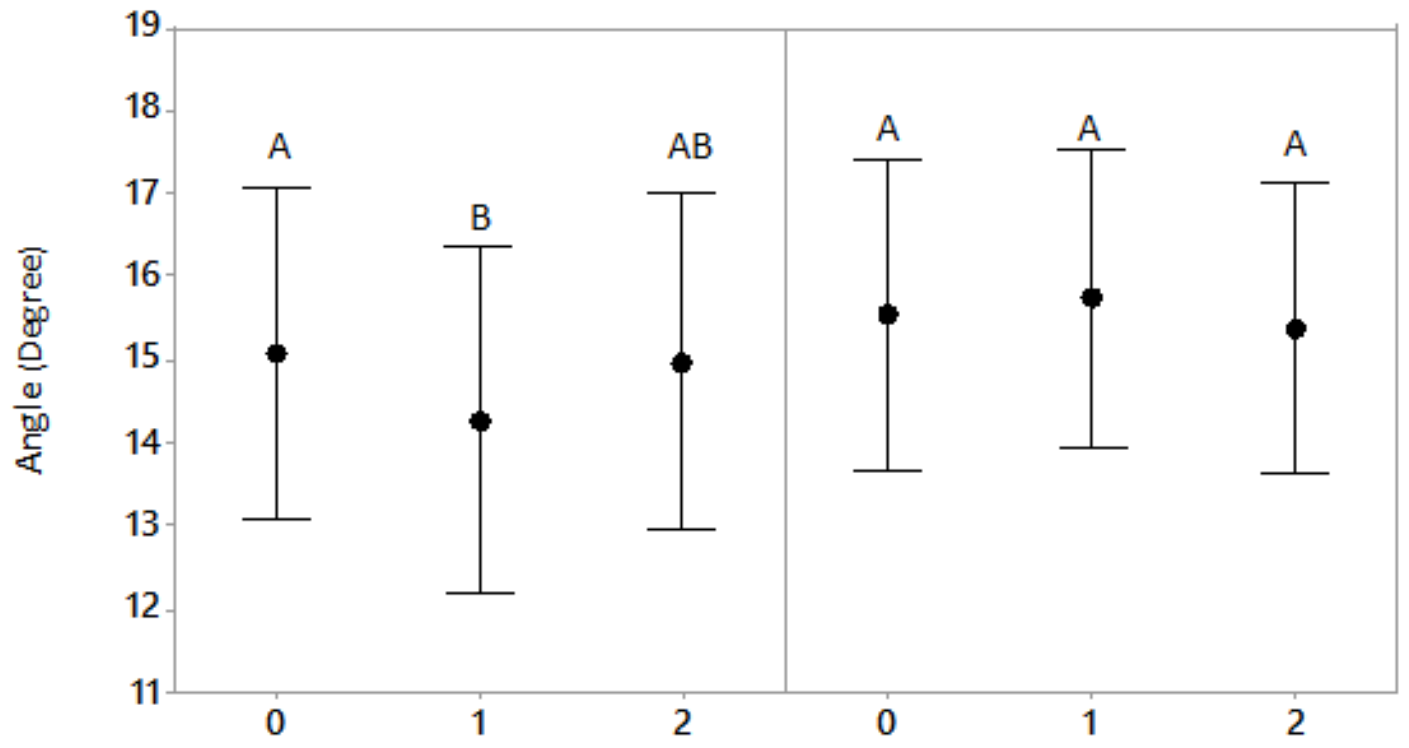

Figure 14: Effects of foot posture on EMG-off lumbar angle

(The left panel represents the RL, and the right panel represents the LL; 0 'corresponds to no-foot posture, 1 corresponds to one-step foot posture and 2 corresponds to two-step foot posture)

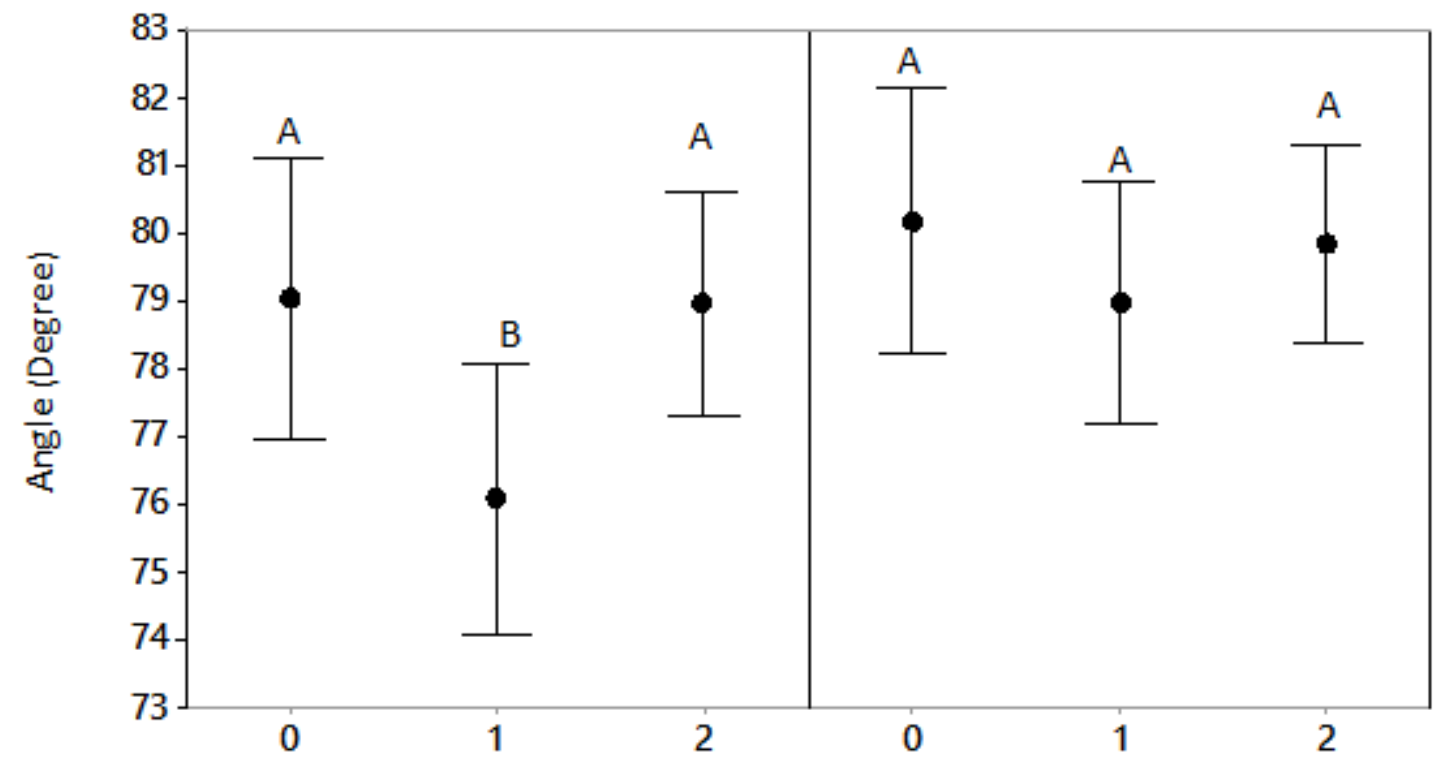

Figure 15: Effects of foot posture on EMG-off trunk angle

(The left panel represents the RT, and the right panel represents the LT; 0'corresponds to no-foot posture, 1 corresponds to one-step foot posture and 2 corresponds to two-step foot posture) 


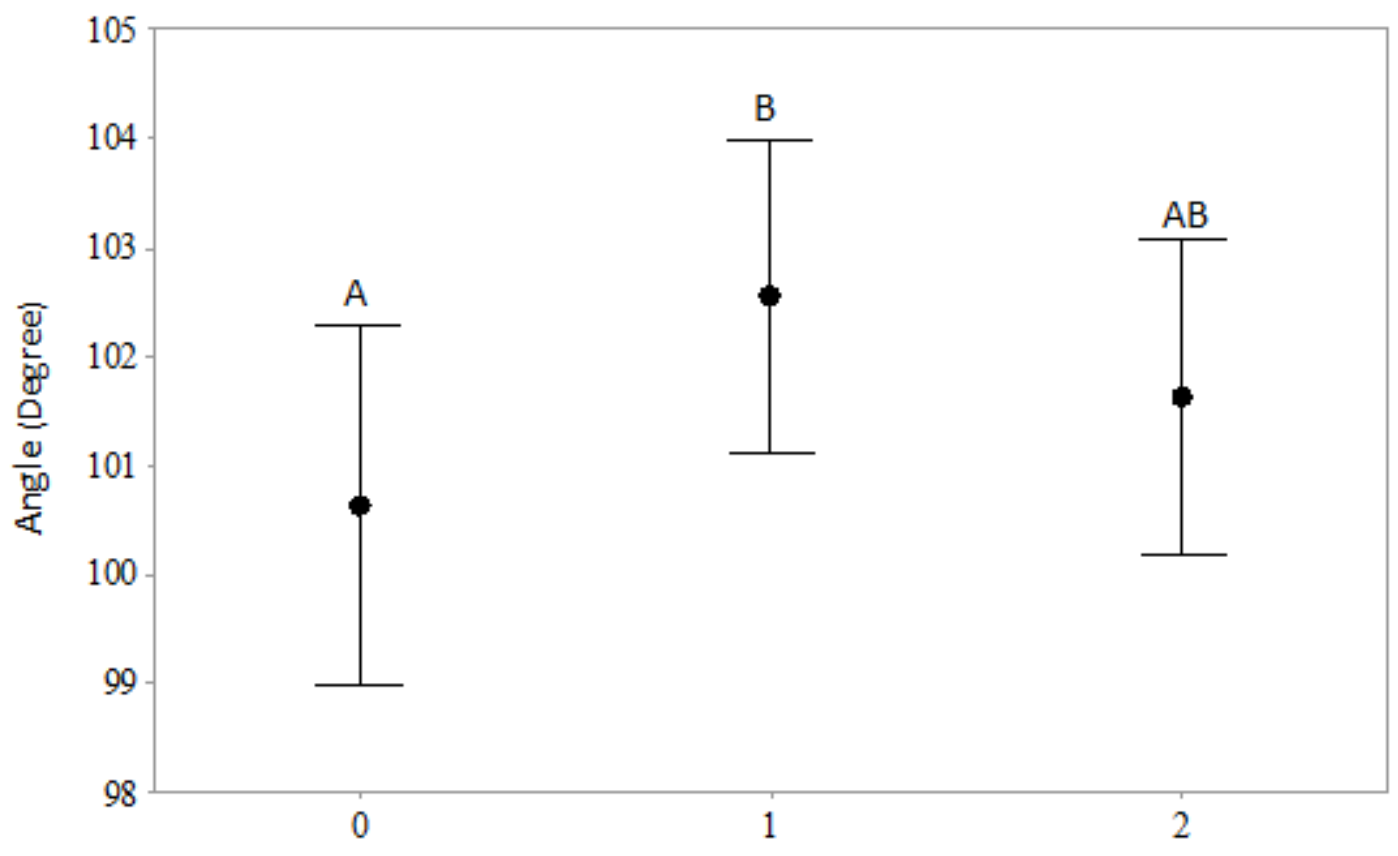

Figure 16: Effects of foot posture on the Max Trunk angle (MT)

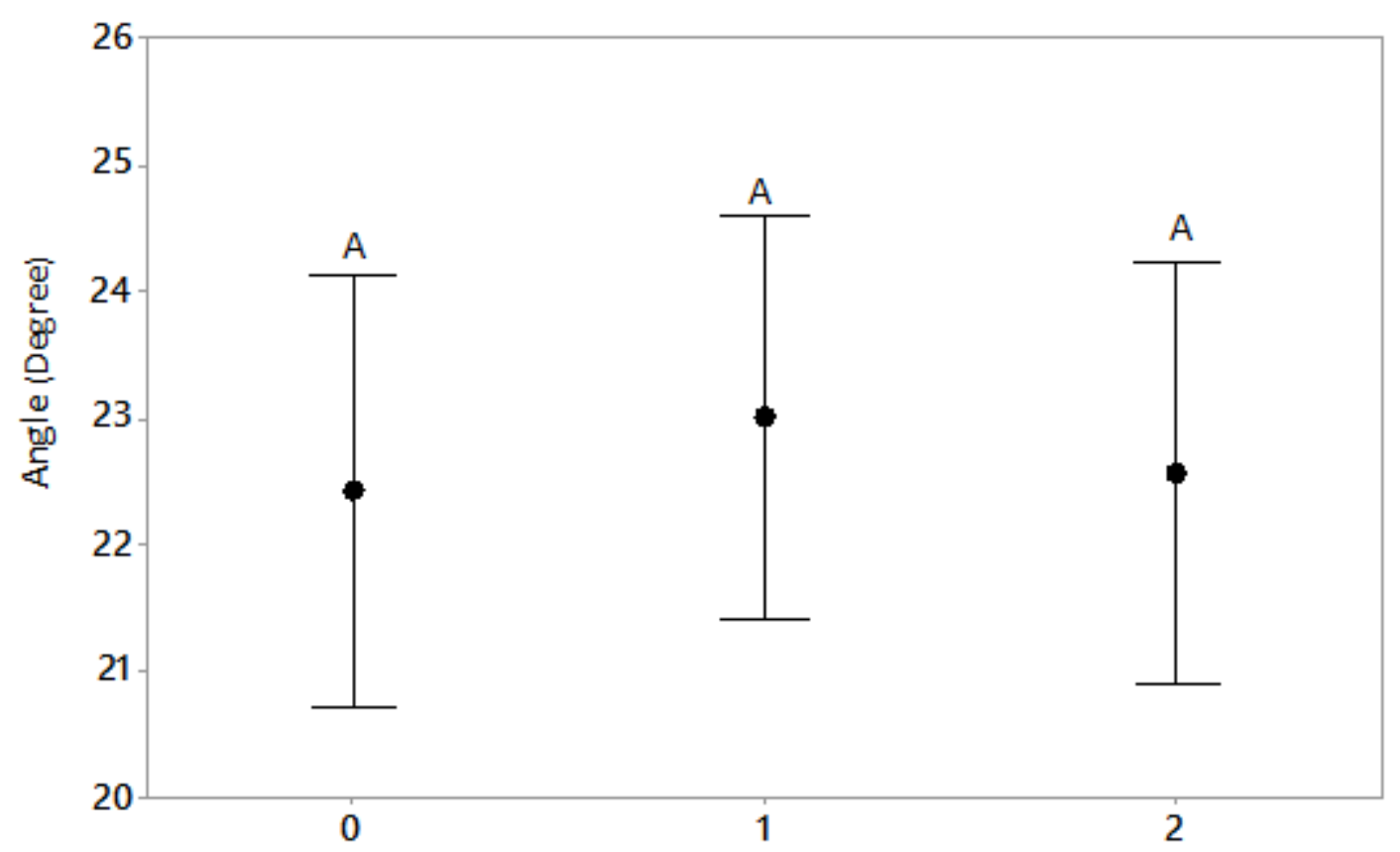

Figure 17: Effects of foot posture on Max Lumbar angle (ML) 


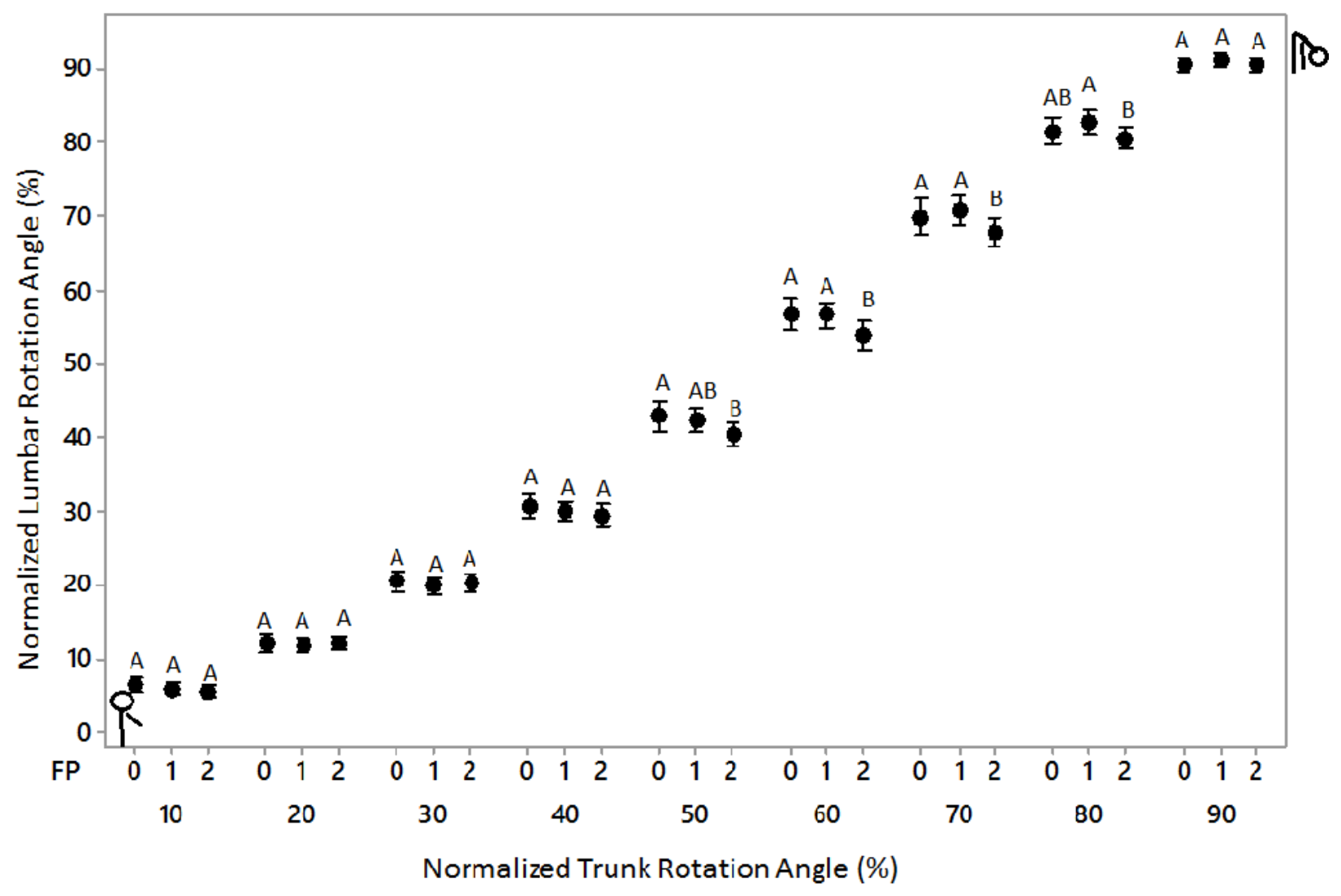

Figure 18: Changes of corresponding lumbar angle in three different foot postures for different percent changes in trunk angle during trunk flexion. 


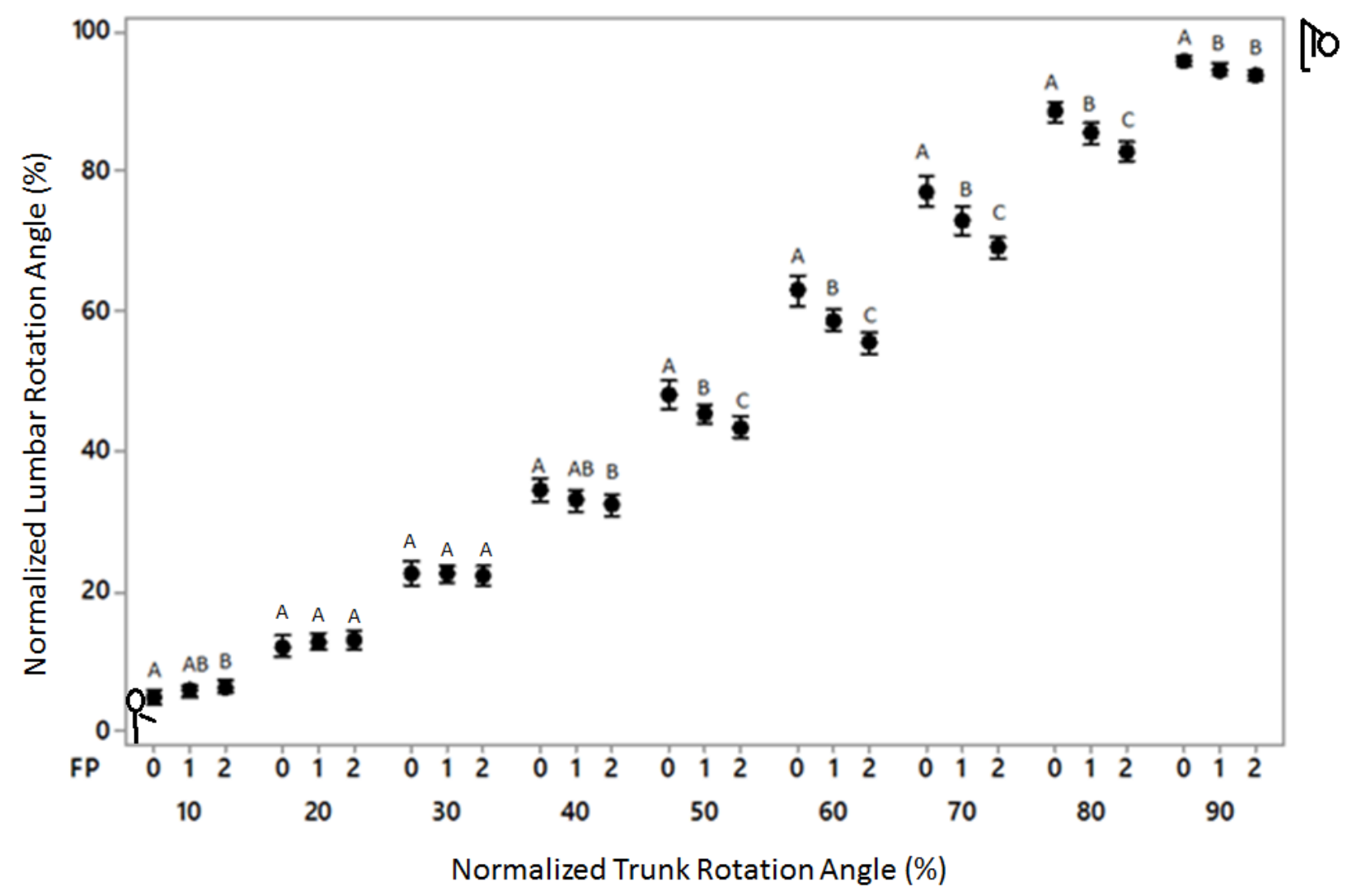

Figure 19: Changes of corresponding lumbar angle in three different foot postures for different percent changes in trunk angle during trunk extension. 


\section{CHAPTER 4. DISCUSSION AND CONCLUSION}

This study aimed to investigate the influence of staggered foot postures on lifting biomechanics and to explore if maintaining a staggered foot posture could affect the spinal tissue loading and its cumulative activation level during lifting and lowering tasks. This study hypothesized that during performing trunk bending motions with staggered foot posture, unbalanced cumulative lumbar muscle exertion is expected among the two sides of lumbar extensor muscles and with the increase of foot distance, trunk kinematics changes, and the flexion-relaxation phenomenon (FRP) of lumbar muscle alters. Fourteen subjects were recruited to perform six different postures each with four repetitions, three different foot postures (closed foot, staggered with right foot $1 \mathrm{ft}$. forward, staggered with right foot $2 \mathrm{ft}$. forward) and two levels of hand load (no load and $15 \mathrm{lbs}$.). We hypothesized that by performing trunk bending motions with staggered foot posture, unbalanced cumulative lumbar muscle exertion is expected, and with the increase of foot distance, trunk kinematics change, and the flexion-relaxation phenomenon (FRP) of lumbar muscle alter. This can elevate CEMG among back muscles in the larger foot distance condition.

The results of our study supported our initial hypotheses. There was a decreasing trend in EMG levels of the left paraspinal lumbar muscles as we step on the right foot one-step forward in both flexion and extension tasks. In the two-step foot posture with the right foot forward, the body forms a geometrically stable, triangular structure along the line of external load and the L5/S1 joint and the ground reaction force acting on the frontal foot provided additional moment about this joint that could help counterbalance the rotational moment created by the external load (Zhou et al., 2013). Figures 11 and 12 showed that there was an overall increasing trend of 
CEMG for both sides of muscles during the increase of the foot separation distance, which means that more active tissues were activated in the two-step condition. In other words, the overall external loading was higher for the two-step condition compared to the no-step posture. Studies have suggested that there is a transition of the load from active lumbar muscles to passive lumbar tissues as we flex further (Ning et al., 2011; Ning et al., 2012). This means that the role of passive tissues is to counterbalance the external moment acting on the lumbar spine, and lumbar extensor muscles will decline activation (Solomonow et al., 2003; Floyd et al., 1951; Allen, 1948).

The EMG data demonstrated that the FRP consistently occurred in all conditions for the paraspinals muscles at L3 level. Results of FRP showed that by increasing foot distance, trunk kinematics might change and the FRP of lumbar muscles would alter. Differences between the right and left sides of the muscles may happen because of asymmetric bending. This asymmetric bending may occur because of the forward pelvic rotation. Previous studies denoted that asymmetric trunk flexion may lead to more tension in the lumbar muscles and this would result in an earlier onset of EMG-off (Hu et al., 2016). The MT increases in one-step compared to nostep. This may happen because the subject can lean on the right foot in one-step and bend more, but for the two-step condition, the bended knee restricts the motion, as such the reduction in MT. Motion coordination results also supported our initial hypotheses. Figures 17 and 18 denote that at deeper trunk flexion postures, percent changes in lumbar angle were smaller than percent changes in trunk angle during trunk flexion and extension for three different foot postures. This shows that less passive tissue and more active tissues are contributed as we get close to the full flexion. During the lowering task, for $70 \%, 60 \%$ and $50 \%$ there are significant differences between no-step and two-step conditions (Figures 17). During the lifting motion, 
except for $20 \%$ and $30 \%$, other percentiles showed significant differences between no-step and two-step, and this difference was larger in higher percentiles (Figures 18). The previous studies emphasis that sagittal trunk movements consist of two different parts: flexion of the lumbar spine and rotation of the pelvis (David et al., 1965, Granata et al., 2000, Murray et al., 2002). The flexion task starts with lumbar rotation, and during final phases, it accomplishes at the pelvis (Farfan, 1975). As subject further bend, at a given percentage of trunk rotation during lowering motion, there was larger lumbar rotation (except at the 90th percentile of normalized trunk rotation) as shown in Figure 17. Similarly, it could be observed from Figure 18 that during the extension, larger lumbar rotation existed at each percentile of normalized trunk rotation (except at the 10th, 20th, and 30th percentile of normalized trunk rotation). Therefore, in the early stages of flexion, the lumbar spine contributed more to the trunk movement while during the final stages the role of the pelvis was greater (Tafazzol et al., 2014; Hu et al., 2015).

Including only male subjects may lead to biased results in this study. This is because of the difference in anthropometric measurements of male and female (anthropometric analysis means to analyze the size, shape, and composition of the human body). To make sure that the gender does not affect the results, we need to exclude the three female subjects in this study. For eleven male subjects, the CEMG results are shown below (Table 2).

Table 2: Results of ANOVA and MANOVA for CEMG and FRP after excluding women subjects.

\begin{tabular}{c|ccccc} 
& MANOVA & \multicolumn{4}{c}{ ANOVA } \\
\hline Variables & & RLCEMGFlex & LCEMGFlex & RCEMGExt & LCEMGExt \\
FP & $<0.001$ & $<0.001$ & $<0.001$ & $<0.001$ & $<0.001$ \\
L & $<0.001$ & $<0.001$ & $<0.001$ & $<0.001$ & $<0.001$ \\
FP*L & $=\mathbf{0 . 6 3 1}$ & - & - & - & -
\end{tabular}


If we compare results of this table with results of table one, the significant variables are the same. The average and SD of their age and body weight and height before and after excluding women subjects are shown in Table 3.

Table 3: Comparing the average and SD of age and body weight and height of subjects before and after excluding women subjects.

\begin{tabular}{c|cccc}
\multicolumn{1}{c}{} & Age (year) & Height $(\mathrm{cm})$ & Weight $(\mathrm{kg})$ \\
\hline \multirow{3}{*}{ Male and Female } & Avg & 27.4 & 171.8 & 71.4 \\
& SD & 4.5 & 9 & 11.5 \\
\multirow{3}{*}{ No Female Subject } & Avg & 27.1 & 175.4 & 76.8 \\
& SD & 4.6 & 4.8 & 5.4
\end{tabular}

In this study, we chose the CEMG as an indicator of the muscle activity, because it gave us the amount of work that each muscle did in a certain amount of time in each task duration.

CEMG works like the average of EMG. The average value of a function $f(x)$ over the interval $[a, b]$ is given by

$$
f_{\mathrm{ovg}}=\frac{1}{b-a} \int_{a}^{b} f(x) d x
$$

So, we can substitute EMG instead of function $\mathrm{f}$ in the above equation, and set:

$\mathrm{a}=$ When the subject gets to the 15-degree trunk angle.

$\mathrm{b}=$ When the subject gets to the 5 degrees before the maximum trunk flexion angle.

Multiplying each observation in the linear statistical model by a constant does not change the significance level (Montgomery 2012). Hence, the average EMG gives us the same results. In this study, since all data points were multiplied by a common multiplier $(0.125)$ and they were 
divided by a common denominator (128) to find the CEMG, we could mathematically just add up all data points to reach to the same ANOVA table. Although the average EMG, gives us the same result as the CEMG, we used CEMG here, because CEMG could help us to introduce new variables. The current study has some limitations that should be considered. First, the number of male and female subjects are not equal. This can make changes in results. Second, to standardize the trials and to eliminate the effect of motion speed, a stop-watch was used to control the rhythm, and the potential interaction between stance posture and motion speed was not explored (Hu et al., 2014). Third, to prevent fatigue, we used one minute of rest between trials for each subject. The rest time can be varied based on the subjects, hand load, and the step distance. In other words, some subjects, especially female subjects, may need more rest after trials that they need to hold the load. Forth, in some trials of the two-step condition, the bended knee can restrict the motion and cause the full-flexion problem. In some cases, the subjects may not be able to reach their maximum trunk angle in the two-step trials. Fifth, we standardized the foot distance using one and two feet. This standardization may influence the results based on the height and the length of the leg for each subject. Finally, this study used only two levels of loads; for heavier loads, the results could change significantly. 


\section{REFERENCES}

Allen CEL: Muscle action potentials used in the study of dynamic anatomy. Br J Phys Med 11:66-73, 1948.

Andersen, J. H., J. P. Haahr, and P. Frost. Risk factors for more severe regional musculoskeletal symptoms: a two-year prospective study of a general working population. Arthritis Rheum. 56:1355-1364, 2007.

Andersson, G. B. Epidemiologic aspects on low-back pain in industry. Spine. 6:53-60, 1981.

Arjmand, N., Plamondon, A., Shirazi-Adl, A., Lariviere, C., \& Parnianpour, M. (2011). Predictive equations to estimate spinal loads in symmetric lifting tasks. Journal of Biomechanics, 44, 84-91.

Ashburn M.A., Rice L.J., eds., The Management of Pain (New York: Churchill Livingstone, 1998): 235-48.

Baldwin, M. (2004). Reducing the costs of work-related musculoskeletal disorders: Targeting strategies to chronic disability cases. Journal of Electromyography and Kinesiology, 14(1), 33-41. doi:10.1016/j.jelekin.2003.09.013

Barr, K., M Griggs, \& T Cadby. (2005). Lumbar stabilization: Core Concepts and current literature, part 1. American Journal of Physical Medicine and Rehabilitation, 84(6), 473-480

Barr, K., M Griggs, \& T Cadby. (2007). Lumbar stabilization: A review of core concepts and current literature, part 2. American Journal of Physical Medicine and Rehabilitation, 86(1), 72-80. 
Battie MC, Videman T, Kaprio J, Gibbons LE, Gill K, Manninen H, et al. The Twin Spine Study: contributions to a changing view of disc degeneration. Spine J 2009; 9:47-59.

Bazrgari, B., A. Shirazi-Adl, and N. Arjmand, Analysis of squat and stoop dynamic liftings: muscle forces and internal spinal loads. Eur Spine J, 2007. 16(5): p. 687-99.

Beaudette SM, Graham RB, Brown SHM (2014) The effect of unstable loading versus unstable support conditions on spine rotational stiffness and spine stability during repetitive lifting. J Biomech 47:491-496

Biering-Sorensen, F. Physical measurements as risk indicators for low back trouble over a one-year period. Spine. 9:106-119, 1984.

BLS, 2016. Number of nonfatal occupational injuries and illnesses involving days away from work by event or exposure leading to injury or illness and industry sector, 2015. US Department of Labor, Bureau of Labor Statistics, Washington, DC.

Bogduk, N., J. E. Macintosh, and M. J. Pearcy. A universal model of the lumbar back muscles in the upright position. Spine. 17:897-913, 1992.

Boshuizen H, Verbeek J, Broersen J, Weel A. Do smokers get more back pain? Ibid.1993; 18(1):35-40.

Bovenzi, M. (January 01, 1996). Low back pain disorders and exposure to whole-body vibration in the workplace. Seminars in Perinatology, 20, 1, 38-53.

Burton AK, Tillotson KM, Troup JDG. Prediction of low-back trouble frequency in a working population. Spine. 1989; 14:939-46.

Byrns, G. E., Bierma T. J., Agnew, J., \& Curbow, B. (2002). A new direction in lowback pain research. American Industrial Hygiene Association Journal, 63, 55-61. 
Cailliet, R. (2004). The illustrated guide to functional anatomy of the musculoskeletal system. Chicago: AMA Press.

Carlsoo S: The static muscle load in different work positions: An electromyographic study. Ergonomics 4:193, 1961.

Cassidy JD, Carroll LJ, Côté P. The Saskatchewan health and back pain survey. The prevalence of low back pain and related disability in Saskatchewan adults. Spine (Phila Pa 1976) 23: 1860-1867, 1998

Chaffin, D. B. (1969). A computerized biomechanical model-development of and use in studying gross body actions. Journal of Biomechanics, 2, 429-441.

Chaffin, D. B. (1974). Human strength capability and low-back pain. Journal of Occupational Medicine, 16, 248.

Chaffin, D. B., \& Park, K. S. (1973). A longitudinal study of low back pain as associated with occupational weight lifting factors. American Industrial Hygiene Association Journal, 34, 513-525.

Chavalinitikul C, Nopteepkangwan N, Kanjanopas F. Improvement of lifting heavy

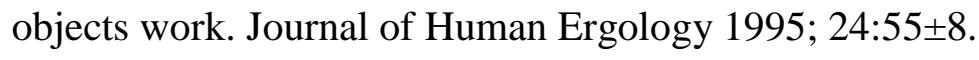

Cholewicki, J., Juluru, K., McGill, S.M., 1999. Intra-abdominal pressure mechanism for stabilizing the lumbar spine. J. Biomech. 32, 13-17.

Craig, B. N., Congleton, J. J., Kerk, C. J., Amendola, A. A., Gaines, W. G., \& Jenkins, O. C. (2003). Prospective field study of the relationship of potential occupational risk factors with occupational injury/illness. American Industrial Hygiene Association Journal, 64, 376-87. 
Dagenais S, Caro J, and Haldeman S. 2008. “A Systematic Review of Low Back Pain Cost of Illness Studies in the United States and Internationally.” The Spine Journal : Official Journal of the North American Spine Society8(1):8-20.

Davis KG, Heaney CA. The relationship between psychosocial work characteristics and low back pain: underlying methodological issues. Clin. Biomech. 2000;15:389-406

Davis KG, Marras WS. The effects of motion on trunk biomechanics. Clin Biomech 2000;15:703-17

Deros, B., Daruis, D., \& Basir, I. (2015). A study on ergonomic awareness among workers performing manual material handling activities. Procedia - Social and Behavioral Sciences, 195, 1666-1673. doi:10.1016/j.sbspro.2015.06.238

Descarreaux et al., 2008 M. Descarreaux, D. Lafond, R. Jeffrey-Gauthier, H. Centomo, V. Cantin Changes in the flexion relaxation response induced by lumbar muscle fatigue BMC Musculoskeletal Disorders, 9 (2008), p. 10

Development and Functional Anatomy of the Spine J. Alan Rawls, PhD and Rebecca E. Fisher, $\mathrm{PhD}$

Deyo RA, Bass JE. Lifestyle and low-back pain. The influence of smoking and obesity. Spine 1989;14(5):501-506.

Dussek, J.E., Fergusson, M.W.J. (Eds.), 1999. Gray_s Anatomy. The Anatomical Basis of Medicine and Surgery. Churchill Livingstone, London.

Farfan, H. F. Muscular mechanism of the lumbar spine and the position of power and efficiency. Orthop. Clin. North Am. 6:135-144, 1975.

Ferguson SA, Marras WS. A literature review of low back disorder surveillance measures and risk factors. Clin. Biomech. 1997;12:211-226 
Fick R: Handbook de anatomie und mechanik der gelenke, Volume 3. Jena, Gustav Fischer, 1911.

Floyd, W.F., Silver, P.H.S. (1951). Function of erectores spinae in flexion of the trunk. Lancet 1, 133-134.

Frymoyer JW, Pope MH, Clements JH, Wilder DG, MacPherson B, Ashikaga T. Risk factors in low back pain. Journal of Bone and Joint Surgery 1983; 64:213-18.

Gail M, Jensen MA. Biomechanics of the lumbar intervertebral disc: a review. J Phys Ther [internet]. 1980 [cited 2015 March 10]; 60:765-773

Garg A, Moore JS. Prevention strategies and the low back in industry. Occupational Medicine. 1992;7:629-40

Gracovetsky S, Kary M, Levy S, Ben Saïd R, Pitchen I, Hélie J. Analysis of Spinal and Muscular Activity during Flexion/Extension and Free Lifts. Spine 15(12) : 1333-1339, 1990.

Granata, K. P., Lee, P. E., \& Franklin, T. C. (2005). Co-contraction recruitment and spinal load during isometric trunk flexion and extension. Clinical Biomechanics, 20(10), 10291037.

Granata, K.P., Marras, W.S., 2000. Cost-benefit of muscle cocontraction in protecting against spinal instability. Spine 25: 1398-1404.

Halpern, M. (1992). Prevention of low back pain: basic ergonomics in the workplace and the clinic. Baillieres Clinical Rheumatology, 6(3), 705-730.

Hangai, M., K. Kaneoka, S. Kuno, S. Hinotsu, M. Sakane, N. Mamizuka, S. Sakai, and N. Ochiai. Factors associated with lumbar intervertebral disc degeneration in the elderly. Spine J, 2007. 
Harcombe, H., McBride, D., Derrett, S., \& Gray, A. (2010). Physical and psychosocial risk factors for musculoskeletal disorders in New Zealand nurses, postal workers and office workers. Injury Prevention, 16, 96-100.

Hartvigsen, J., Nielsen, J., Kyvik, K. O., Fejer, R., Vach, W., Iachine, I., \& LeboeufYde, C. (January 01, 2009). Heritability of spinal pain and consequences of spinal pain: a comprehensive genetic epidemiologic analysis using a population-based sample of 15,328 twins ages 20-71 years. Arthritis and Rheumatism, 61, 10, 1343-51.

Heliovaara M, Makela M, Knekt P, et al. Determinants of sciatica and low back pain. Spine 1991;16:608-614.

Herrin, G.D., Jaraiedi, M., Anderson, C.K., 1986. Prediction of overexertion injuries using biomechanical and psychophysical models. AIHA Journal 47 (6), 322e330

Hirsch C, Ingelmark B, Miller M: The anatomical basis for low back pain. Acta Orthop Scand 33:1-17, 1963

Hodges, P.W., Gandevia, S.C., 2000. Changes in intra-abdominal pressure during postural and respiratory activation of the human diaphragm. J. Appl. Physiol. 89, 967-976.

Holbein-Jenny, M. A., McDermott, K., Shaw, C., \& Demchak, J. (May 01, 2007). Validity of functional stability limits as a measure of balance in adults aged 23-73 years. Ergonomics, 50, 5, 631-646.

Holleran, K., Pope, M., Haugh, L., \& Absher, R. (January 01, 1995). The response of the flexion-relaxation phenomenon in the low back to loading. The Iowa Orthopaedic Journal, 15, 24-8. 
Hoozemans, M. J. M., Van Der Beek, A. J., Frings-Dresen, M. H. W., Van Dijk, F. J. H., \& Van Der Woude, L. H. V. (1998). Pushing and pulling in relation to musculoskeletal disorder: A review of risk factor. Ergonomics, 41(6), 757-781.

Hu, B., Ning, X., Dai, F., \& Almuhaidib, I. (January 01, 2016). The changes of lumbar muscle flexion-relaxation phenomenon due to antero-posteriorly slanted ground surfaces. Ergonomics, 59, 9, 1251-8.

Hu, B., Ning, X., Dai, F., Almuhaidib, I., 2015. The changes of lumbar muscle flexionrelaxation phenomenon due to antero-posteriorly slanted ground surfaces. Ergonomics, DOI: 10.1080/00140139.2015.1124146.

Hu, B., Ning, X., Nimbarte, A.D., 2013. The changes of lumbar muscle flexionrelaxation response due to laterally slanted ground surfaces, Ergonomics. 56(8): 1295-1303.

Hu, B., Shan, X., Zhou, J., Ning, X., 2014. The effects of stance width and foot posture on lumbar muscle flexion-relaxation phenomenon, Clinical Biomechanics 29(3): 311-316.

Hulshof CTJ, Veldhnijzen van Zanten OBA: Whole-body vibration and low back pain-A review of epidemiological studies. Int Arch Occup Environ Health 59:205-220, 1987

International Social Security Association: Vibration at work. Paris, Institut National de Recherche et de S\&urit (INRS), 1989

Jayson M, Barks JS: Structural changes in intervertebral discs. Ann Rheum Dis 32:1015,1973

Johansson J, Rubenowitz S. Risk indicators in the psychosocial and physical work environment for work-related neck, shoulder, and low back symptoms; a study among blue- and white- collar workers in eight companies. Scand. J. Rehabil. Med. 1994; 26:131-142. 
Junqueira, D. R., Ferreira, M. L., Refshauge, K., Maher, C. G., Hopper, J. L., Hancock, M., Carvalho, M. G., Ferreira, P. H. (January 01, 2014). Heritability and lifestyle factors in chronic low back pain: results of the Australian twin low back pain study (The AUTBACK study). European Journal of Pain (london, England), 18, 10, 1410-8.

Kaigle, A.M.; Wesberg, P.; Hansson, T.H. Muscular and kinematic behavior of the lumbar spine during flexion-extension. J. Spinal Disord. 1998, 11, 163-174.

Katz, J.N., Lumbar disc disorders and low-back pain: socioeconomic factors and consequences. J Bone Joint Surg Am, 2006. 88 Suppl 2: p. 21-4.

Kelsey JL, Golden AL. Occupational and workplace factors associated with low back pain.Occupational Medicine 1988; 3:7-16.

Knapik, G. G., \& Marras, W. S. (2009). Spine loading at different lumbar levels during pushing and pulling. Ergonomics, 52, 60-70

Kulak RF, Belytschko TB, Schultz AB, et al: Non-linear behavior of the human intervertebral disc under axial load. J Biomech 9:377-396, 1976

Kumar, S. (2001). Theories of musculoskeletal injury causation. Ergonomics, 44(1), 1747.

Lagerstrom M, Josephson M, Pingel B, Tjernstrom G, Hagberg M. Evaluation of the implementation of an education and training programme for nursing personnel at a hospital in Sweden. International Journal of Industrial Ergonomics 1998; 21(1):79 \pm 90.

Lavender, S.A., et al., The effects of preview and task symmetry on trunk muscle response to sudden loading. Hum Factors, 1989. 31(1): p. 101-15. 
Lavender, S.A., W.S. Marras, and R.A. Miller, The development of response strategies in preparation for sudden loading to the torso. Spine (Phila Pa 1976), 1993. 18(14): p. 2097105.

Levy, B. S, \& Wegman, D. H., (Eds.) (1994). Occupational Health: Recognizing and Preventing Work-Related Disease (3rd ed.). Philadelphia: Lippincott Williams \& Wilkins.

Liira, J. P., Shannon, H. S., Chambers, L. W., \& Haines, T. A. (1996). Long-term low back MSDs and physical work exposures in the 1990 Ontario Health Survey. American Journal of Public Health, 86(3), 382-387.

Lings, S., \& Leboeuf-Yde, C. (June 01, 2000). Whole-body vibration and low back pain: a systematic, critical review of the epidemiological literature 1992-1999. International Archives of Occupational and Environmental Health, 73, 5, 290-297

Lings, S., \& Leboeuf-Yde, C. (June 01, 2000). Whole-body vibration and low back pain: a systematic, critical review of the epidemiological literature 1992-1999. International Archives of Occupational and Environmental Health, 73, 5, 290-297.

Luo, X., R. Pietrobon, S. X. Sun, G. G. Liu, and L. Hey. Estimates and patterns of direct health care expenditures among individuals with back pain in the United States. Spine. 29:79$86,2004$.

Macintosh, J. E., Bogduk, N. The biomechanics of the lumbar multifidus. Clinical Biomechanics. 1:205-213, 1986.

Macnab I: Backache. Baltimore, Williams \& Wilkins Co, 1977, pp 1-9

Magora A: Investigation of the relation between low back pain and occupation. Scand J Rehabil Med 5:186-190, 1973 
Marras W.S., Mirka G.A. (1992). A comprehensive evaluation of trunk response to asymmetric trunk motion, Spine, 17, 318-326.

Marras WS, Davis KG, Heaney CA, Maronitis AB, Allread WG. The influence of psychosocial stress, gender, and personality on mechanical loading of the lumbar spine. Spine. 2000;

Marras WS, Lavender SA, Leurgans SE, et al. Biomechanical risk factors for occupationally related low back disorders. Ergonomics 1995; 38:377-410

Marras, W. S. (2000). Occupational low back MSDs causation and control. Ergonomics, 43(7), 880-902.

Marras, W. S. (January 01, 2012). The complex spine: the multidimensional system of causal pathways for low-back disorders. Human Factors, 54, 6, 881-9.

Marras, W. S., Knapik, G. G., \& Ferguson, S. (2009). Loading along the lumbar spine as influenced by speed, control, load magnitude, and handle height during pushing. Clinical Biomechanics, 24, 155-163.

Marras, W. S., Parakkat, J., Chany, A. M., Yang, G., Burr, D., \& Lavender, S. A. (2006). Spine loading as a function of lift frequency, exposure duration, and work experience. Clinical Biomechanics, 21, 345-352.

Marras, W. S., S. L. Rangarajulu, and S. A. Lavender. Trunk loading and expectation. Ergonomics. 30:551-562, 1987.

Marras, W.S., Davis, K.G., Ferguson, S.A., Lucas, B.R., Gupta, P. (2001a). Spine loading characteristics of patients with low back pain compared with asymptomatic individuals. Spine, 26, 2566-2574. 
McCoy, C.E., et al., Work-related low back injuries caused by unusual circumstances. J Orthop Sports Phys Ther, 1997. 26(5): p. 260-5.

McGill, S. M. (January 01, 1997). The biomechanics of low back injury: Implications on current practice in industry and the clinic. Journal of Biomechanics, 30, 5, 465-475.

Mehrdad R, Dennerlein JT, Haghighat M, Aminian O. Association between psychosocial factors and musculoskeletal symptoms among Iranian nurses. Am. J. Ind. Med. 2010; 53:1032-1039.

Mirka, G.A., Marras, W.S., 1993. A stochastic model of trunk muscle coactivation during trunk bending. Spine 18, 1396-1409.

Montgomery, D.C., 2012. Design and Analysis of Experiments. 7th ed. New York: John Wiley and Sons.

Morris JM, Benner G, Lucas DB: An electromyographic study of the intrinsic muscles of the back in man. J. M. Morris, Gordon Benner, D. B. Lucas J Anat. 1962 Oct; 96(Pt 4): 509520.

Nachemson A, Elfstrom G. Intravital dynamic pressure measurements in lumbar discs.Scandinavian Journal of Rehabilitation Medicine 1970; Suppl1:1-42.

Nachemson, A. (1975). Toward a better understanding of back pain. Rheumatology Rehabilitation. 14. 129.

Nevalapuranen N. Effects of occupationally-oriented rehabilitation on farmers work techniques musculoskeletal symptoms, and work ability. Journal of Occupational Rehabilitation 996;6(3):191 \pm 200 .

Ning, X., Haddad, O., Jin S. , Mirka, G.A. (2011). Influence of asymmetry on the flexion relaxation response of the low back musculature. Clin. Biomech, 26(1), 35-39. 
Ning, X., Hu, B., Alessa, F., Almuhaidib, I., 2015. Ergonomic Interventions for Steel Manufacturing Workers, Iron \& Steel Technology (Dec): 36-41.

Ning, X., Jin, S., Mirka, G.A. (2012). Describing the active region boundary of EMGassisted biomechanical models of the low back. Clinical Biomechanics, 27(5), 422-427.

Ning, X., Nussbaum, M.A., 2015. Passive Lumbar Tissue Loading during Trunk Bending at

Ning, X., Nussbaum, M.A., in print. (n.d.). Passive Lumbar Tissue Loading during Trunk Bending at Three Speeds: an in vivo Study. To appear on Clinical Biomechanics.

NIOSH, 1997. In: Bernard, B.P. (Ed.), Musculoskeletal Disorders and Workplace Factors: A Critical Review of Epidemiologic Evidence for Work-related Musculoskeletal Disorders of the Neck, Upper Extremity, and Low Back. Department of Health and Human Services (DHHS), Public Health Service, Centers for Disease Control, National Institute for Occupational Safety and Health (NIOSH), Cincinnati, OH.

Nyg_ard CH, Merisalo T, Arola H, Manka ML, Huhtala H. Effects of work changes and training in lifting technique on physical strain- a pilot study among female workers of different ages. International Journal of Industrial Ergonomics 1998; 21(1):91 \pm 8 .

Okada, E., Matsumoto, M., Fujiwara, H., \& Toyama, Y. (April 01, 2011). Disc degeneration of cervical spine on MRI in patients with lumbar disc herniation: comparison study with asymptomatic volunteers. European Spine Journal, 20, 4, 585-591.

Olsen T, Anderson R, Dearwater SR, et al. The epidemiology of low back pain in an adolescent population. Am J Public Health. 1992; 82:606-8.

Omino, K. and Y. Hayashi, Preparation of dynamic posture and occurrence of low back pain. Ergonomics, 1992. 35(5-6): p. 693-707. 
Plouvier, S., Renahy, E., Chastang, J. F., \& Leclerc, A. (2008). Biomechanical strains and low back disorders: quantifying the effects of the number of years of exposure on various types of pain. Journal of Occupational and Environmental Medicine, 65, 268-274.

Punnett, L., L. J. Fine, W. M. Keyserling, G. D. Herrin, and D. B. Chaffin. Back disorders and nonneutral trunk postures of automobile assembly workers. Scand J Work Environ Health. 17:337-346, 1991.

Raj, P Prithvi. “Intervertebral disc: anatomy-physiology-pathophysiologytreatment." Pain practice: the official journal of World Institute of Pain 81 (2008): 18-44.

Schenk RJ, Doran RL, Stachura JJ. Learning effects of a back education program. Spine 1996;21(19):2183 \pm 8 .

Schibye, B., Sogaard, K., Martinsen, D., \& Klausen, K. (2001). Mechanical load on the low back and shoulders during pushing and pulling of two-wheeled waste containers compared with lifting and carrying of bags and bins. Clinical Biomechanics, 16, 549-559.

Singh, Sarbjeet, and Sunand Kumar. "Factorial Analysis of Lifting Task to Determine the Effect of Different Parameters and Interactions." Journal of Manufacturing Technology Management 23.7 (2012): 947-53. ProQuest. Web. 2 Aug. 2017.

Skotte, J. H. (January 01, 2001). Estimation of low back loading on nurses during patient handling tasks: the importance of bedside reaction force measurement. Journal of Biomechanics, 34, 2, 273-276.

Shin, G., \& Mirka, G. a. (2007). An in vivo assessment of the low back response to prolonged flexion: Interplay between active and passive tissues. Clinical Biomechanics, 22, 965- 
Shin, G., Mirka, G., 2004. The effects of a sloped ground surface on trunk kinematics and L5/S1 moment during lifting. Ergonomics 15: 646-659.

Snook, S. (1991). Epidemiology and cost. In:Pope M, ed. Occupational low back pain. St. Louis, MO: Mosby Year Book.

Shirazi-Adl, A., et al., Spinal muscle forces, internal loads and stability in standing under various postures and loads--application of kinematics-based algorithm. Eur Spine J, 2005. 14(4): p. 381-92.

Sorensen, C., Haddad, O., Campbell, S., \& Mirka, G. (2011). The effect of stance width on trunk kinematics and trunk kinetics during sagittally symmetric lifting. International Journal of Industrial Ergonomics, 41(2), 147-152. doi:10.1016/j.ergon.2010.12.007

Sorensen FB, Thomsen C. Medical, social and occupational history as risk indicators for low back trouble in a general population. Ibid.1986; 11:720-725.

STATISTICS CANADA 1991, Work Injuries, $1988 \pm 1990$ (Ottawa).

STATISTICS CANADA 1995, Work Injuries (Ottawa).

St-Vincent M, Tellier C, Lortie M. Training in handling: an evaluative study.

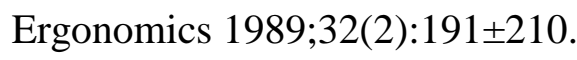

Tafazzol, A., N. Arjmand, A. Shirazi-Adl, and M. Parnianpour. Lumbopelvic rhythm during forward and backward sagittal trunk rotations: Combined in vivo measurement with inertial tracking device and biomechanical modeling. Clin. Biomech. 29(1):7-13, 2014.

Three Speeds: an in vivo Study, Clinical Biomechanics

DOI:10.1016/j.clinbiomech.2015.04.014. 
Videman T, Rauhala H, Asp S, Lindstrom K, Cedercreutz G, Kamppi M, et al. Patienthandling skill back injuries and back pain: An intervention study in nursing. Spine 1989; $14: 148 \pm 56$.

Violante F, Graziosi F, Bonfiglioli R, Curti S, Mattioli S. Relationship between occupational, psychosocial, and individual factors and three different categories of back disorder among supermarket workers. Int. Arch. Occup. Environ. Health. 2005; 78:613-624.

Wagner, H., C Anders, C Puta, A Petrovitch, F Mori, N Schilling, H Witte, \& R lickhan. (2005). Musculoskelatal support of lumbar spine stability. Pathophysiology, 12, 257-265.

Wang, D., Dai, F., Ning, X., 2015. Risk assessment of work-related musculoskeletal disorders in construction: a state of the art review. Journal of Construction Engineering and Management.

Waters T.R., Putz-Anderson, V., Garg, A, Fine, L.J., (1993). Revised NIOSH equation for the design and evaluation of manual lifting tasks. Ergonomics, 36(7), 749- 776.

Weiler, C., Lopez-Ramos, M., Mayer, H. M., Korge, A., Siepe, C. J., Wuertz, K., Weiler, V., ... Nerlich, A. G. (January 01, 2011). Histological analysis of surgical lumbar intervertebral disc tissue provides evidence for an association between disc degeneration and increased body mass index. Bmc Research Notes, 4.

Wilke HJ, W. S., Claes LE, Arand M, Wiesend A. Stability increase of the lumbar spine with different muscle groups. A biomechanical in vitro study. Spine. 20:192-198, 1995.

Williams, P.L., Bannister, L.H., Berry, M.M., Collins, P., Dyson, M., Yang, G., Marras, W. S., \& Best, T. M. (June 01, 2011). The biochemical response to biomechanical tissue loading on the low back during physical work exposure. Clinical Biomechanics, 26, 5, 431-437. 
Zhou, J., Ning, X., Hu, B., \& Dai, B. (June 01, 2016). The influences of foot placement on lumbopelvic rhythm during trunk flexion motion. Journal of Biomechanics, 49, 9, 16921697.

Zhou, J., Dai, B., \& Ning, X. (2013). The assessment of material handling strategies in dealing with sudden loading: influences of foot placement on trunk biomechanics. Ergonomics, 56(10), 1569-1576. 


\section{APPENDIXES}

\section{APPENDIX A: Approval Letter}

\section{WestVirginiaUniversity. \\ Office of Research Integrity and Compliance \\ 886 CHESNUT RIDGE ROAD MORGANTOWN, WV 26506}

\section{Approval Letter Expedited}

Action Date

To

From

Approval Date

Expiration Date

Subject

Protocol Number

Title
$04 / 04 / 2017$

Xiaopeng Ning

WVU Office of Research Integrity and Compliance

04/04/2017

$04 / 03 / 2018$

Protocol Approval Letter

1702485325

The influence of foot posture and load on lumbar muscle FRP during trunk bending.

The above-referenced research study was reviewed by the West Virginia University Institutional Review Board IRB and was approved in accordance with 46 CFR $46.101 \mathrm{~b}$.

It has been determined that this study is of minimal risk and meets the criteria as defined by the expedited categories listed below:

- Category 7. Research on individual or group characteristics or behavior (including, but not limited to, research on perception, cognition, motivation, identity, language, communication, cultural beliefs or practices, and social behavior) or research employing survey, interview, oral history, focus group, program evaluation, human factors evaluation, or quality assurance methodologies. [NOTE: Some research in this category may be exempt from the DHHS regulations for the protection of human subjects. See Exempt Categories and 45 CFR 46.101(b)(2) and (b)(3). This listing refers only to research that is not exempt.]

Documents reviewed and/or approved as part of this submission:

Rational.pdf: 2017-03-02-05:00

Consent Form.pdf: 2017-04-02-04:00

Recruitment letter.pdf: $2017-04-02-04: 00$

Documents for use in this study are available in the WVUkc system in the Notes and Attachments section of your protocol. 
The Office of Research Integrity and Compliance is here to provide assistance to you from the initial submission of an IRB protocol and all subsequent activity. Please feel free to contact us by phone at 304.293.7073 with any question you may have. Thank you.

WVU Office of Research Integrity and Compliance

Date:04/04/2017

Signed:

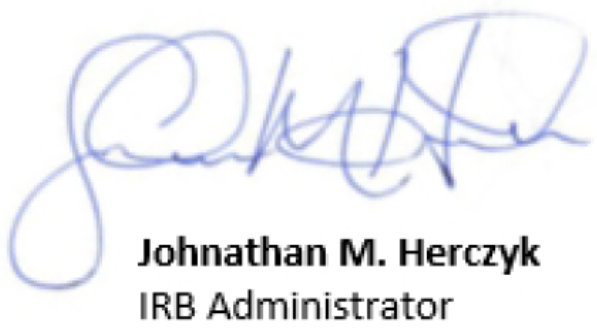

wing regulations apply: encountered in this research study must be reported to the

2. Any modifications to the study protocol or informed consent form must be reviewed and approved by the IRB prior to implementation via submission of an amendment.

3. You may not use a modified informed consent form until it has been approved and validated by the IRB. 


\title{
APPENDIX B: Consent Form
}

\author{
WestViginiaunniversity. \\ Human Research Protocol \\ Only Minimal Risk Consent Form \\ Without HIPAA

\begin{tabular}{|c|c|}
\hline & $\begin{array}{c}\text { Only Minimal Risk } \\
\text { Consent Information Form (without HIPAA) }\end{array}$ \\
\hline Principal Investigator & Ning, Xiaopeng \\
\hline Department & ENGINEERING-Ind./Mgt. Sys. Engineering \\
\hline Protocol Number & 1702485325 \\
\hline Study Title bending. & The influence of foot posture and load on lumbar muscle FRP during trunk \\
\hline Co-Investigator(s) & Malekinezhad, Atefeh \\
\hline
\end{tabular}

\section{Contact Persons}

During the data collection, if you experience any discomfort, fatigue or injury, you should contact Dr. Xiaopeng Ning at (304) 293-9474. (After hours contact: Dr. Xiaopeng Ning at (515)520-1951). If you have any questions, concerns, or complaints about this research, you can contact Dr. Xiaopeng Ning at (304)293-9474. For information regarding your rights as a research subject, to discuss problems, concerns, or suggestions related to the research, to obtain information or offer input about the research, contact the Office of Research Integrity \& Compliance at (304) 293-7073.

\section{Introduction}

You, have been asked to participate in this research study, which has been explained to you by Mrs. Atefeh Malekinezhad. This study is conducted by Dr. Xiaopeng Ning (PhD) and Atefeh Malekinezhad from the Department of Industrial and Management System Engineering at West Virginia University. The protocol of this study has been approved by WVU institutional review board (IRB).

\section{Purpose(s) of the Study}

In this study, we try to understand if changing foot postures can help workers lift boxes and weights more easily.

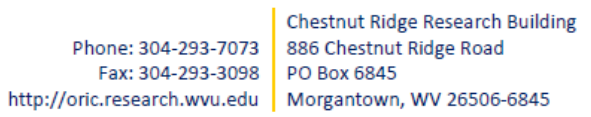

P a g e | 1 http://oric.research.wvu.edu Morgantown, WV 26506-684

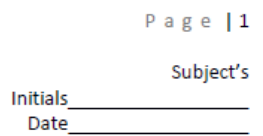

Approved:4-Apr-2017Expires:3-Apr-2018Number:1702485325 


\section{Description of Procedures}

A) Before data collection, the experimental procedure will be fully described to you. There will be a five-minutes warm up session to have you become familiar with the experiment. B) Surface electromyography electrodes and motion sensors will then be placed on the skin surface above your lumbar muscles. Electromyography is the recording of electric signal that generated when muscle contracts, powerful contraction generates large signal, weak contraction generates smaller signal. C) At the beginning of the experiment you will be asked to perform two maximum voluntary contraction exertions, each exertion lasts $\sim$ six seconds and one minute of rest will be given between trials to avoid muscle fatigue. In each of these trials, you will stand in the back-flexion extension attachment with your pelvis and lower extremities fully secured. Then you will perform two repetitions of isometric trunk extension exertion in a 20-degree trunk forward flexion posture. D) you will complete a total of 24 trunk flexion and extension motions. In each trial, you will be asked to use different foot postures, either have an empty hand or holding a $15 \mathrm{lbs}$ weight to perform pace controlled trunk bending motions. Again, one minutes of rest will be given between trials to avoid the accumulation of muscle fatigue.

\section{Discomforts}

There are no known or expected risks from participating in this study. There is a possibility of feeling tired from the task performance.

\section{Alternatives}

You do not have to participate in this study.

\section{Benefits}

You may not receive any direct benefit from this study. The knowledge gained from this study may eventually benefit others.

\section{Financial Considerations}

You will not receive any compensation for participation in the study and will not incur any costs related to the study. It is very important for you to understand that neither the investigator nor WVU or it associated affiliates has the funds set aside to pay for the cost work wages or any care or treatment that might be necessary because you get hurt or sick taking part in this study. Any injuries that may result from this study would not be eligible for workers' Compensation as this is not a job-related injury. Understand that any treatments necessary will be billed to the participant or to your personal health insurance, and you may wish to consult your insurance provider before participating in this study.

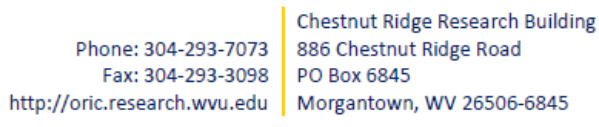

Approved:4-Apr-2017Expires:3-Apr-2018Number:1702485325
Page 12

Subject's

Initials

Date 


\section{W- WestVirginiaUniversity.}

Human Research Protocol

Only Minimal Risk Consent Form

Without HIPAA

\section{Confidentiality}

Any information about you that is obtained because of your participation in this research will be kept as confidential as legally possible. Your research records and test results, just like hospital records, may be subpoenaed by court order or may be inspected by the study sponsor or federal regulatory authorities (including the FDA if applicable) without your additional consent.

In addition, there are certain instances where the researcher is legally required to give information to the appropriate authorities. These would include mandatory reporting of infectious diseases, mandatory reporting of information about behavior that is imminently dangerous to your child or to others, such as suicide, child abuse, etc.

In any publications that result from this research, neither your name nor any information from which you might be identified will be published without your consent.

\section{Voluntary Participation}

Participation in this study is voluntary. You are free to withdraw your consent to participate in this study at any time.

Refusal to participate or withdrawal will not affect your class standing or grades, as appropriate and will involve no penalty to you. Refusal to participate or withdrawal will not affect your future care, or your employee status at West Virginia University.

In the event, new information becomes available that may affect your willingness to participate in this study, this information will be given to you so that you can make an informed decision about whether or not to continue your participation.

You have been given the opportunity to ask questions about the research, and you have received answers concerning areas you did not understand.

Upon signing this form, you will receive a copy.

I willingly consent to participate in this research.

\section{Signatures}

Signature of Subject

$\begin{array}{lll}\text { Printed Name } & \text { Date Time }\end{array}$

The participant has had the opportunity to have questions addressed. The participant willingly

\begin{tabular}{r|lr} 
& Chestnut Ridge Research Building & P a g e | 3 \\
Phone: 304-293-7073 & 886 Chestnut Ridge Road & Subject's \\
Fax: 304-293-3098 & PO Box 6845 & Initials \\
http://oric.research.wvu.edu & Morgantown, WV 26506-6845 & Date_
\end{tabular}

Approved:4-Apr-2017Expires:3-Apr-2018Number:1702485325 
agrees to be in the study.

Signature of Investigator or Co-Investigator

\begin{tabular}{lll}
\hline Printed Name & Date & Time
\end{tabular}

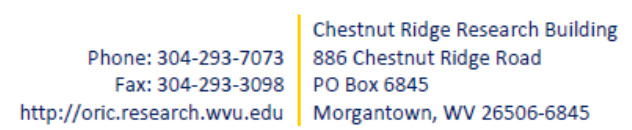
http://oric.research.wvu.edu

Date

Time

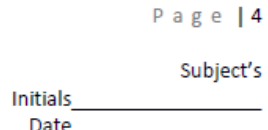

Date

Approved:4-Apr-2017Expires:3-Apr-2018Number:1702485325 


\title{
APPENDIX C: Recruitment Letter
}

\author{
Dear [Mr. LAST NAME],
}

I am writing to tell you about a research study that is being conducted at the ergonomics lab at West Virginia University (WVU) by Dr. Xiaopeng Ning (Principal Investigator) and Atefeh Malekinezhad (CoInvestigator). The title of this research study is "The influence of foot posture and load on lumbar muscle Flexion-Relaxation Phenomenon during trunk bending.". In this study, we try to understand if changing foot postures can help workers lift boxes and weights more easily. Generally, the study involves total of 24 trunk flexion and extension motions (3 Foot Postures 2 levels of load 4 repetitions). Each trial involves seven seconds to move from upright standing posture to reach to a fully flexed trunk posture, stay six seconds then use another seven seconds to move back to upright standing with and without holding external weight of $15 \mathrm{lb}$. The study also consists of 4 trials to measure the maximal voluntary contraction each lasts six seconds with one minute rests between each trial. Participant will be attached with 4 electromyography sensors on the lower back muscles and 3 motion sensors on the spine. The study lasts for around 40 minutes.

The protocol of this study has been approved by WVU institutional review board (IRB).

You may be eligible for participating in this study if you have no current or history of low back pain.

It is important to know that this letter is not to tell you to join this study. It is your decision. Your participation is voluntary. Whether you participate in this study will have no effect on your grades or your standing at WVU.

If you are interested in participating in this study, please respond to this email to provide you with all the information about this study. You do not have to respond if you are not interested in this study. If you do not respond, no one will contact you.

Thank you for your time and consideration. We look forward to hearing from you.

Sincerely 


\section{APPENDIX D: Statistical Analysis}

\section{Normality of residuals and homogeneity of variance components tests:}

- CEMG related variables:
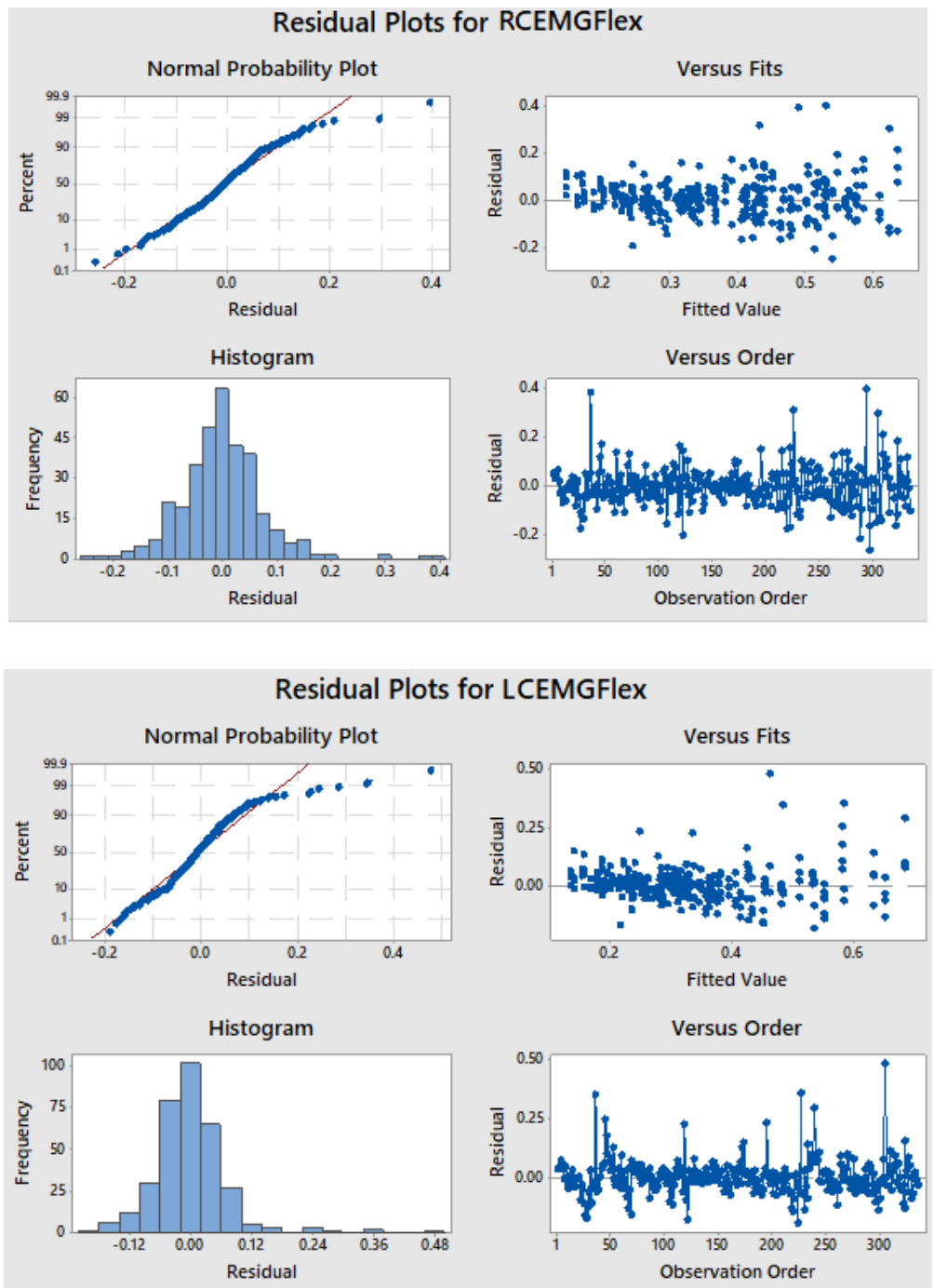

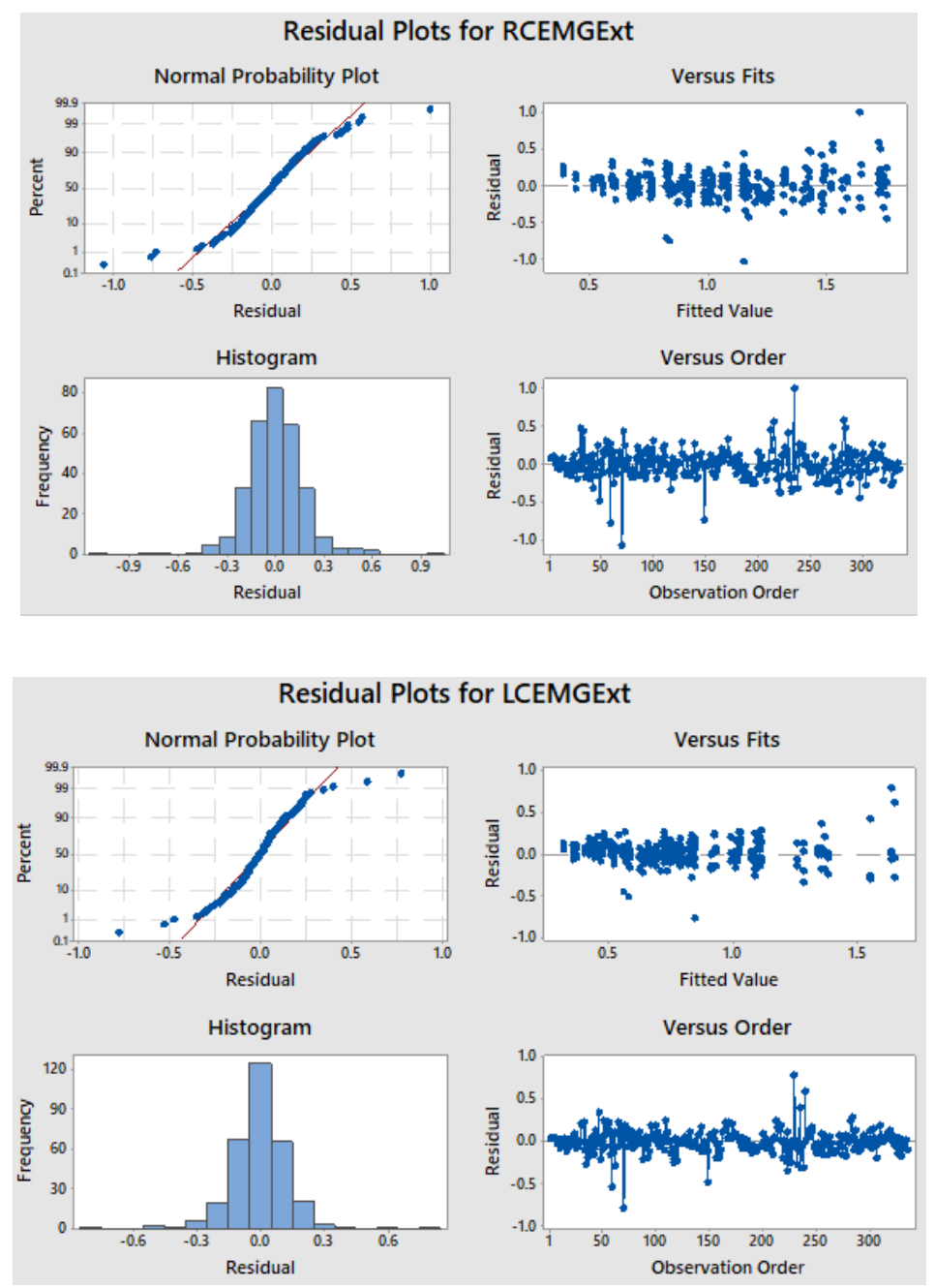

- FRP related variables
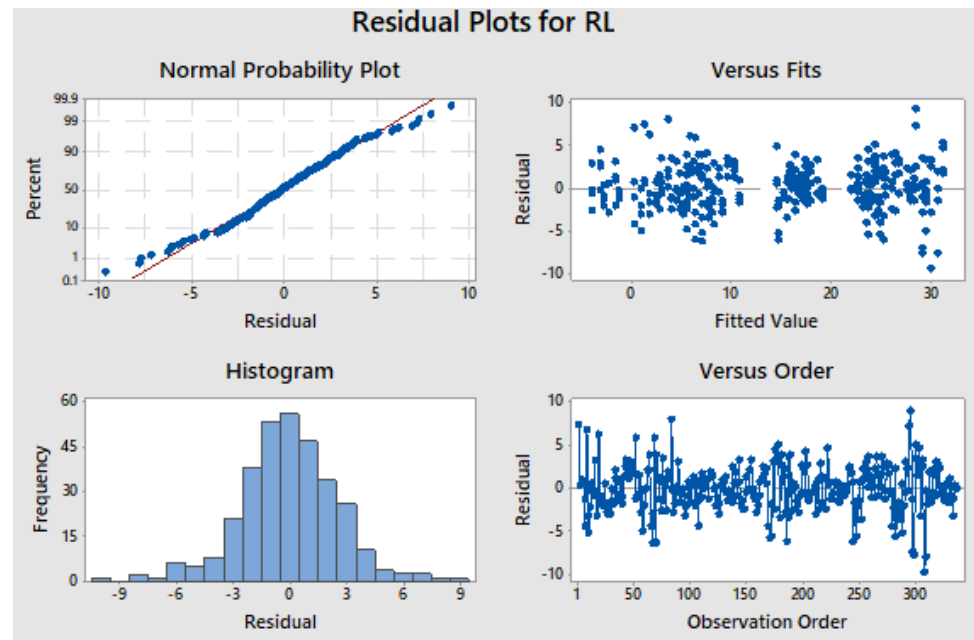

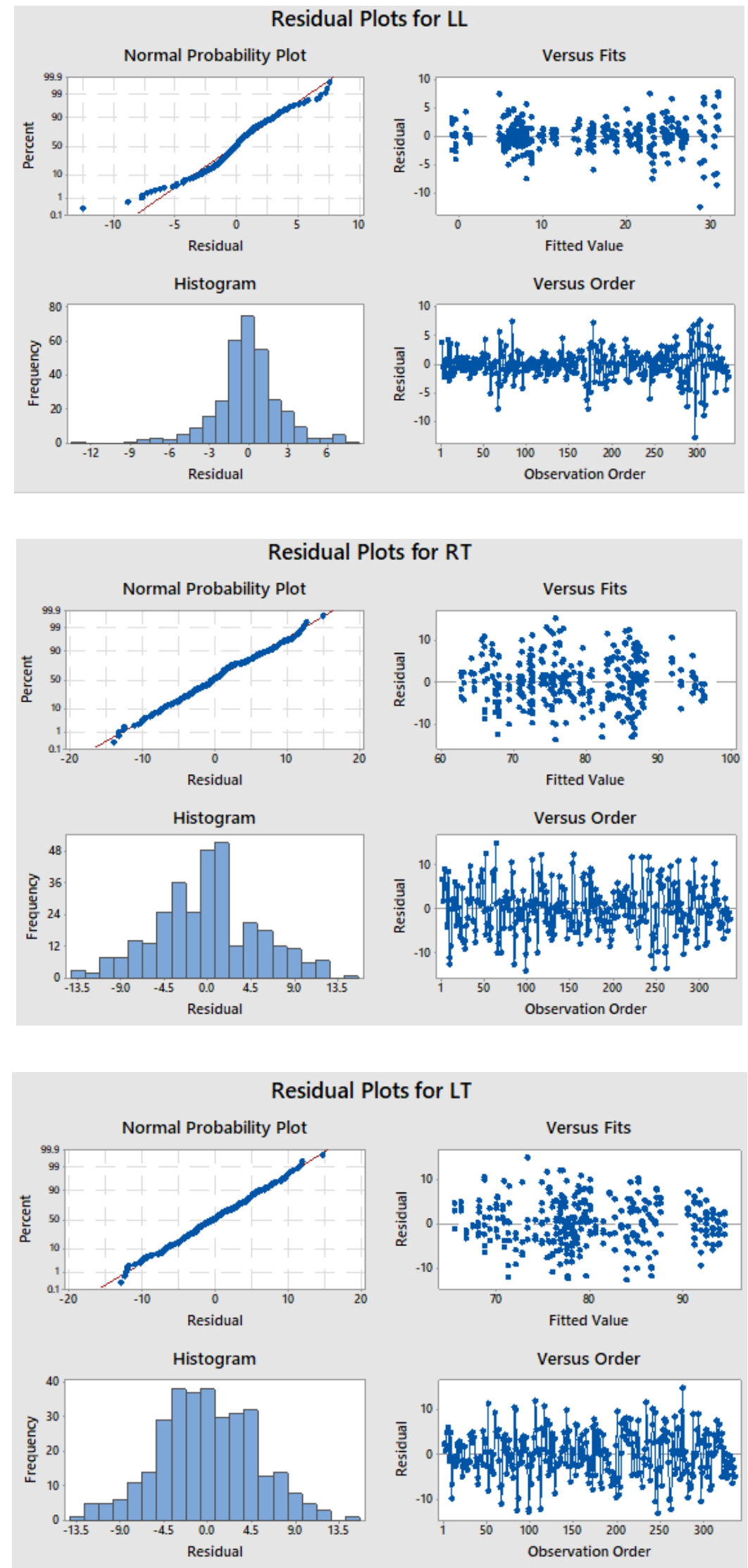

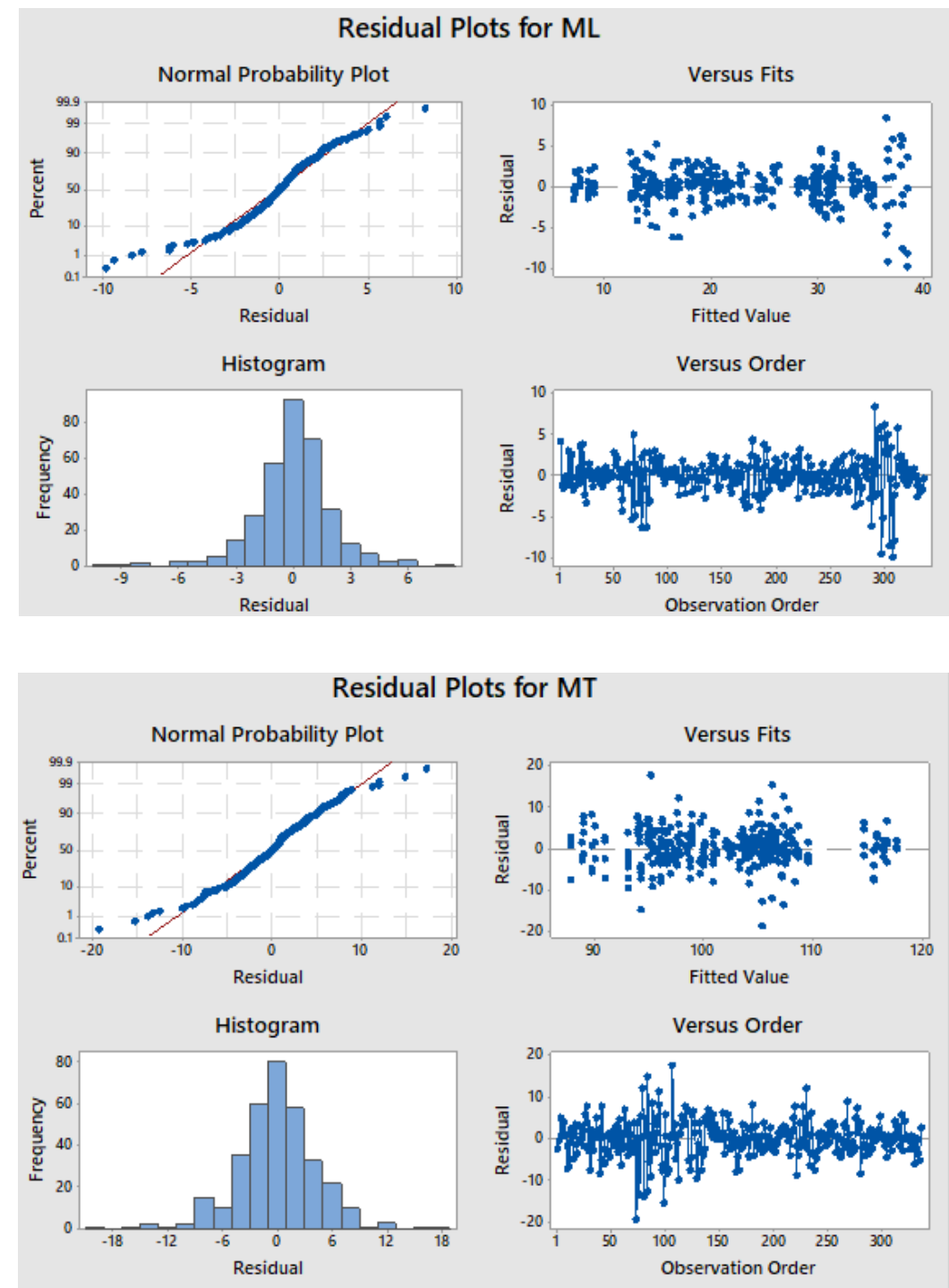
Motion coordination variables

a) Flexion:
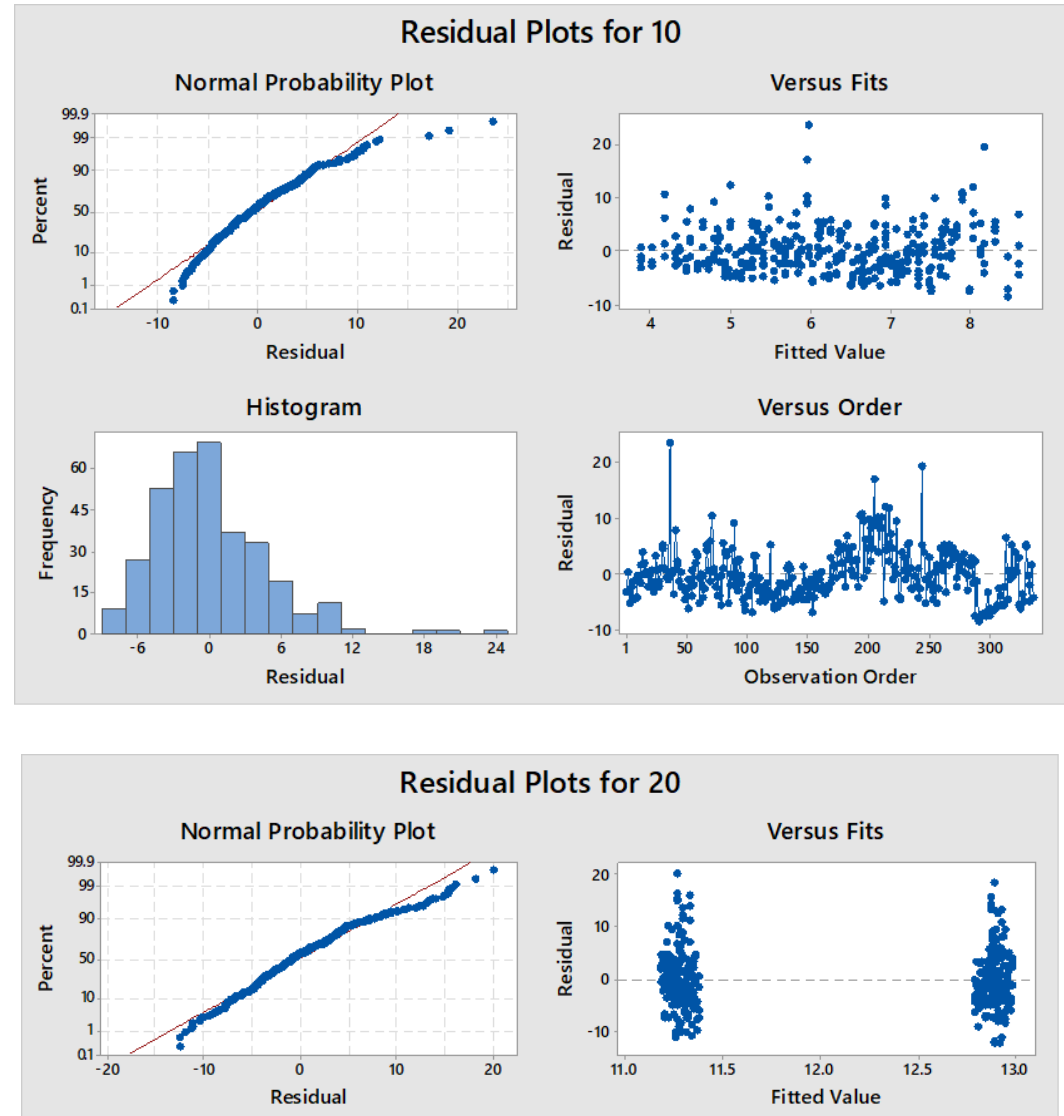

\section{Plots for 20}
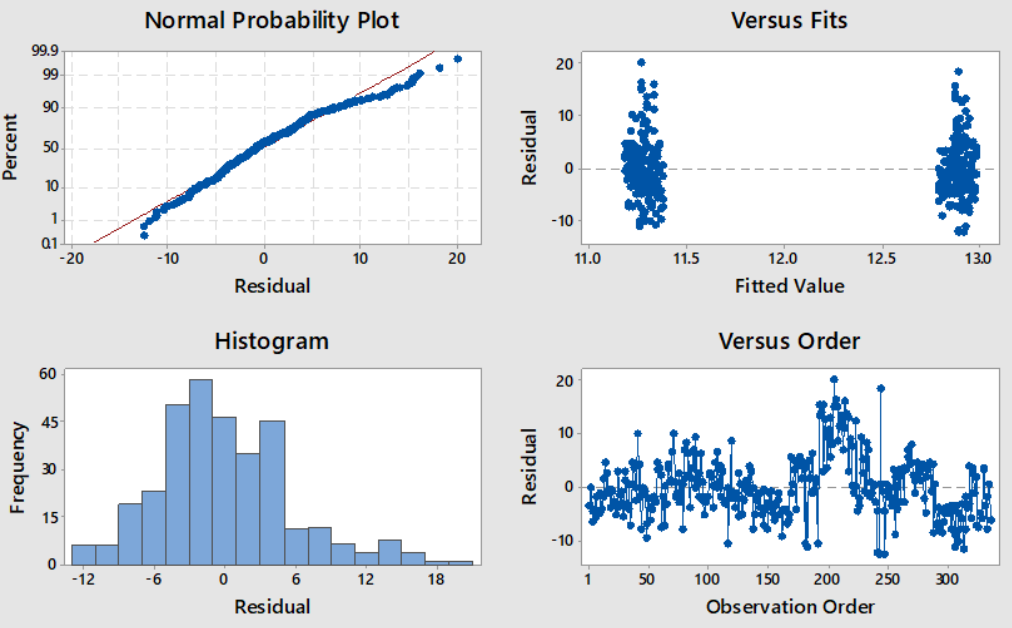

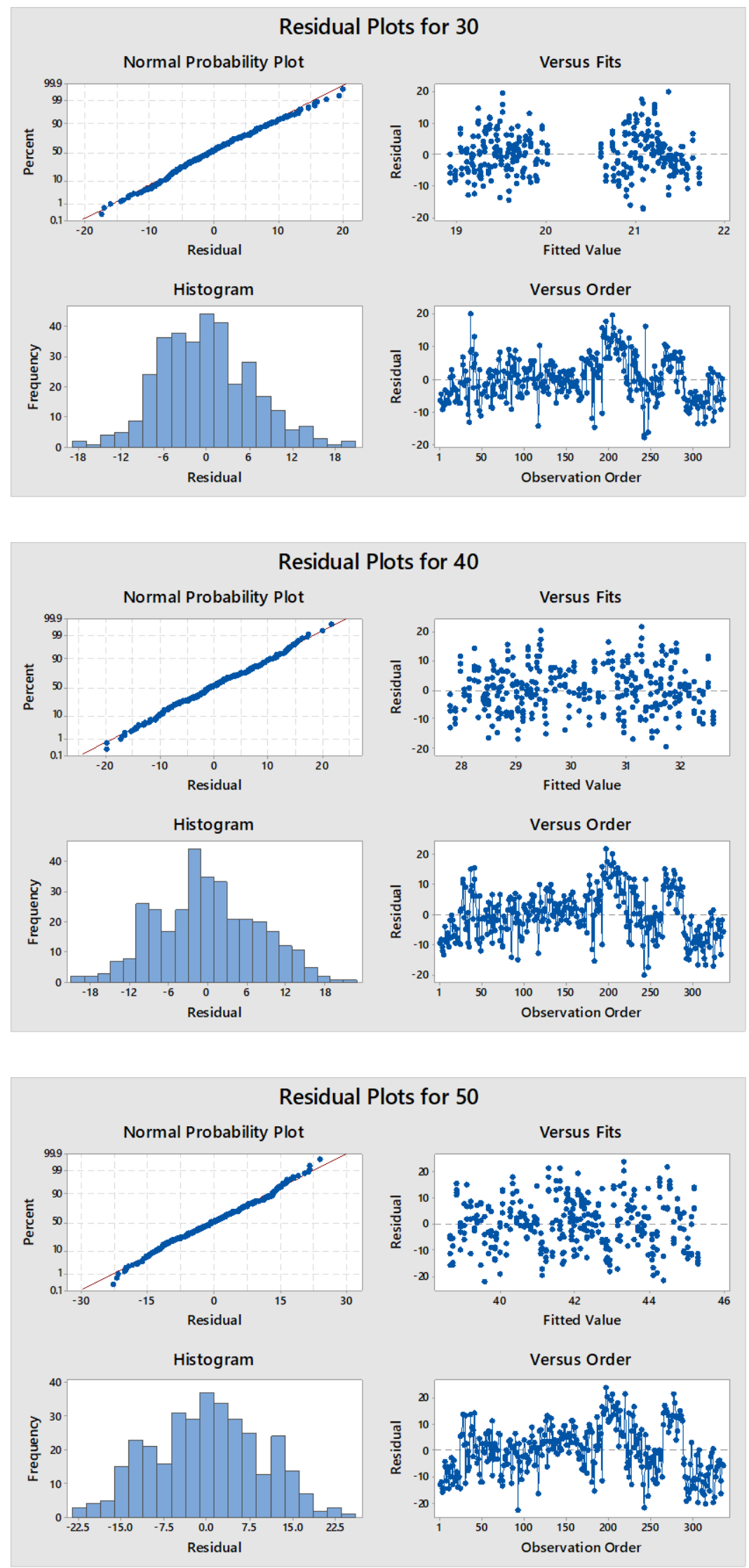

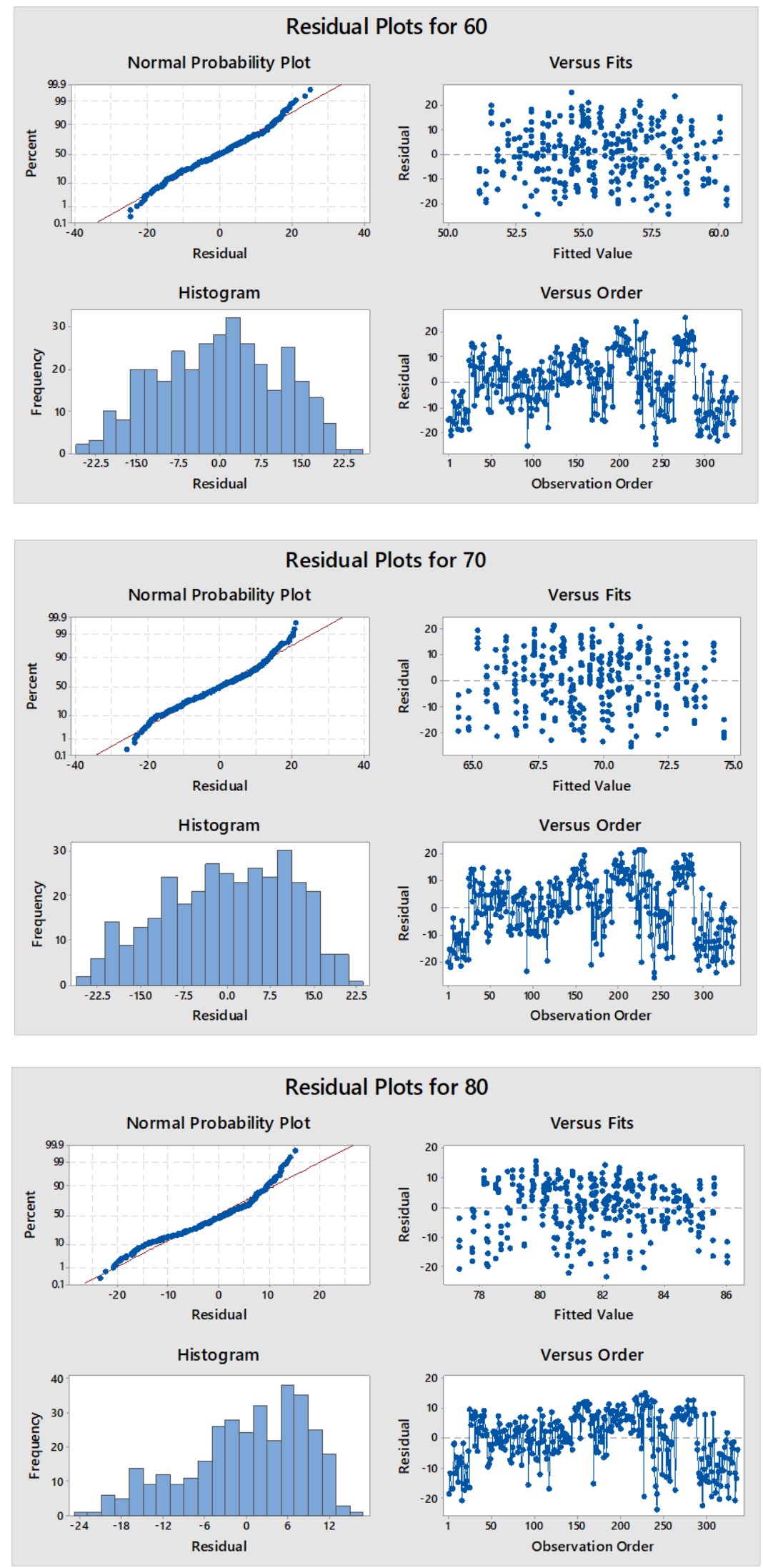


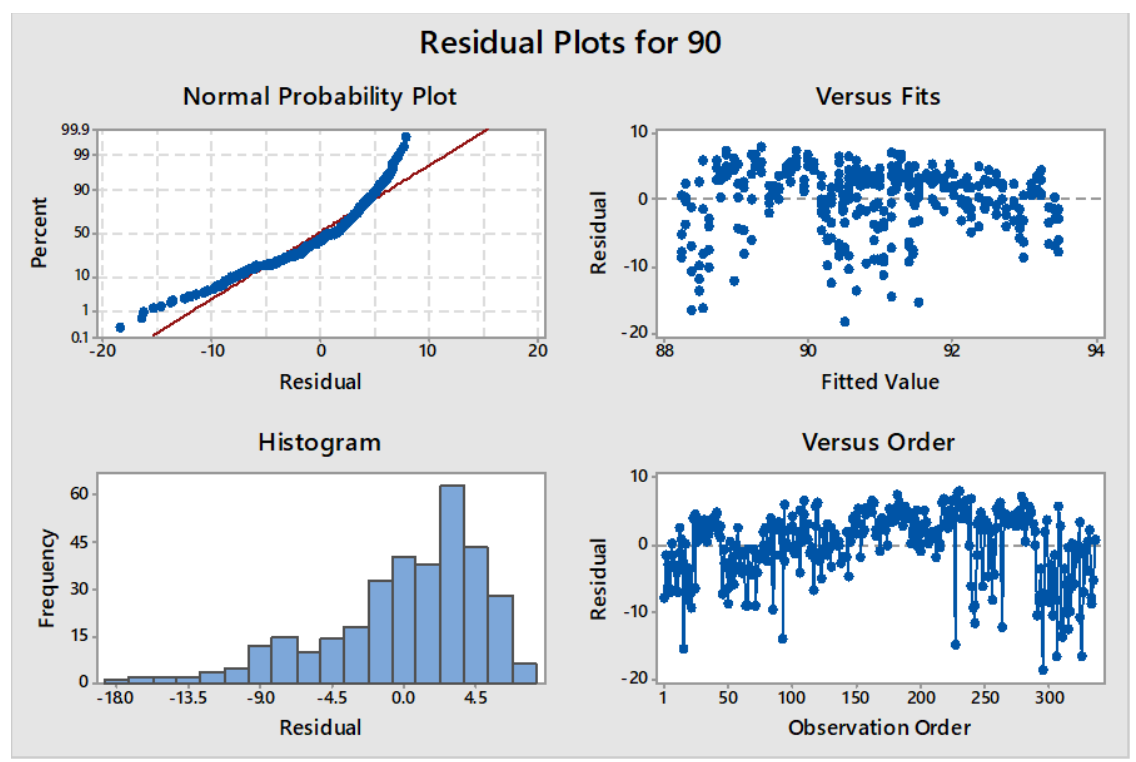

b) Extension:

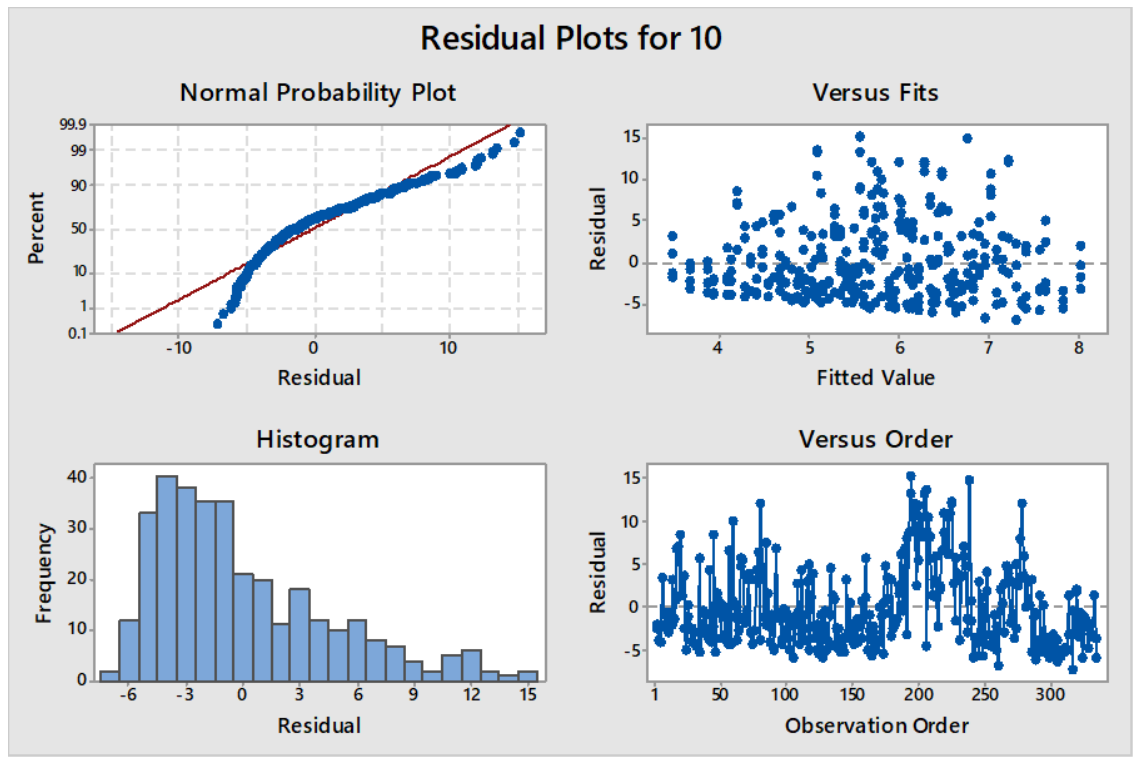



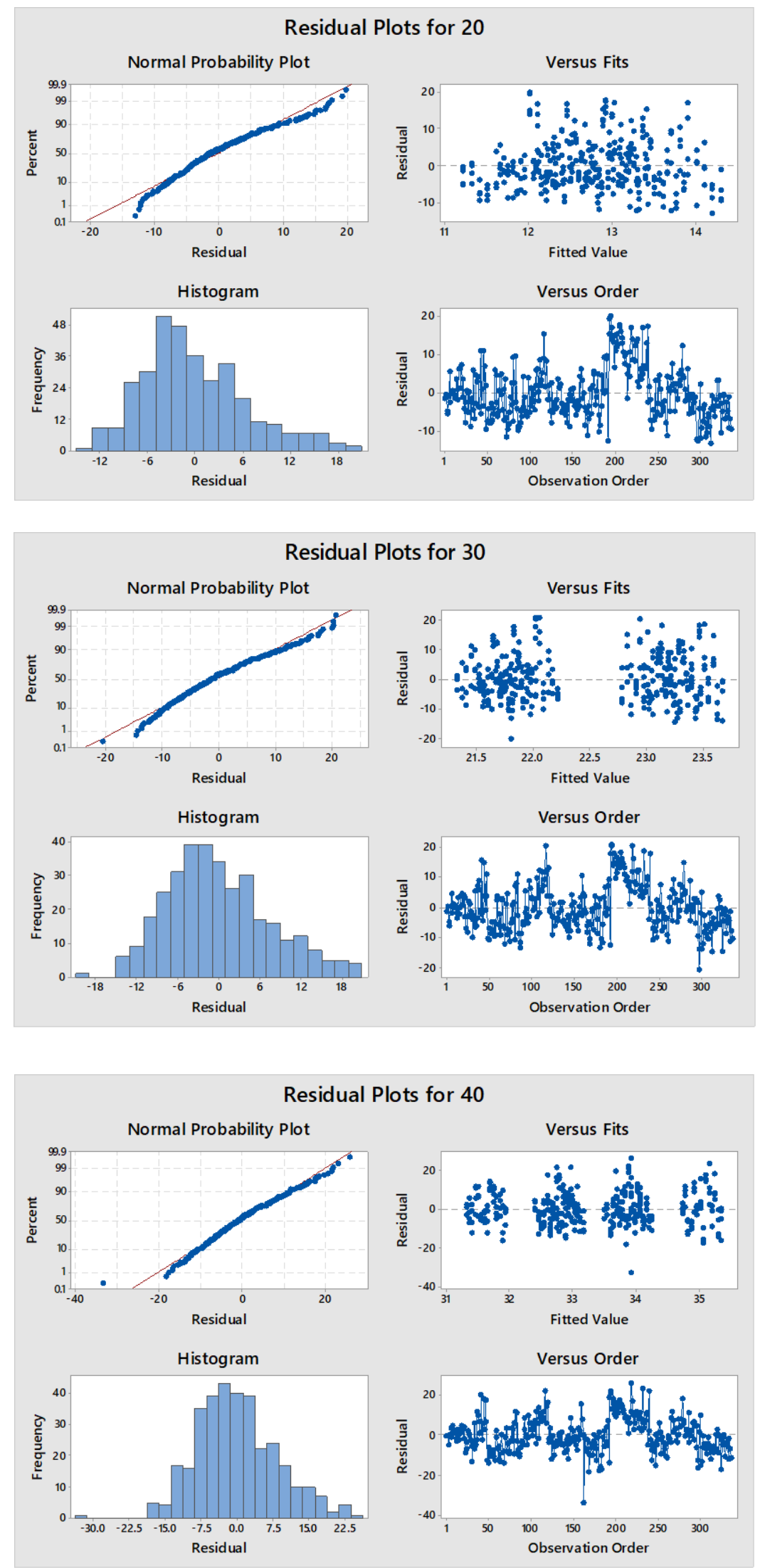

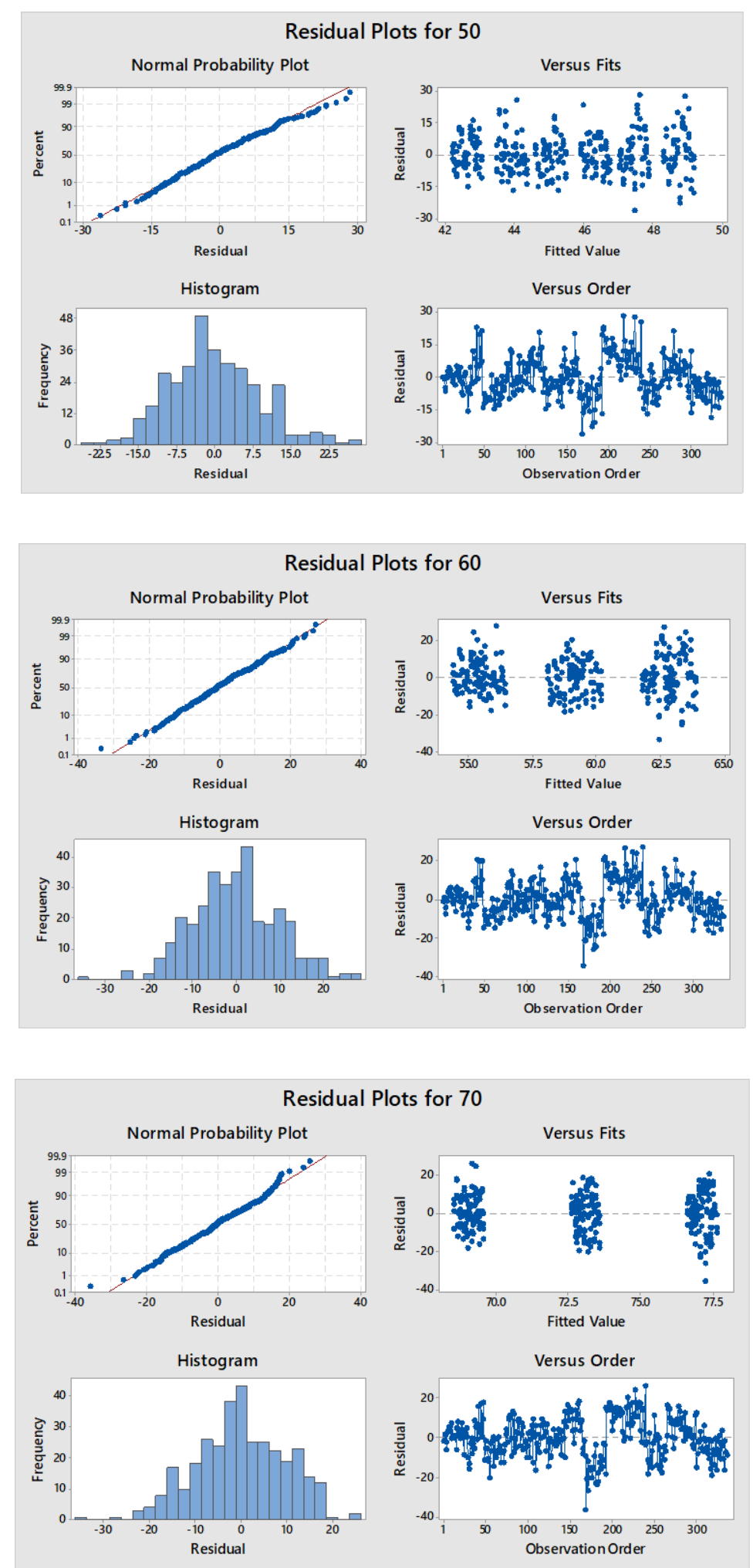

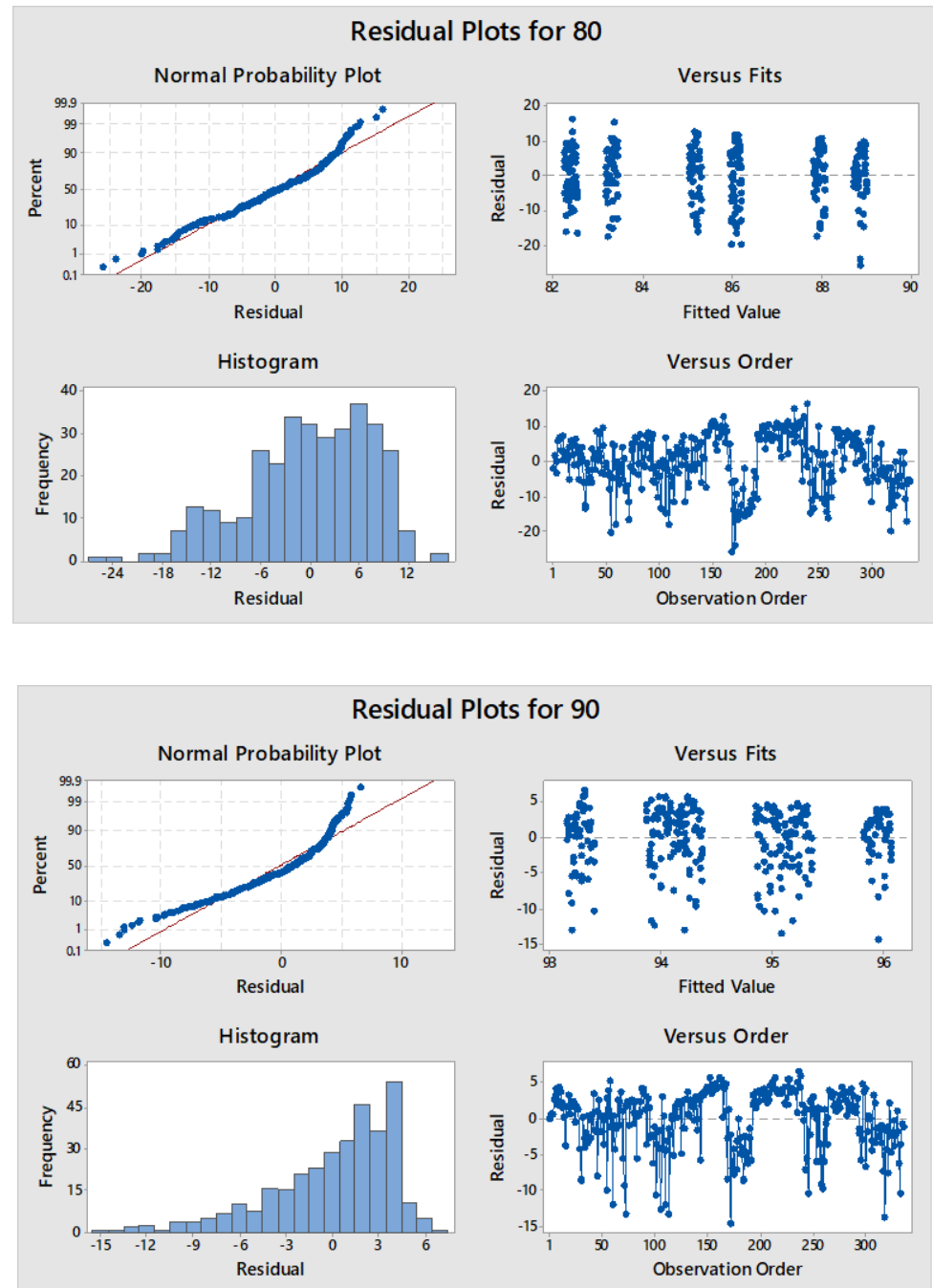


\section{ii) Equality of variance test:}

- CEMG related variables:

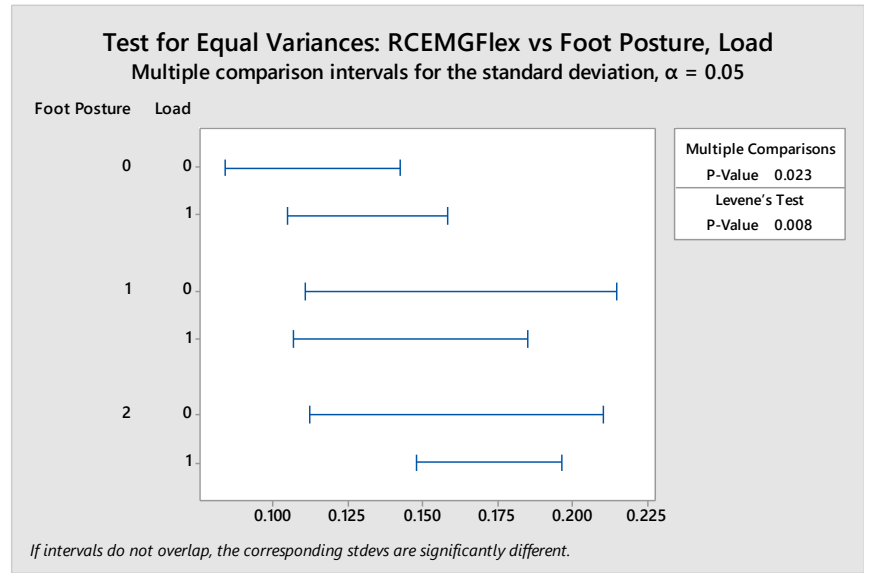

Test for Equal Variances: LCEMGFlex vs Foot Posture, Load Multiple comparison intervals for the standard deviation, $\alpha=0.05$ Foot Posture Load

0

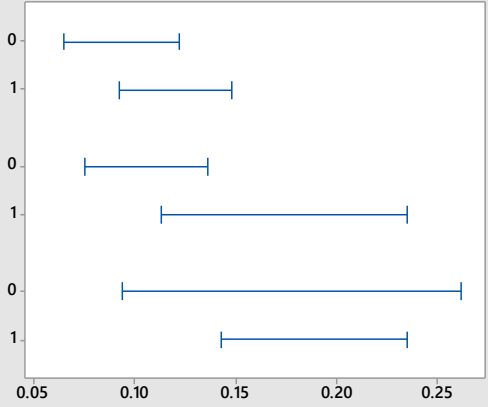

Multiple Comparison P-Value 0.004 P-Value 0.015

1

If intervals do not overlap, the corresponding stdevs are significantly different.

Test for Equal Variances: RCEMGExt vs Foot Posture, Load Multiple comparison intervals for the standard deviation, $\alpha=0.05$

Foot Posture Load

0

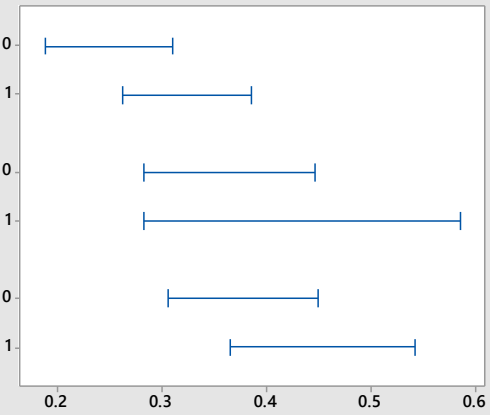

If intervals do not overlap, the corresponding stdevs are significantly different.

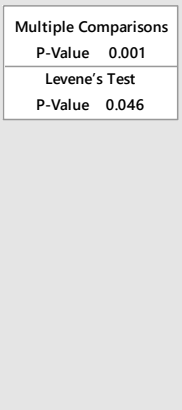




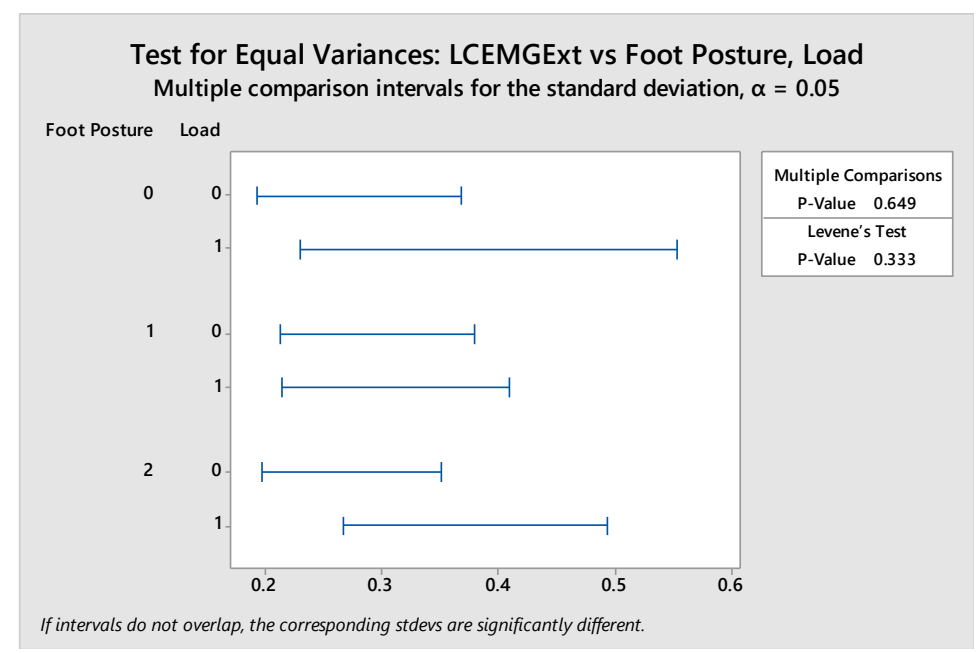

- FRP related variables
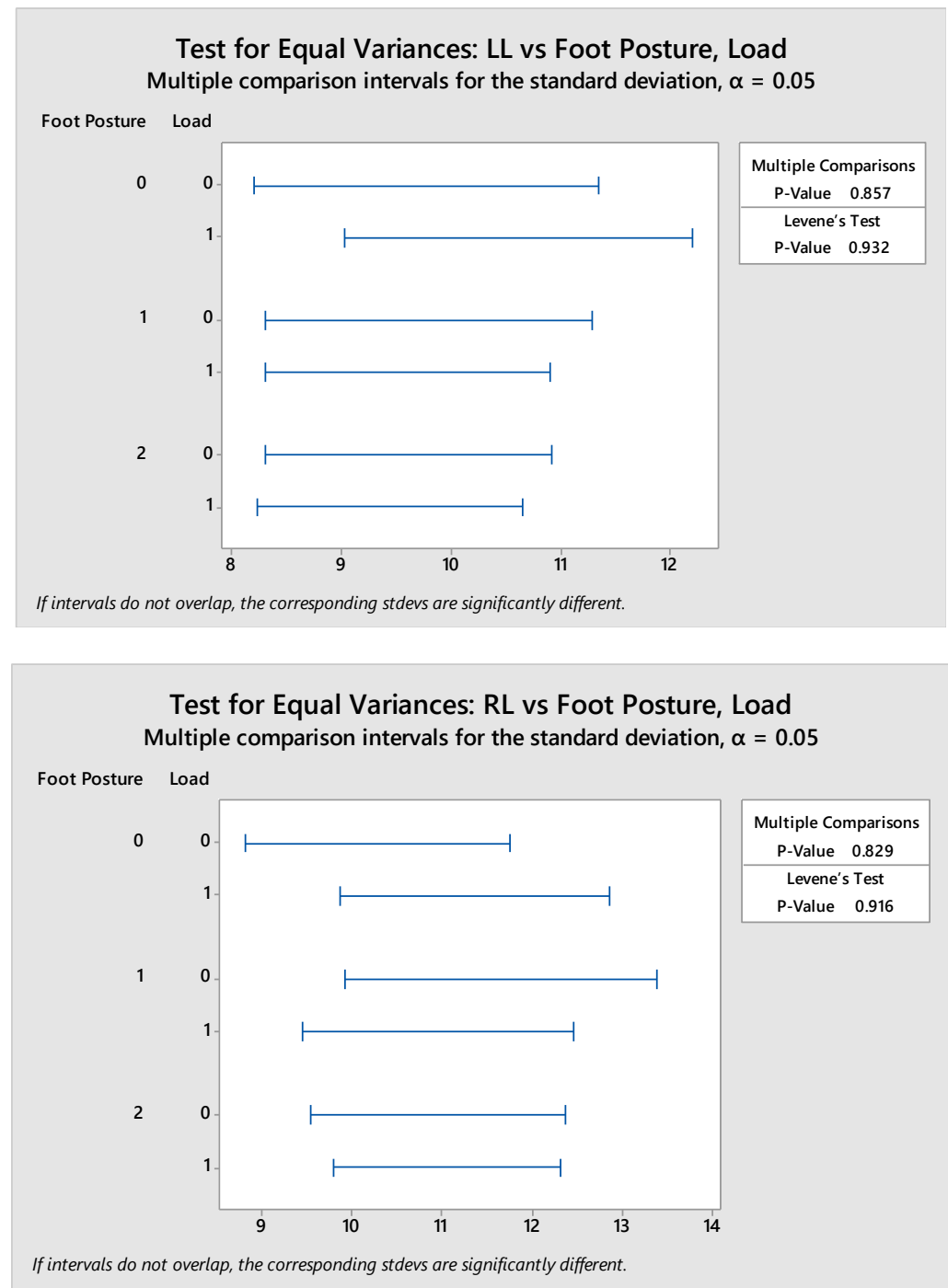
Test for Equal Variances: LT vs Foot Posture, Load

Multiple comparison intervals for the standard deviation, $\alpha=0.05$

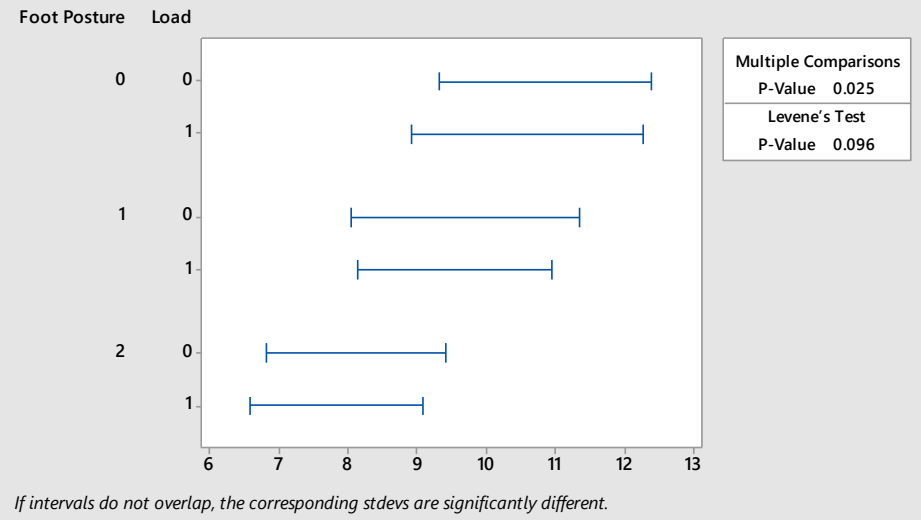

Test for Equal Variances: RT vs Foot Posture, Load

Multiple comparison intervals for the standard deviation, $\alpha=0.05$

Foot Posture Load

0

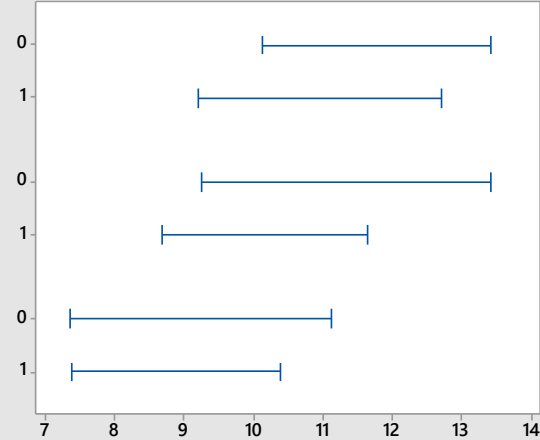

Multiple Comparisons P-Value 0.090 Levene's Test P-Value 0.070

1

2

If intervals do not overlap, the corresponding stdevs are significantly different.

Test for Equal Variances: MT vs Foot Posture, Load Multiple comparison intervals for the standard deviation, $\alpha=0.05$ Foot Posture Load

0

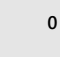

0.

1

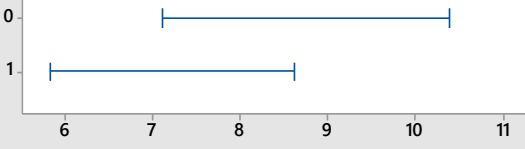

If intervals do not overlap, the corresponding stdevs are significantly different.

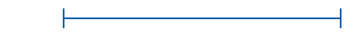

Multiple Comparisons P-Value 0.367 Levene's Test P-Value 0.440 


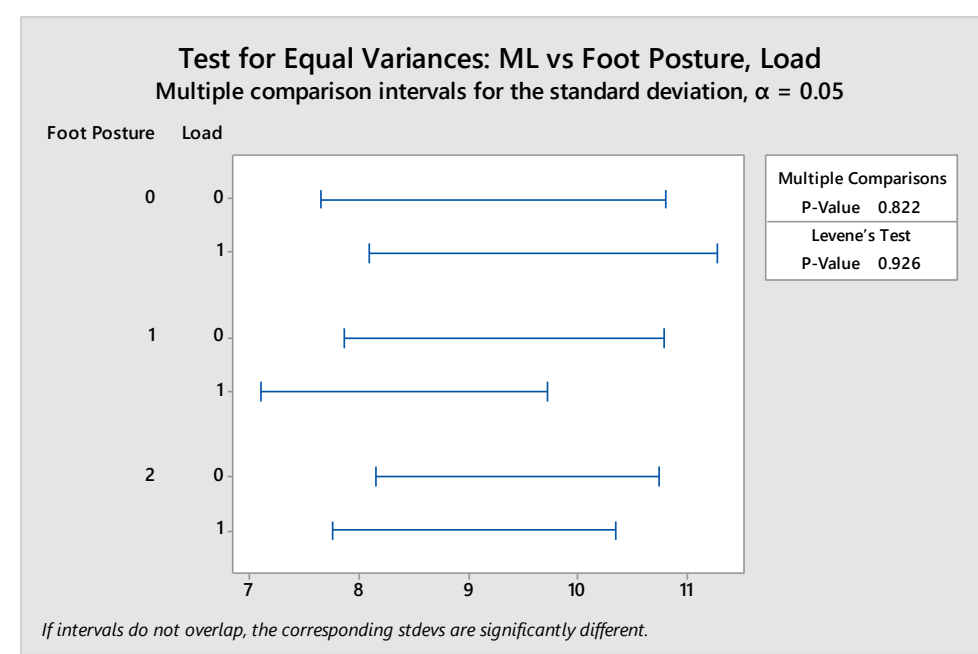

- Motion coordination variables

a) Flexion:

Test for Equal Variances: 10 vs Foot Posture, Load

Multiple comparison intervals for the standard deviation, $\alpha=0.05$

Foot Posture Load

0

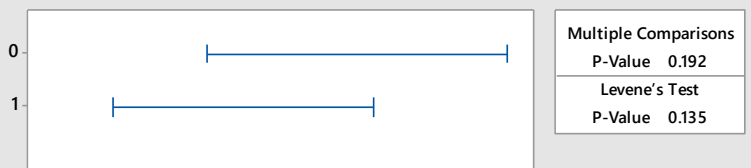

1

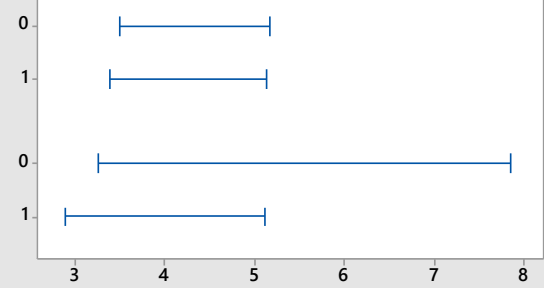

If intervals do not overlap, the corresponding stdevs are significantly different.

Test for Equal Variances: 20 vs Foot Posture, Load

Multiple comparison intervals for the standard deviation, $\alpha=0.05$

Foot Posture Load

0

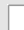
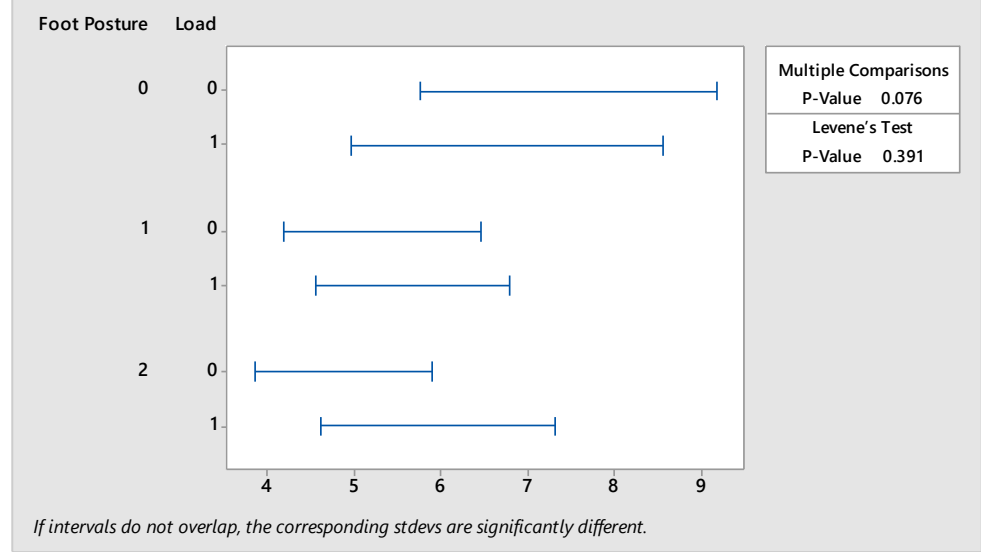
Test for Equal Variances: 30 vs Foot Posture, Load

Multiple comparison intervals for the standard deviation, $\alpha=0.05$

Foot Posture Load

0

0

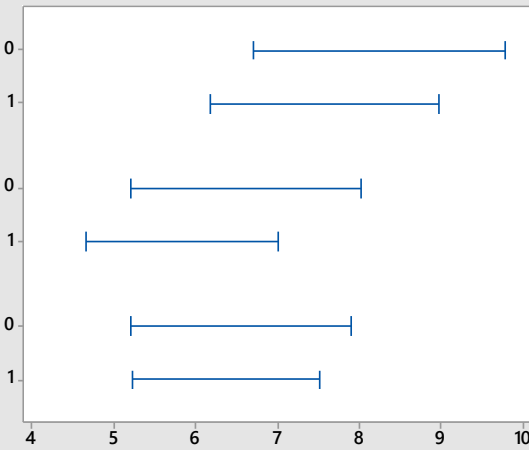

Multiple Comparisons P-Value 0.118 Levene's Test P-Value 0.216

1

Test for Equal Variances: $\mathbf{4 0}$ vs Foot Posture, Load Multiple comparison intervals for the standard deviation, $\alpha=0.05$ Foot Posture Load

0

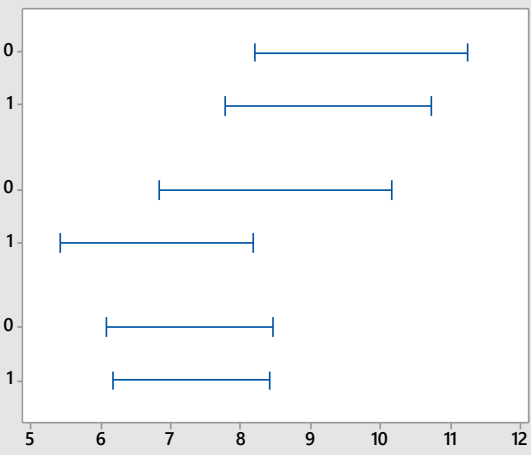

Multiple Comparisons P-Value 0.048 Levene's Test P-Value 0.027

If intervals do not overlap, the corresponding stdevs are significantly different.

Test for Equal Variances: 50 vs Foot Posture, Load Multiple comparison intervals for the standard deviation, $\alpha=0.05$ Foot Posture Load

0

0

0.

1.

1

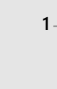

2

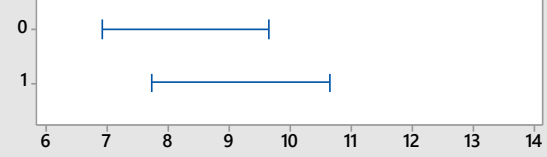

If intervals do not overlap, the corresponding stdevs are significantly different. 
Test for Equal Variances: 60 vs Foot Posture, Load

Multiple comparison intervals for the standard deviation, $\alpha=0.05$

Foot Posture Load

0

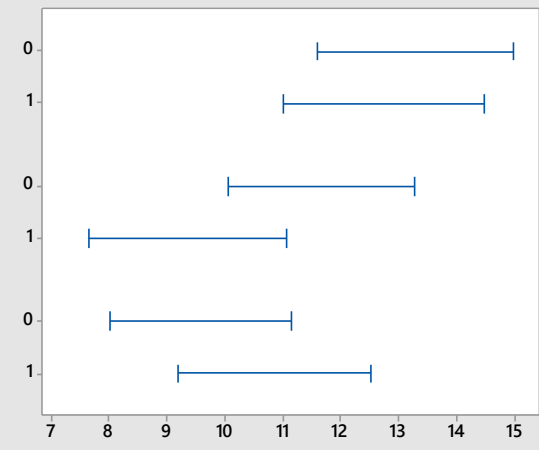

Multiple Comparisons P-Value 0.013 Levene's Test

0.001

1

2

Test for Equal Variances: 70 vs Foot Posture, Load

Multiple comparison intervals for the standard deviation, $\alpha=0.05$

Foot Posture Load

0

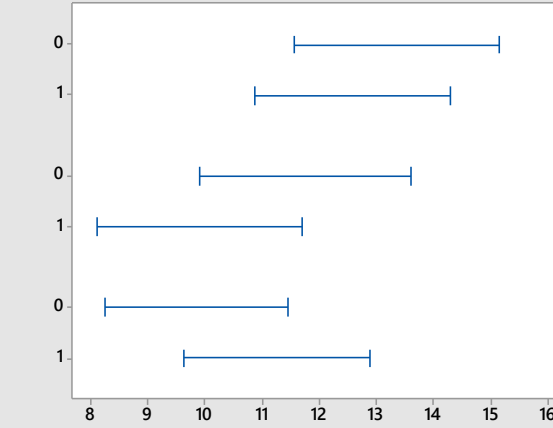

Multiple Comparisons

P-Value 0.040

Levene's Test

P-Value 0.023

If intervals do not overlap, the corresponding stdevs are significantly different.

Test for Equal Variances: 80 vs Foot Posture, Load

Multiple comparison intervals for the standard deviation, $\alpha=0.05$

Foot Posture Load

0

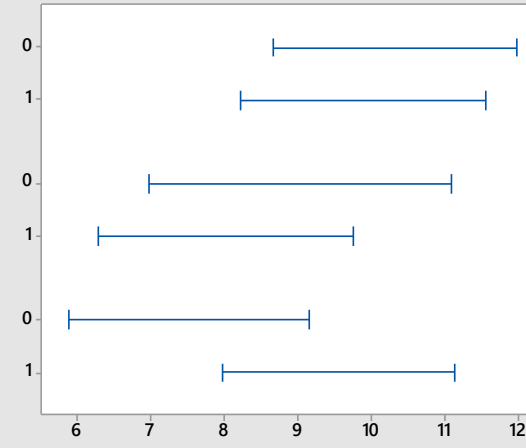

Multiple Comparisons P-Value 0.148 Levene's Test P-Value 0.070

If intervals do not overlap, the corresponding stdevs are significantly different. 
Test for Equal Variances: 90 vs Foot Posture, Load

Multiple comparison intervals for the standard deviation, $\alpha=0.05$

Foot Posture Load
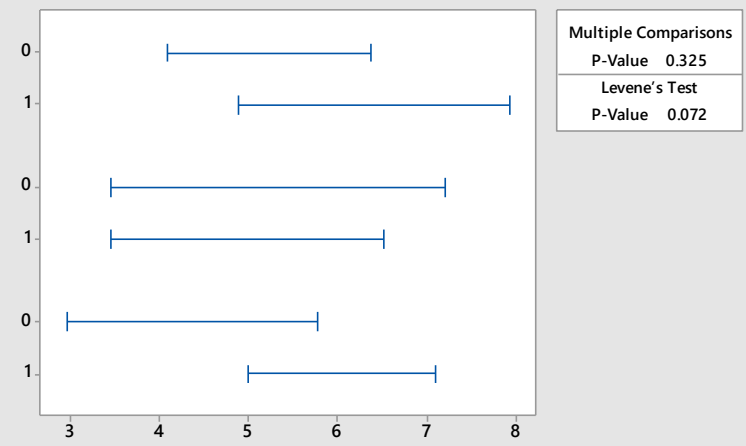

If intervals do not overlap, the corresponding stdevs are significantly different.

\section{b) Extension:}

Test for Equal Variances: 10 vs Foot Posture, Load

Multiple comparison intervals for the standard deviation, $\alpha=0.05$

Foot Posture Load

0

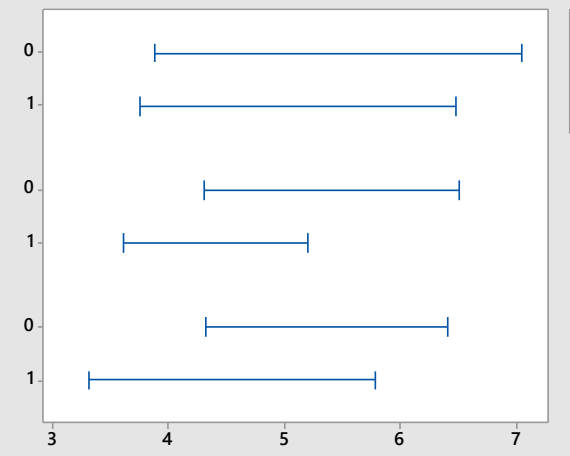

Multiple Comparisons P-Value 0.687 Levene's Test

P-Value 0.836

1

If intervals do not overlap, the corresponding stdevs are significantly different.

Test for Equal Variances: 20 vs Foot Posture, Load Multiple comparison intervals for the standard deviation, $\alpha=0.05$ Foot Posture Load

0

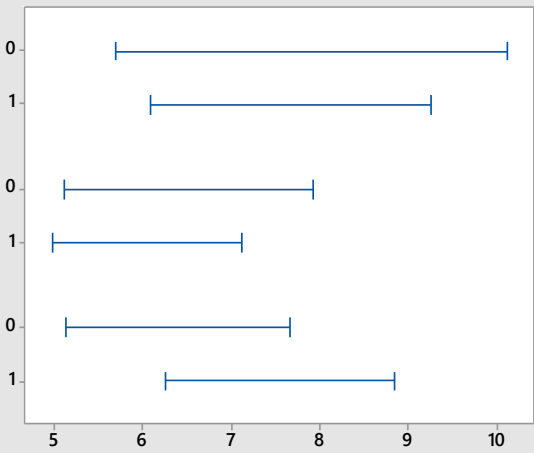

Multiple Comparisons P-Value 0.468 Levene's Test P-Value 0.573

If intervals do not overlap, the corresponding stdevs are significantly different. 
Test for Equal Variances: 30 vs Foot Posture, Load

Multiple comparison intervals for the standard deviation, $\alpha=0.05$ Foot Posture Load

0

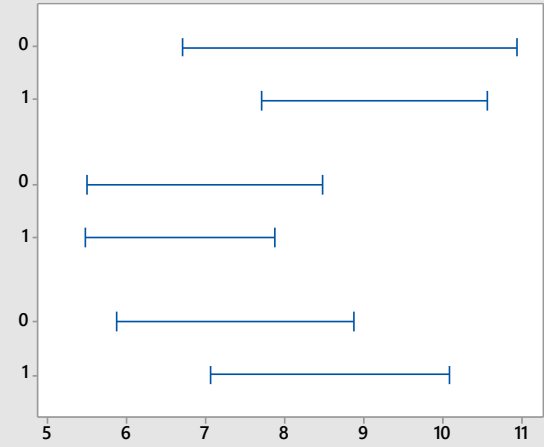

Multiple Comparison P-Value 0.078 Levene's Test P-Value 0.259

1

2

If intervals do not overlap, the corresponding stdevs are significantly different.

Test for Equal Variances: $\mathbf{4 0}$ vs Foot Posture, Load

Multiple comparison intervals for the standard deviation, $\alpha=0.05$

Foot Posture Load

0

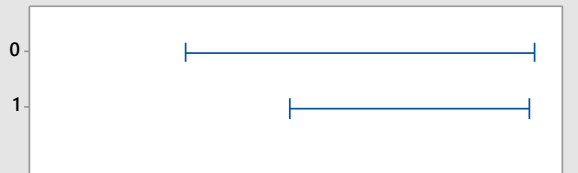

Multiple Comparisons P-Value 0.053 Levene's Test P-Value 0.222

1

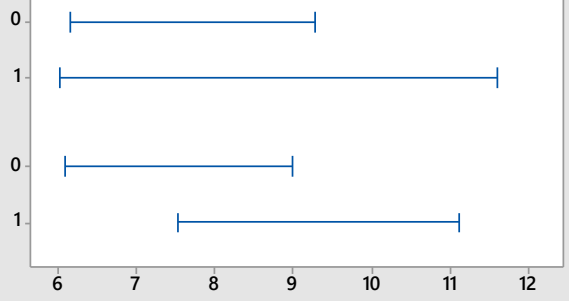

If intervals do not overlap, the corresponding stdevs are significantly different.

Test for Equal Variances: 50 vs Foot Posture, Load Multiple comparison intervals for the standard deviation, $\alpha=0.05$

Foot Posture Load

0

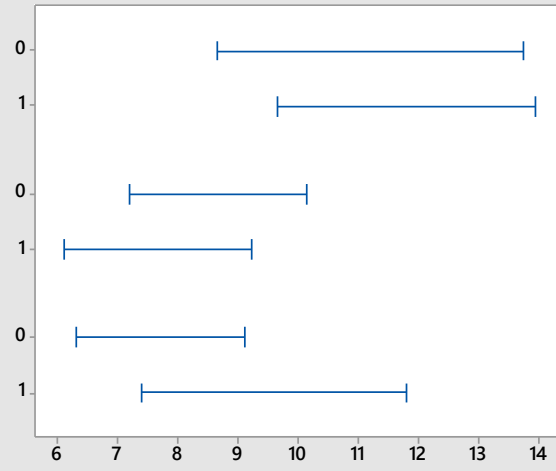

If intervals do not overlap, the corresponding stdevs are significantly different. 
Test for Equal Variances: 60 vs Foot Posture, Load

Multiple comparison intervals for the standard deviation, $\alpha=0.05$

Foot Posture Load

0

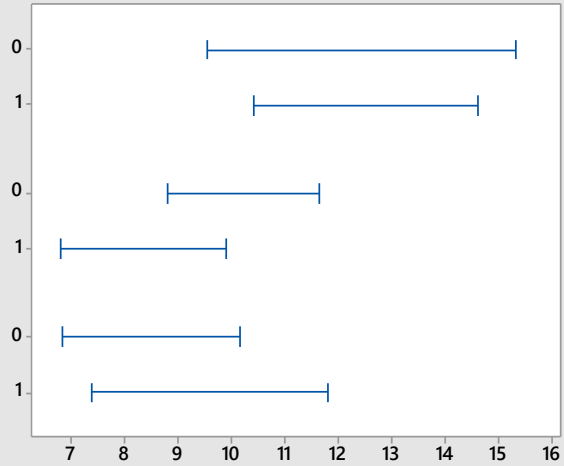

Multiple Comparisons

P-Value 0.014

Levene's Test

P-Value 0.022

1

2

If intervals do not overlap, the corresponding stdevs are significantly different.

Test for Equal Variances: 70 vs Foot Posture, Load

Multiple comparison intervals for the standard deviation, $\alpha=0.05$

Foot Posture Load

0

0

0.
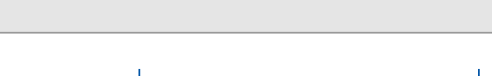

Multiple Comparisons

1.
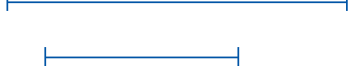

P-Value 0.113

Levene's Test

P-Value 0.025

1

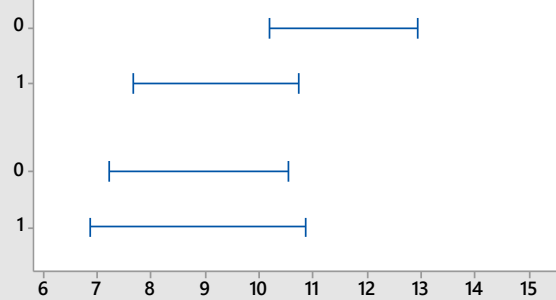

If intervals do not overlap, the corresponding stdevs are significantly different.

Test for Equal Variances: 80 vs Foot Posture, Load

Multiple comparison intervals for the standard deviation, $\alpha=0.05$

Foot Posture Load

0

0.

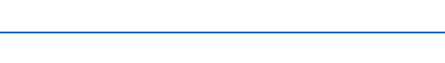

1

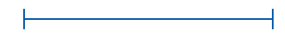

P-Vare 0.172 P-Value 0.172

Levene's Test P-Value 0.137

1

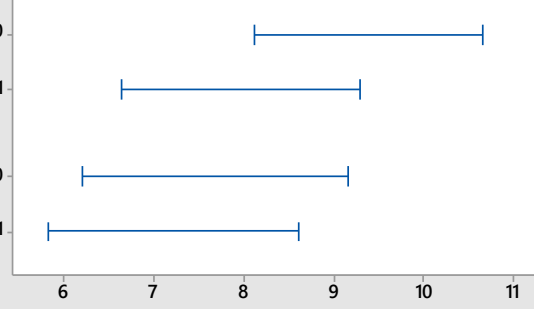

If intervals do not overlap, the corresponding stdevs are significantly different. 
Test for Equal Variances: 90 vs Foot Posture, Load Multiple comparison intervals for the standard deviation, $\alpha=0.05$

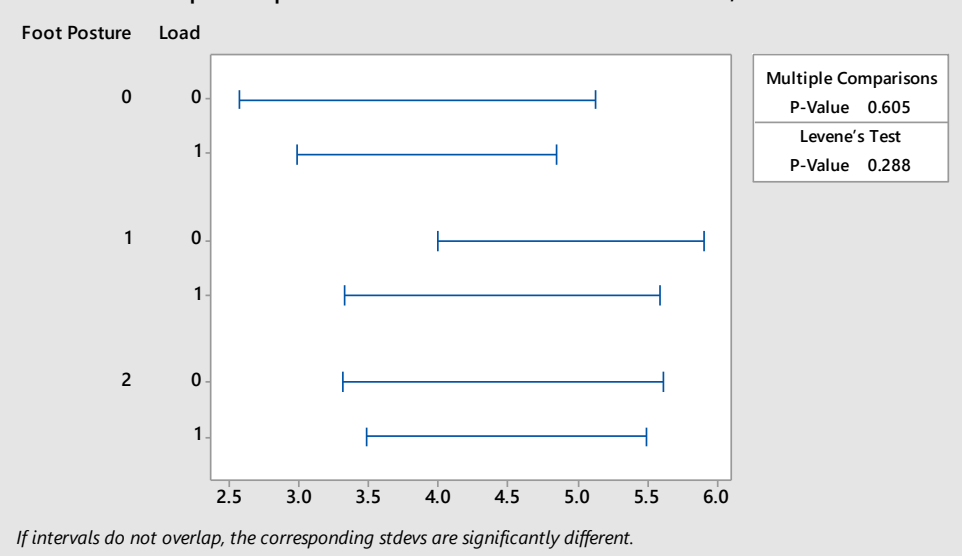

